\title{
Influência de uma intervenção nutricional baseada no Sistema de Pontos para Controle de Colesterol e Gordura no Sangue em indivíduos hiperlipidêmicos coronarianos usuários de sinvastatina
}

Marcia de Araujo Leite Nacif

Tese apresentada ao Programa de Pós - Graduação em Saúde Pública da Faculdade de Saúde Pública da Universidade de São Paulo para a obtenção do título de Doutor em Saúde Pública.

Área de Concentração: Nutrição

Orientadora:

Profa Assoc. Elizabeth A.F.S.Torres

São Paulo 2007

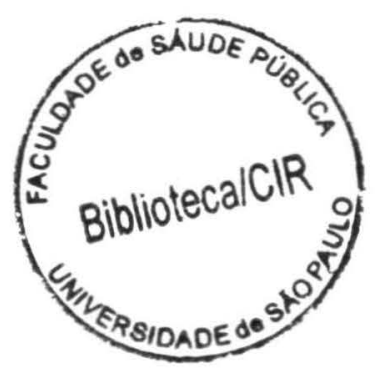


É expressamente proibida a comercialização deste documento, tanto na sua forma impressa como eletrônica. Sua reprodução total ou parcial é permitida exclusivamente para fins acadêmicos e científicos, desde que na reprodução figure a identificação do autor, título, instituição e ano da tese.

$$
48735 / 2007 d x
$$




\section{DEDICO ESTE TRABALHO .....}

Meus pais Marcio e Maria Inês

por serem tudo em minha vida

\section{Cezar ...........}

por todo o amor, incentivo, compreensão, paciência, cumplicidade e carinho

\section{Geraldo}

por todo o amor que sempre dedicou as suas queridas netas 


\section{AGRADECIMENTOS}

Este trabalho só pôde ser realizado devido ao auxílio de pessoas muito especiais que direta ou indiretamente contribuíram para a sua elaboração. Quero aqui mencioná-las demonstrando minha gratidão !

À minha orientadora Prof Assoc. Elizabeth Aparecida Ferraz da Silva Torres, pela oportunidade de realizar o Doutorado, pela sua amizade, apoio e incessantes orientações.

À Prof ${ }^{a}$ Dra Nágila Raquel Damasceno, pela amizade, atenção, disponibilidade e conselhos valiosos, sem os quais este trabalho não poderia ser realizado.

À Dra Edeli Simoni de Abreu, pela constante amizade, apoio e colaboração na elaboração deste trabalho.

Aos Prof Dr Raul Maranhão e Dr Raul dos Santos pela gentileza e colaboração na elaboração deste trabalho.

Ao Prof Dr Luiz Antonio Machado César pela gentileza e auxílio durante a coleta de dados deste estudo.

A Todos os funcionários do laboratório de Análises Clínicas do Instituto do Coração da Universidade de São Paulo. 
À amiga Milena Bueno, pelo incentivo e apoio na parte estatística deste trabalho.

À Letícia Bertoldi Sanches pela preciosa ajuda na análise bioquímica.

Às amigas Renata, Geni, Emília, Yara, Rosana e Bettina obrigada pelo constante apoio e incentivo !

Minhas queridas irmãs Gisele e Beatriz, por todo o exemplo de determinação, carinho e estímulo.

Aos pacientes da Unidade de Coronariopatia Crônica, do Instituto do Coração do Hospital das Clínicas da Faculdade de Medicina da Universidade de São Paulo, sem os quais seria impossível a realização desta pesquisa. 


\section{RESUMO}

Nacif, MAL. Influência de uma intervenção nutricional baseada no Sistema de Pontos para Controle de Colesterol e Gordura no Sangue em indivíduos hiperlipidêmicos coronarianos usuários de sinvastatina. São Paulo; 2007 [Tese de Doutorado - Faculdade de Saúde Pública da USP].

Introdução: $\mathrm{O}$ tratamento das dislipidemias consiste em mudanças no estilo de vida (introdução de dieta e atividade física) e uso de hipolipemiantes. As estatinas diminuem a mortalidade em pacientes com doença cardiovascular e em indivíduos em risco de desenvolverem cardiopatias. No entanto, poucas informações existem sobre a interação destes medicamentos com o tratamento dietético. Objetivo: Avaliar o efeito de uma dieta com baixo índice de colesterol e gordura saturada baseada no Sistema de Pontos para Controle de Colesterol e Gordura no Sangue, sobre marcadores bioquímicos e antropométricos em indivíduos dislipidêmicos coronarianos sob o uso de estatinas. Metodologia: Foi realizado um ensaio clínico randomizado controlado, com pacientes hiperlipidêmicos portadores de doença coronariana, em uso de sinvastatina. Este protocolo de pesquisa acompanhou os seguintes grupos de pacientes: coronarianos fazendo uso de sinvastatina, orientados a seguir sua dieta habitual e com colesterol total $>200 \mathrm{mg} / \mathrm{dL}$ (DHCA); indivíduos coronarianos fazendo uso de sinvastatina, orientados a seguir sua dieta habitual e com colesterol total $<200 \mathrm{mg} / \mathrm{dL}$ (DHCB); pacientes coronarianos fazendo uso de sinvastatina, orientados a seguir a dieta proposta pelo Sistema de Pontos e com colesterol total $>200 \mathrm{mg} / \mathrm{dL}$ (DPCA); pacientes coronarianos fazendo uso de 
sinvastatina, orientados a seguir a dieta de pontos e com colesterol total $<200 \mathrm{mg} / \mathrm{dL}$ (DPCB). Alterações sobre as variáveis antropométricas, perfil lipídico, proteína C reativa e auto-anticorpos anti-LDL-ox foram comparadas entre os grupos de estudo utilizando a análise de variância para medidas repetidas por meio do modelo linear generalizado (GLM). Resultados: Em relação ao consumo alimentar pôde-se observar que os pacientes do grupo DPCB consumiram quantidades significantemente menores de lipídios, ácidos graxos saturados, trans e colesterol quando comparados aos do grupo DHCB $(\mathrm{p}<0,050)$. O grupo DPCA apresentou menor consumo de ácidos graxos saturados e maior ingestão de fibras e vitaminas C e E que o DHCA $(p<0,050)$. Verificou-se que o grupo DPCB apresentou média significantemente menor de circunferência abdominal, colesterol total, LDL e proteína $\mathrm{C}$ reativa ao final da pesquisa, quando comparado ao grupo DHCB $(\mathrm{p}<0,050)$. Observou-se que o grupo DPCA teve aumento significativo de HDL e redução de VLDL, triglicérides e PCR quando comparado ao DHCA $(\mathrm{p}<0,050)$. Os dois grupos que seguiram a dieta de pontos apresentaram média maior de autoanticorpos anti-LDLox ao final do estudo $(p<0,001)$. Conclusão: Houve uma melhora de perfil lipídico e marcadores inflamatórios para doenças cardiovasculares nos indivíduos que seguiram a dieta de pontos, mesmo sendo usuários de sinvastatina.

Descritores: indice de colesterol/gordura saturada (CSI), estatinas, aterosclerose, lipoproteínas, Proteína C reativa, auto-anticorpos anti-LDLox. 


\begin{abstract}
Nacif, MAL. Influência de uma intervenção nutricional baseada no Sistema de Pontos para Controle de Colesterol e Gordura no Sangue em indivíduos hiperlipidêmicos coronarianos usuários de sinvastatina. Effects of a dietary treatment based on the Points System to Control serum lipids and Cholesterol in patients with coronary heart disease making use of sinvastatin. São Paulo (BR); 2007 [Tese de Doutorado - Faculdade de Saúde Pública da USP].
\end{abstract}

Introduction: The treatment of the hypercholesterolemic patients consists of diet introduction, lifestyle changes, physical activity and pharmacologic intervention. The statins decreases cardiovascular morbidity in patients with coronary heart disease and in healthy men at risk for coronary heart disease. However limited information exists on the interaction between diet and statins. Objective: To evaluate the effect of a diet with low cholesterol and saturated fat index based in the Points System to Control Serum lipids and Cholesterol levels on biochemimists and antropometric biomarker in patients with coronary heart disease making use of statins. Methods: A randomized controlled trial, was carried on hypercholesterolemic patients with cardiovascular disease, making use of sinvastatin. This protocol accompanied the following groups of patients: patients with coronary heart disease making sinvastatin use, guided to follow their habitual diet and with total cholesterol $>200 \mathrm{mg} / \mathrm{dL}$ (DHCA); patients with coronary heart disease making sinvastatin use guided to follow their habitual diet and with total cholesterol $<200 \mathrm{mg} / \mathrm{dL}$ (DHCB); patients with coronary heart disease making use of sinvastatin, guided to follow the diet 
proposed by the Points System and with total cholesterol $>200 \mathrm{mg} / \mathrm{dL}$ (DPCA); patients with coronary heart disease making use of sinvastatin, guided to follow the diet proposed by the Points System and with total cholesterol and with total cholesterol $<200 \mathrm{mg} / \mathrm{dL}$ (DPCB). Changes on antropometric variables, serum lipids, C reactive protein, and autoantibodies anti-LDL-ox were compared between the groups by analysis of variance for repeted measures using the general linear model (GLM). Results: It was observed that group DPCB presented significant lesser intake of fats, saturated fatty acids, trans fatty acids and cholesterol when compared with group DHCB $(\mathrm{p}<0,050)$. The group DPCA presented significant lesser intake of saturated fatty acids and increased dietary fiber, vitamin C and E than DHCA $(p<0,050)$. It was verified that the group DPCB presented significant lesser average of abdominal circumference, total cholesterol, $\mathrm{LDL}$, and $\mathrm{C}$ reactive protein at the end of the research when compared with group DHCB $(\mathrm{p}<0,001)$. It was observed that group DPCA had significant increase of HDL and reduction of VLDL, triglycerides and $\mathrm{C}$ reactive protein when compared with DHCA $(\mathrm{p}<0,001)$. The two groups that followed the diet of points presented bigger average of autoantibodies anti-LDL-ox at the end of the study ( $p<0,001$ ). Conclusion: A low fat diet reduced biomarker of inflammation and serum lipids even in hypercholesterolemic patients treated with statins.

Keywords: cholesterol/saturated fat index (CSI), statins, atherosclerosis, lipoproteins, $\mathrm{C}$ reactive protein, autoantibodies anti-LDLox. 


\section{ÍNDICE}

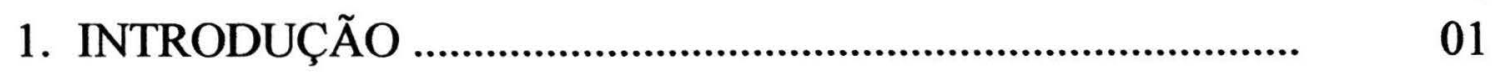

1.1. As doenças cardiovasculares .................................................... 01

1.2. Fatores de risco para doenças cardiovasculares......................... 04

1.3. Dislipidemias .........................................................................

1.4. Classificação das dislipidemias ............................................... 10

1.5. Aterogênese ............................................................................... 11

1.5.1. Modificação oxidativa da LDL .............................................. 13

1.5.2. Proteína C Reativa ................................................................

1.6. Alimentação e dislipidemias ........................................................ 19

1.7. Potencial aterogênico dos alimentos ........................................ 21

1.8. Tratamento das dislipidemias ................................................ 23

1.8.1. Tratamento dietético das dislipidemias .................................. 24

1.8.2. Tratamento farmacológico das dislipidemias ....................... 26

1.9. Índice de colesterol .................................................................... 28

2. JUSTIFICATIVA …………………………………………...

3. OBJETIVOS ………………………………………….......

3.1. Objetivo geral …………………………………………......

3.2. Objetivos específicos .............................................................

4. METODOLOGIA ……………………………………….....

4.1. Delineamento do estudo ........................................................

4.2. População e local de estudo .....................................................

4.3. Amostra ……………………………………………….....

4.4. Critérios de seleção e exclusão …………………………….....

4.5. Coleta de dados …………………………………………... 
4.6. Protocolo de Pesquisa ..............................................................

4.7. Variáveis de estudo ................................................................

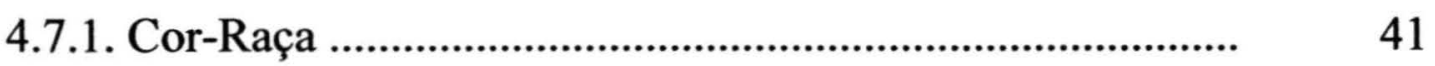

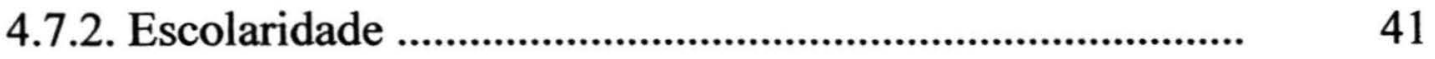

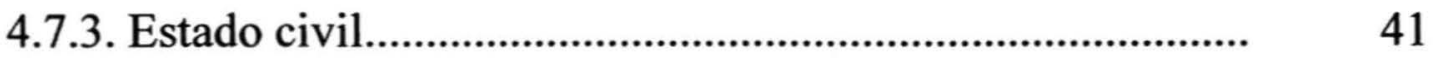

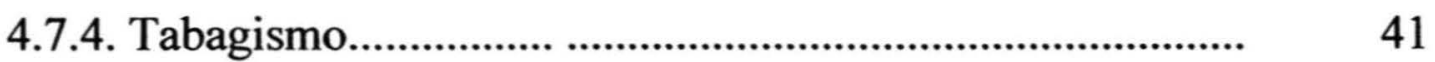

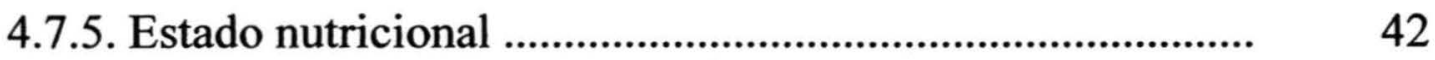

4.7.6. Consumo alimentar .............................................................. 44

4.7.7. Avaliação do perfil lipídico ................................................ 46

4.7.8. Avaliação da Proteína C Reativa ......................................... 47

4.7.9. Detecção de Auto-anticorpos Anti-LDLox no Plasma ...

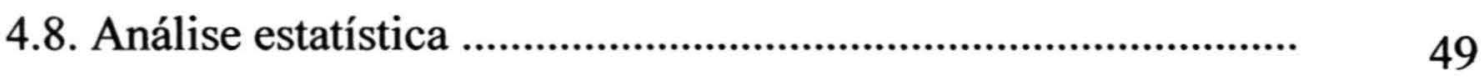

4.9. Aspectos Éticos ............................................................... $\quad 50$

5. RESULTADOS ................................................................. 52

5.1. Características da população em estudo ..................................... 52

5.2. Avaliação do efeito da dieta proposta pelo Sistema de Pontos 57 para Controle de Colesterol e Gordura no Sangue

5.2.1. Consumo Alimentar ............................................................ 57

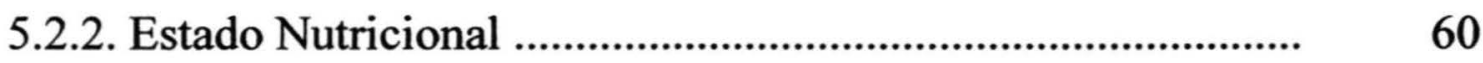

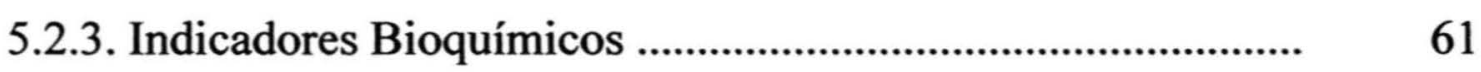

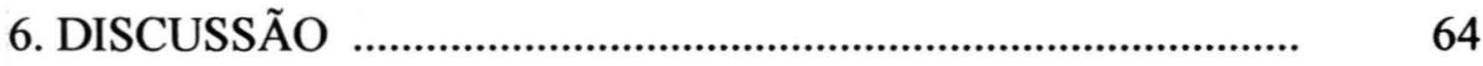

6.1. Características da população em estudo ..................................... 64

6.2. Avaliação do efeito da dieta proposta pelo Sistema de Pontos 66 sobre o estado nutricional 
6.3. Avaliação do efeito da dieta proposta pelo Sistema de Pontos sobre o perfil lipídico

6.4. Avaliação do efeito da dieta proposta pelo Sistema de Pontos sobre marcadores inflamatórios

7. CONCLUSÃO

8. REFERÊNCIAS

\section{ANEXOS}

ANEXO I - Dieta tradicional para o controle de dislipidemias ......

ANEXO II - Sistema de Pontos para Controle de Colesterol e Gordura no Sangue

ANEXO III - Termo de Consentimento Livre e Esclarecido

ANEXO IV - Instrumentos de coleta de dados

ANEXO V - Parecer do Comitê de Ética da Faculdade de Saúde

Pública da Universidade de São Paulo, sobre o presente estudo .... ANEXO VI - Dados descritivos da população em estudo 


\section{LISTA DE QUADROS}

Quadro 1 - Recomendações dietéticas para o tratamento de 25

hipercolesterolemia

Quadro 2 - Classificação do estado nutricional de adultos, segundo o Índice

de Massa Corporal

Quadro 3 - Medida abdominal e risco para complicações metabólicas associadas à obesidade em caucasianos

Quadro 4 - Valores de referência de lipídeos séricos para indivíduos com 20 anos de idade ou mais.

Quadro 5 - Valores de referência de proteína C reativa 


\section{LISTA DE FIGURAS}

Figura 1 - Metabolismo de lipoproteínas

Figura 2 - Processo de formação da lesão ateromatosa

Figura 3 - Delineamento do Estudo

Figura 4 - Delineamento do Estudo.

Figura 5 - Boxplot do Índice de Massa Corporal (IMC) dos indivíduos, segundo grupos de estudo. São Paulo, 2007 


\section{LISTA DE TABELAS}

Tabela 1 - Medidas-resumo da idade (anos) dos indivíduos, segundo grupo de estudo. São Paulo, 2007.

Tabela 2 - Características sócio-demográficas dos indivíduos, segundo grupos de estudo. São Paulo, 2007

Tabela 3 - Distribuição dos indivíduos, segundo estado nutricional e grupos de estudo. São Paulo, 2007

Tabela 4 - Valor energético e de macronutrientes, segundo grupos de estudo ao final da pesquisa. São Paulo, 2007

Tabela 5 - Variáveis lipídicas, segundo grupos de estudo. São Paulo, 2007.

Tabela 6 - Consumo de vitaminas antioxidantes, segundo grupos de estudo.

São Paulo, 2007

Tabela 7 - Variáveis antropométricas, segundo grupos de estudo. São Paulo, 2007

Tabela 8 - Variáveis de perfil lipídico, segundo grupos de estudo. São Paulo, 61 2007

Tabela 9 - Média das variáveis inflamatórias, segundo grupos de estudo. São 62 Paulo, 2007 


\section{RELAÇÃO DAS ABREVIATURAS}

\section{Sigla Descrição}

AHA American Heart Association

ANVISA Agência Nacional de Vigilância Sanitária

Anti-LDLox Anticorpos para LDLox

CA Circunferência abdominal

CELAFISCS Centro de estudos do Laboratório de Aptidão Física de São Caetano

CETP Proteína de transferência de colesterol esterificado

CDC Centers for Disease Control and Prevention

CI Índice de Colesterol (cholesterol index)

CSI Índice de colesterol/gordura saturada

DCV Doença cardiovascular

ECNT Enfermidades Crônicas Não Transmissíveis

EDTA Etilenodiaminotetracético

ERO Espécies reativas de oxigênio

GLM General Linear Models

HDL Lipoproteína de alta densidade

HMG-CoA Hidroxi-metil-glutaril CoA

IBGE Instituto Brasileiro de Geografia e Estatística

IDL-c Lipoproteína de densidade intermediária

IMC Índice de Massa Corporal

IPAQ International Physical Activity Questionnaire

KAPS Kuopio Atherosclerosis Prevention Study

LCAT Lecitina colesterol acil transferase

LDL Lipoproteína de baixa densidade

LDL-ox Lipoproteína de baixa densidade oxidada

LPL Lipase lipoprotéica

MDA Malonaldeído 


$\begin{array}{cl}\text { MONICA } & \text { Monitoring trends and determinants in Cardiovascular disease } \\ \text { NCEP } & \text { Nation Cholesterol Education Program } \\ \text { NDS } & \text { Nutrition Data System } \\ \text { NHANES } & \text { National Health and Nutrition Examination } \\ \text { PASS } & \text { Power Analysis and Sample Size } \\ \text { PCR } & \text { Proteína C reativa } \\ \text { PHS } & \text { Physician'Health Study } \\ \text { PLAC } & \text { Pravastatin Limitation of Atherosclerosis in the Coronary Arteries } \\ \text { POFs } & \text { Pesquisas de Orçamento Familiar } \\ \text { SBAN } & \text { Sociedade Brasileira de Alimentação e Nutrição } \\ \text { SBC } & \text { Sociedade Brasileira de Cardiologia } \\ \text { SPSS } & \text { Statistical Package for Social Science } \\ 4 S & \text { Scandinavian Sinvastatin Survival Study Group } \\ \text { SUS } & \text { Sistema Único de Saúde } \\ \text { VLDL } & \text { Lipoproteína de muito baixa densidade } \\ \text { WHO } & \text { World Health Organization }\end{array}$


1. INTRODUÇÃO 


\section{INTRODUÇÃO}

Nas últimas décadas têm-se observado nos países desenvolvidos e em desenvolvimento, modificações na sua estrutura etária, com o aumento da expectativa de vida e conseqüente envelhecimento da população. Tal processo tem sido associado a alterações no perfil de morbimortalidade da população, com a crescente importância das chamadas enfermidades crônicas não transmissíveis (ECNT) em comparação às condições infecciosas e parasitárias, com destaque para as doenças cardiovasculares (LAURENTI, 1982; LOLIO, 1994; MONTEIRO, 1995; JUNIOR e col., 2003).

Paralelamente ao envelhecimento da população e alterações no perfil de morbimortalidade, observa-se um aumento no consumo de alimentos processados, refinados, ricos em lipídeos, sódio e açúcar, em detrimento dos alimentos integrais (MONDINI e MONTEIRO, 1994; MONTEIRO e col., 1995; DREWNOWSKI e POPKIN, 1997; MONTEIRO e col., 2000). Estas modificações nos hábitos alimentares foram acompanhadas pela adoção de um estilo de vida mais sedentário, o que contribui para o aumento das ECNT.

\subsection{As doenças cardiovasculares}

Para caracterizar o problema das doenças cardiovasculares (DCV) é importante citar alguns aspectos referentes à evolução da população mundial a partir do início do século XX. Esse período foi marcado por uma rápida e sustentada 
modificação dos padrões de morbimortalidade, da expectativa de vida ao nascer e da fertilidade (LAURENTI, 1982; LOLIO, 1994).

A conquista de melhores condições de saneamento do meio, imunização em massa e melhoria dos padrões de vida e nutrição tornou possível a queda da mortalidade infantil e de crianças em idade pré-escolar e o aumento da expectativa de vida da população (LAURENTI, 1982; JUNIOR e col., 2003).

Com todas essas transformações, vem ocorrendo, sobretudo nos países desenvolvidos, mas também naqueles em desenvolvimento, uma mudança da estrutura da população, com maior proporção de idosos e menor de jovens. Este fenômeno é denominado TRANSIÇÃO DEMOGRÁFICA. A ela tem se associado o fenômeno TRANSIÇÃO EPIDEMIOLÓGICA, que é a modificação do quadro de morbimortalidade da sociedade: as enfermidades infecciosas e parasitárias vêm sendo substituídas pelas ECNT na prevalência e na mortalidade da população (LOLIO, 1994).

Como conseqüência do envelhecimento da população, começaram a destacarse outras enfermidades, e destas particularmente as doenças cardiovasculares (DCV) (LAURENTI, 1982; LOTUFO e LOLIO, 1995).

As DCV constituem um conjunto de afeç̧ões com etiologias e manifestações clínicas diversas de grande importância. Elas representam a primeira causa de óbito nos países desenvolvidos e em muitos países em desenvolvimento, incluindo o 
Brasil, onde representam um terço de todas as mortes (LOTUFO e LOLIO, 1995; LOTUFO, 1996; LOTUFO, 1998; LAURENTI e BUCHALLA, 2001; MANSUR e col., 2001; LESSA, 2004).

A participação das enfermidades cardiovasculares na mortalidade da população brasileira vem crescendo desde meados do século XX. Em 1950, apenas $14,2 \%$ das mortes ocorridas nas capitais brasileiras eram atribuídas às moléstias circulatórias; passaram a $21 \%$ em 1960, 24,8 \% em 1970 e $30 \%$ em 1980 (MINISTÉRIO DA SAÚDE, 1993; LOTUFO e LOLIO, 1995). Em 2001, as cardiopatias contribuíram com $32 \%$ de todos os óbitos nas capitais dos estados brasileiros (MINISTÉRIO DA SAÚDE, 2003; JUNIOR e col., 2003).

As moléstias do aparelho circulatório, além de contribuírem de modo destacado para a mortalidade, são causas freqüentes de morbidade, implicando 10,74 milhões de dias de internação pelo Sistema Único de Saúde (SUS) e representando a principal causa dos gastos em assistência médica - 16,2 \% do total (LOTUFO e LOLIO, 1995; LOTUFO, 1996).

As DCV, além do seu papel no perfil da mortalidade, têm importância ao serem analisadas quanto às alterações patológicas que acarretam aos indivíduos, muitas vezes irreversíveis com conseqüentes incapacidades. Apresentam, como outras ECNT, uma história natural prolongada, caracterizada por um longo período de latência, extenso curso assintomático, envolvimento de múltiplos fatores de risco e participação importante do ambiente (LESSA, 1998). 
Faz-se necessária, portanto, a investigação das causas determinantes das atuais condições de saúde e de vida dos indivíduos bem como o tratamento e controle das enfermidades cardiovasculares que incidem na população.

\subsection{Fatores de risco para doenças cardiovasculares}

Nas últimas décadas, os estudos epidemiológicos sobre aterosclerose, principalmente o de Framingham (ANDERSON e col., 1987; D'AGOSTINO e col., 2001), mostraram que certas condições biológicas e hábitos de vida, denominados fatores de risco, encontravam-se com maior freqüência em indivíduos portadores de doenças cardiovasculares.

A presença desses fatores de risco em determinados indivíduos não significa, necessariamente, que eles desenvolverão a enfermidade cardiovascular, mas indica que estão predispostos ao seu aparecimento (ARAÚJO, 2002).

A Sociedade Brasileira de Cardiologia, por meio de seu Departamento de Aterosclerose (SBC, 2001) aponta os seguintes fatores de risco para o aparecimento de doenças cardiovasculares:

- idade e sexo: o risco de doença cardiovascular aumenta de acordo com a idade, principalmente a partir dos 45 anos para homens e dos 55 anos para mulheres. $\mathrm{O}$ sexo masculino apresenta maior risco para esse tipo de doença em praticamente todas as faixas etárias; 
- história familiar: o parentesco de primeiro grau com indivíduos que apresentaram doença cardiovascular prematura representa outro fator de risco;

- tabagismo: indivíduos que não são tabagistas ou que deixaram de fumar diminuem o risco de doenças cardiovasculares;

- hipertensão arterial sistêmica: para a prevenção de doenças cardiovasculares, recomenda-se que os níveis pressóricos mantenham-se inferiores a 140/90 $\mathrm{mmHg}$;

- diabetes mellitus: diabéticos são considerados portadores de aterosclerose, devido a elevada incidência de lesões ateroscleróticas nestes indivíduos;

- HDL-colesterol: o nível sérico de HDL-colesterol inferior a $40 \mathrm{mg} / \mathrm{dL}$ representa um risco para o aparecimento e desenvolvimento de doença cardiovascular; no entanto valor a partir de $60 \mathrm{mg} / \mathrm{dL}$ é considerado fator de proteção, podendo anular algum fator de risco positivo;

- LDL-colesterol: há três categorias de riscos que modificam os níveis recomendados de LDL-colesterol. Na presença de doença arterial coronariana já instalada $-<100 \mathrm{mg} / \mathrm{dL}$; na presença de dois ou mais fatores de risco dos citados acima $-<130 \mathrm{mg} / \mathrm{dL}$; e, na presença de até um desses fatores de risco $-<160$ $\mathrm{mg} / \mathrm{dL}$.

São apontados, ainda, como fatores de risco para a doença cardiovascular a obesidade representada por alto Índice de Massa Corporal (IMC), aumento do perímetro abdominal e do percentual de gordura corporal (MARTINS e col., 1989; BJORNTORP, 1995; DAVI e col., 2002; ESPOSITO e col., 2003); sedentarismo (MATSUDO, 1996; MATSUDO e col., 2002a; MATSUDO e col. 2002b); uso de 
medicamentos, como os contraceptivos orais (BARROS e MARTINEZ, 1995); estresse (MACAMBIRA e col., 2001) e fatores dietéticos (CERVATO e col., 1997; FORNÉS e col., 1998; FORNÉS e col., 2000).

De maneira geral, os fatores de risco não ocorrem de modo isolado nos indivíduos, sendo comum a presença de duas ou mais condições. Segundo dados do estudo de Framingham, os riscos relacionados a cada um dos fatores citados, articulam-se de forma sinérgica quando eles ocorrem concomitantemente (CASTELLI, 1984).

\subsection{Dislipidemias}

Os lipídeos presentes no plasma mais importantes do ponto de vista fisiológico e clínico são os ácidos graxos, os triglicérides, os fosfolipídeos e o colesterol (SANTOS e MARANHÃO, 1998).

Os lipídeos são insolúveis em meio aquoso. Sendo assim, para que sejam transportados na circulação sistêmica, organizam-se em estruturas macromoleculares denominadas lipoproteínas, que consistem de uma camada externa que contém proteínas (apolipoproteínas), lipídeos polares (fosfolipídeos e colesterol nãoesterificado) e um núcleo de lipídeos neutros (triglicérides, ésteres de colesterol e vitaminas lipossolúveis) (STEIN e MYERS, 1994). As apolipoproteínas têm diversas funções no metabolismo das lipoproteínas como: componente estrutural (apo B100 e 
B48), meio ligante a receptores de membrana (apo B100 e E) ou co-fatores enzimáticos (apos CII, CIII e AI) (RADER e WILSON, 1995; SBC, 2001).

Existem cinco classes principais de lipoproteínas: quilomícrons (rico em triglicérides e menos densos); VLDL (lipoproteína de densidade muito baixa, rica em triglicérides, de origem hepática); IDL (lipoproteína de densidade intermediária, produzida a partir do metabolismo da VLDL); LDL (lipoproteína de baixa densidade, rica em colesterol) e HDL (lipoproteína de alta densidade, rica em proteínas e colesterol) (HIRATA e HIRATA, 2002).

Os quilomícrons são os responsáveis pelo transporte dos lipídeos provenientes da dieta (via exógena). O transporte de lipídeos de origem hepática ocorre por meio da VLDL e LDL que caracteristicamente contêm apoB-100 (via endógena). Os triglicérides das VLDL, assim como os dos quilomícrons, são hidrolizados pela lipase lipoprotéica (LPL). Os ácidos graxos são liberados para os tecidos e metabolizados. Os quilomícrons se transformam em remanescentes que são removidos pelo fígado por receptores específicos (SBC, 2001).

Uma parte da VLDL ao perder componentes lipídicos e protéicos se transforma em LDL, que transporta o colesterol ao fígado e tecidos periféricos. A VLDL troca triglicérides por ésteres de colesterol com as HDL e LDL por intermédio da proteína de transferência de colesterol esterificado (CETP). Tanto a VLDL como a LDL são removidas no fígado por intermédio de ligação com receptores específicos. Dentre eles, o receptor da LDL também denominado receptor B/E é o 
mais importante. A expressão desses receptores é a principal responsável pelo nível de colesterol no sangue e depende da atividade da enzima HMG-CoA redutase (hidroxi-metil-glutaril CoA redutase) que é a enzima limitante da síntese do colesterol (SBC, 2001).

As partículas de HDL são sintetizadas no fígado e no intestino ou a partir de componentes das lipoproteínas ricas em triglicérides que sofrem ação enzimática da lipase lipoprotéica (MEDEIROS, 2005). A apo A-I e a apo AII representam o principal conteúdo protéico da HDL. São as mais densas partículas de lipoproteínas, e estão envolvidas no transporte reverso de colesterol, o único processo pelo qual o colesterol livre dos tecidos periféricos é transportado para o fígado para ser metabolizado ou excretado (SBC, 2001).

Neste processo, o colesterol é esterificado por ação da LCAT (lecitina colesterol acil transferase) tendo a apo A-I como cofator. Estas partículas são captadas pelo fígado através dos receptores $\mathrm{E}$ ou B/E. A HDL capta o colesterol das células e os transfere com outras lipoproteínas (especialmente a VLDL), ou leva-o para o fígado onde será metabolizado. O organismo dispõe desse processo para eliminar o colesterol através da bile, como colesterol livre ou como ácidos biliares (SBC, 2001). A Figura 1 apresenta o metabolismo de lipoproteínas plasmáticas, por meio da via endógena e o transporte reverso de colesterol.

Quando ocorre um desequilíbrio no metabolismo das lipoproteínas têm-se as dislipidemias (LIMA, 1999). Quando os níveis séricos das lipoproteínas estão acima 
dos valores de referência, a dislipidemia é denominada hiperlipidemia; se estiverem abaixo dos valores determinados, é denominada hipolipidemia (SBC, 1996).

A importância da hiperlipidemia reside na comprovada relação que essa alteração metabólica mantém com o desenvolvimento de doença arterial coronariana Assim, para a redução da morbidade e da mortalidade cardiovascular, é de suma importância um diagnóstico adequado, visando o tratamento eficaz.

Figura 1 - Metabolismo de lipoproteínas

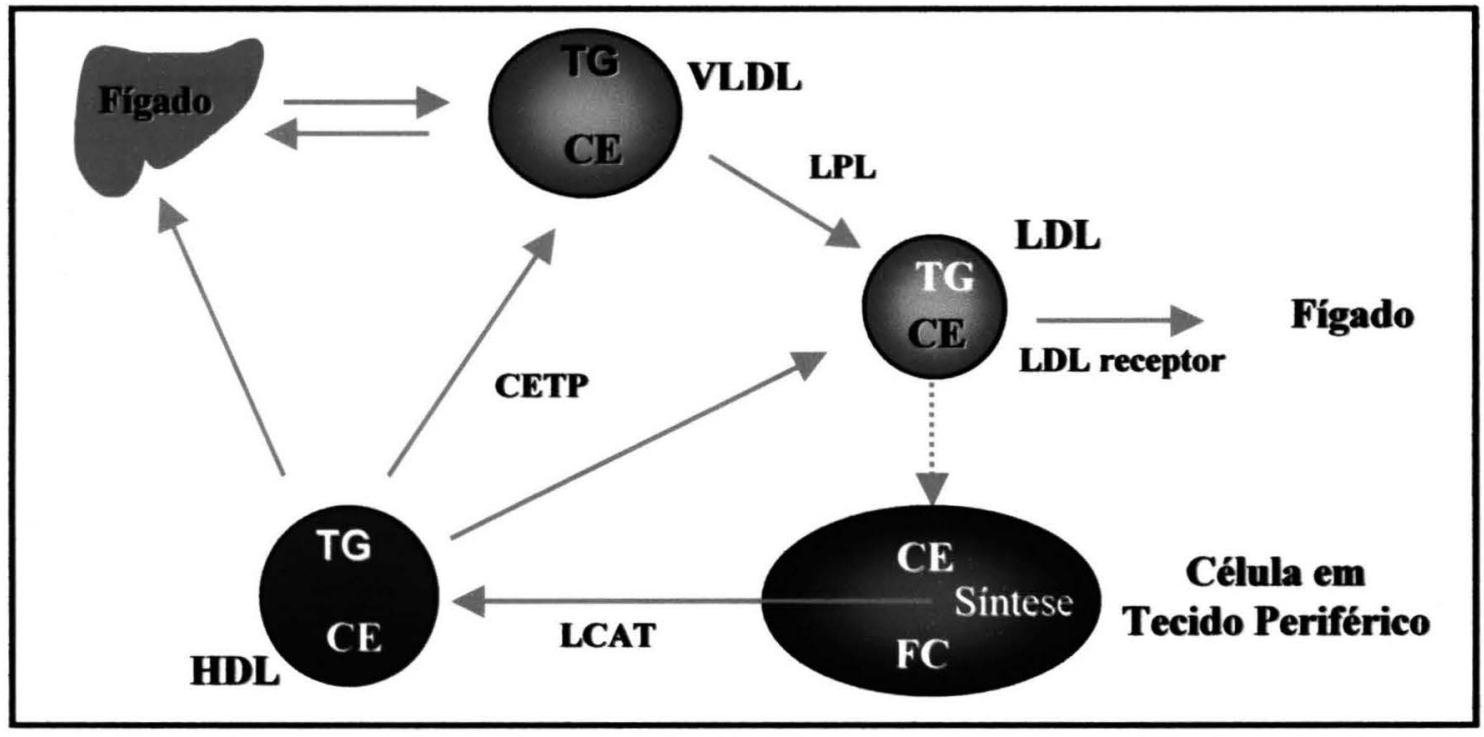

Fonte: Adaptado de BITTENCOURT JR e SENNA (2002) 


\subsection{Classificação das dislipidemias}

As III Diretrizes Brasileiras sobre Dislipidemias e Diretrizes de Prevenção da Aterosclerose do Departamento de Aterosclerose da Sociedade Brasileira de Cardiologia de 2001 classificam as dislipidemias de duas formas:

\section{Classificação laboratorial}

- hipercolesterolemia isolada: aumento do colesterol total ( $>240 \mathrm{mg} / \mathrm{dL})$ e/ou de LDL-colesterol (>160 mg/dL);

- hipertrigliceridemia isolada: aumento dos triglicérides ( $>200 \mathrm{mg} / \mathrm{dL})$;

- hiperlipidemia mista: aumento do colesterol total (>240 mg/dL) e dos triglicérides ( $>200 \mathrm{mg} / \mathrm{dL})$;

- diminuição isolada da HDL-colesterol ( $<40 \mathrm{mg} / \mathrm{dL})$ ou associada ao aumento dos triglicérides ( $>200 \mathrm{mg} / \mathrm{dL})$ ou LDL-colesterol ( $>160 \mathrm{mg} / \mathrm{dL})$.

\section{Classificação etiológica}

- dislipidemias primárias: de origem genética, homozigótica ou heterozigótica;

- dislipidemias secundárias: causada por outras doenças (hipotiroidismo, diabetes mellitus, síndrome nefrótica, insuficiência renal crônica, obesidade, alcoolismo, icterícia obstrutiva) ou pelo uso de medicamentos (altas doses de diuréticos, betabloqueadores, corticosteróides e anabolizantes). 


\subsection{Aterogênese}

O aumento do colesterol total e, mais especificamente, da fração LDL têm sido diretamente relacionados ao desenvolvimento de lesões ateroscleróticas (PYORALA, 1987; DIETSCHY, 1997; XAVIER e col., 2004).

A aterogênese é um processo dinâmico, crônico e multifatorial, caracterizado por uma sucessão de desordens nas camadas íntima e média das paredes vasculares (SBC, 2001; PORTAL e col., 2003). Dentre essas alterações estão o aumento de permeabilidade do endotélio, infiltração de monócitos, proliferação de células musculares lisas, agregação plaquetária e acúmulo de lipídeos, cálcio e de componentes da matriz celular (BITTENCOURT JR e SENNA, 2002).

Tem sido proposta a seguinte hipótese para o desenvolvimento da lesão aterogênica: na presença de altos níveis de LDL no plasma, sua concentração na íntima arterial aumenta e o maior número de partículas disponíveis no interstício leva a geração da LDL-ox (lipoproteína de baixa densidade oxidada), uma lipoproteína extremamente aterogênica (OLIVEIRA e QUINTÃO, 1992; BITTENCOURT JR e SENNA, 2002; PORTAL e col., 2003).

Estas lipoproteínas oxidadas atuam sobre as células endoteliais promovendo injúria e formação de moléculas de adesão, facilitando a migração dos monócitos para a camada íntima do vaso. Os monócitos sofrem modificações fenotípicas que os transformam em macrófagos e sob ação das LDL-ox, passam a acumular colesterol e 
ésteres de colesterol transformando-se em foam cells (células espumosas). As LDLs nativas também passam para o interior do vaso, transformando-se em LDL-ox em razão da interação com as células endoteliais. As células da musculatura lisa do vaso, sob a ação das LDL-ox, também migram para a camada íntima tornando-se foam cells (OLIVEIRA e QUINTÃO, 1992; BITTENCOURT JR e SENNA, 2002).

Diferentes mediadores inflamatórios são liberados no espaço intimal, perpetuando e ampliando o processo, levando finalmente à formação da placa aterosclerótica. Esta é constituída por elementos celulares, componentes da matriz extracelular e núcleo lipídico. Ao longo da vida, pequenas rupturas (tromboses) parecem ocorrer, determinando a remodelação das placas, freqüentemente sem manifestações clínicas. Todavia, o grau de trombose sobreposta à placa rota determinará a magnitude do evento cardiovascular (SBC, 2001). A Figura 2 ilustra a formação da placa de ateroma nos vasos sanguíneos. 
Figura 2 - Processo de formação da lesão ateromatosa

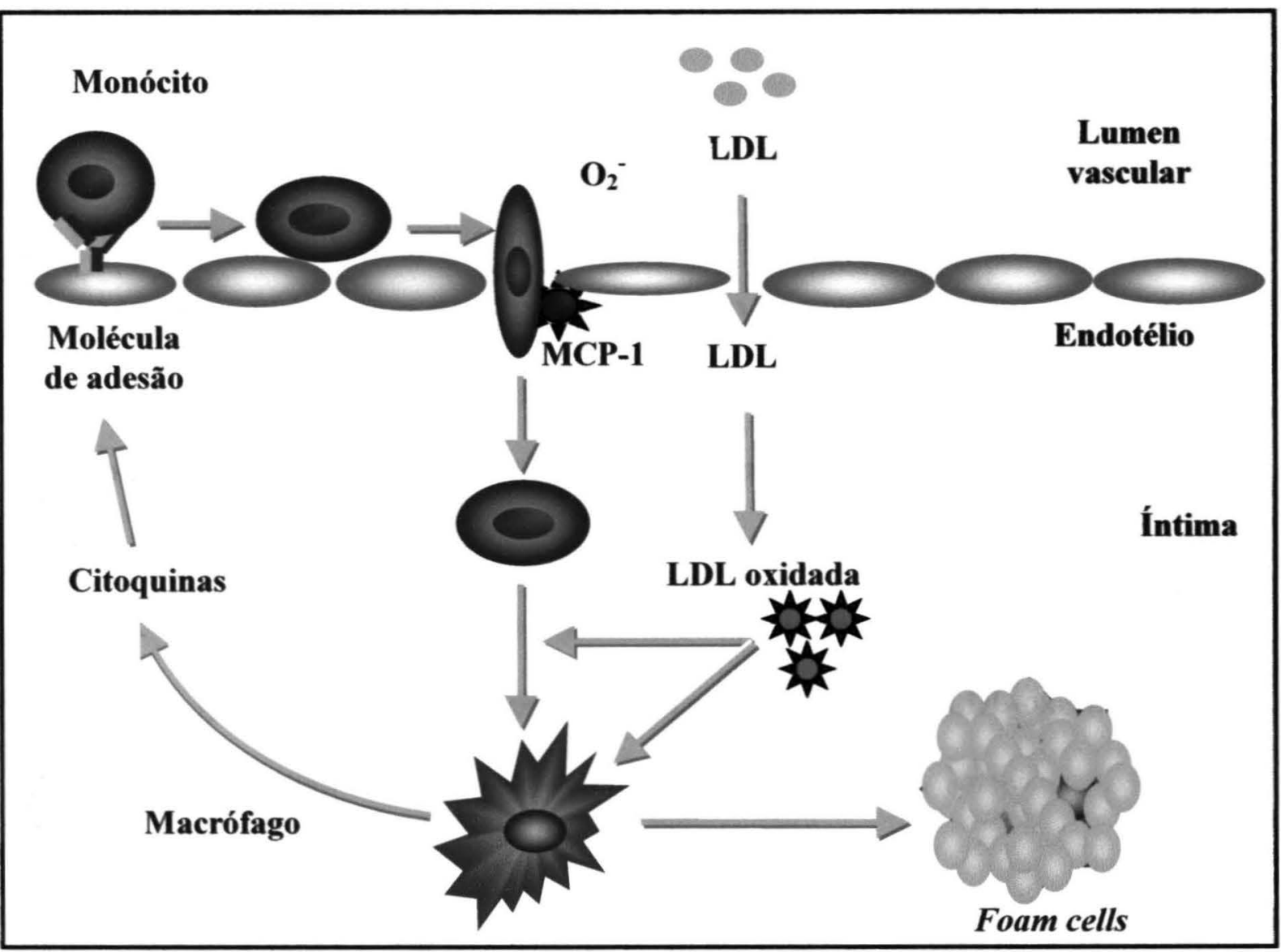

Fonte: Adaptado de BITTENCOURT JR e SENNA (2002)

\subsubsection{Modificação oxidativa da LDL}

Nos últimos anos, consolidou-se progressivo conjunto de informações de que as modificações oxidativas das partículas de LDL tem um papel fundamental na origem inflamatória e autoimune da aterosclerose (BATLOUNI, 1997; CHANG e col., 1997; DAMASCENO e col., 2000; PORTAL e col., 2003; FERNVIK e col., 2004). Nesse sentido, estudos experimentais in vitro e in vivo mostram que a 
elevação isolada nos níveis de LDL, por si só, não é capaz de explicar a totalidade dos processos envolvidos na aterogênese.

Recentemente, foi demonstrado que níveis plasmáticos elevados de LDL-ox se relacionam diretamente com a instabilidade da placa em lesões ateroscleróticas de artérias coronárias humanas (XAVIER e col., 2004). Estudo realizado por EHARA e col. (2001) por meio de dosagem dos níveis de LDL-ox em pacientes com infarto agudo do miocárdio, angina instável, angina estável e controles, revelou uma correlação positiva com a gravidade da síndrome coronariana aguda. Os valores de LDL-ox eram quatro vezes mais elevados em pacientes com infarto agudo do miocárdio, quando comparados aos controles, sugerindo que a LDL-ox circulante pode ser um marcador de gravidade em eventos cardiovasculares.

Há evidências de que, na maioria das dislipidemias, há aumento do tempo de permanência das lipoproteínas no compartimento plasmático, facilitando a modificação de partículas, como a lipoproteína de baixa densidade (LDL), por processos de oxidação, mediados por metais de transição (principalmente cobre e ferro), e espécies reativas de oxigênio (ERO) ou nitrogênio geradas por células endoteliais, macrófagos, células do músculo liso, monócitos e neutrófilos ativados (ABDALLA e col., 1994; ARAÚJO e col., 1995; ABDALLA, 2001). Como conseqüência da oxidação, ocorre o acúmulo de subprodutos, tais como o malonaldeído (MDA), considerado como marcador do processo de oxidação no organismo (NAVAB e col., 1996). 
A modificação oxidativa da LDL resulta em alterações de suas características físico-químicas e estruturais, que a torna um mediador importante em diversas etapas da aterosclerose. Esta subfração da LDL (LDL-ox) é trombogênica, citotóxica para células endoteliais, quimiotática para monócitos circulantes, induz a diferenciação e a adesão de monócitos às células endoteliais (BARROS e col., 2006). A captação da LDL-ox pelos macrófagos, leva a formação de células espumosas, mediada por um grupo de receptores chamados scavengers (SR).

Além disso, a LDL-ox é imunogênica e induz à produção de anticorpos e, subseqüente, formação de imunocomplexos. Estes, quando captados pelos leucócitos, favorecem o acúmulo de colesterol éster nestas células e também promovem sua ativação, e subseqüente, liberação de citoquininas, como a interleucina 1 (IL-1) e o fator de necrose tumoral $\alpha$ (TNF- $\alpha)$ (BERTOLAMI, 1995).

Estas citoquininas, além de apresentarem a capacidade de alterar os níveis lipídicos e lipoprotéicos, podem promover a expressão de várias moléculas de adesão celular (VCAM-1 e ICAM-1), o que induz a aderência de leucócitos às células endoteliais. Finalmente, estas células favorecem a atividade procoagulante e ao incremento de permeabilidade vascular (BERTOLAMI, 1995).

A LDL-ox tem sido reconhecida como um importante antígeno, e a resposta das células $T$ à LDL-ox pode induzir a ativação de células $B$, com produção concomitante de anticorpos (FERNVIK e col., 2004). Anticorpos da classe IgM e 
IgG específicos para LDL-ox, têm sido encontrados em algumas lesões e no sangue de pacientes com aterosclerose (BARROS e col., 2006).

A presença ou ausência de anticorpos anti-LDLox tem sido proposta como um importante marcador do desenvolvimento da aterosclerose e doença cardiovascular. No entanto, os estudos disponíveis são inconsistentes e muitas vezes contraditórios (FERNVIK e col., 2004).

Várias linhas de investigação têm demonstrado forte correlação entre valores elevados de LDL-ox e a presença de seus auto-anticorpos com o desenvolvimento da aterosclerose, a severidade da doença coronariana, o desenvolvimento da aterosclerose em pacientes transplantados e a instabilidade da placa ateromatosa (BARROS e col., 2006). De forma contrária, alguns estudos encontraram valores reduzidos de anticorpos anti-LDLox em pacientes portadores de doença coronariana e em fumantes. Outros autores concluíram que os anticorpos anti-LDLox não parecem estar associados a morbimortalidade cardiovascular ou falharam em demonstrar uma associação entre esses anticorpos e a aterosclerose (FERNVIK e col., 2004).

Os anticorpos para LDLox (anti-LDLox) são detectáveis em praticamente todos os indivíduos e em todas as idades, representando um marcador biológico indireto da peroxidação lipídica na LDL (SALONEN e col., 1992; GETZ, 2005). 


\subsubsection{Proteína C Reativa}

Atualmente, novos marcadores de risco têm demonstrado sua eficiência na detecção e prevenção da aterosclerose (JENKINS e col., 2003; KOENIG e col., 2003; MADSEN e col., 2003). Estes vêm determinar aqueles casos nos quais, pacientes aparentemente sem risco, acabam por desenvolver placa de ateroma e, posterior, evento coronariano. A identificação destes marcadores pode aumentar o entendimento sobre os mecanismos fisiopatológicos desta doença e possibilitar o desenvolvimento de novas medidas preventivas ou terapêuticas (SBC, 2001).

A Proteína $\mathrm{C}$ reativa é um marcador do processo inflamatório em indivíduos sadios e tem estabilidade comparável ao colesterol total (SBC, 2001; SANTOS e col., 2003) A PCR tem sido consistentemente associada ao risco cardiovascular e sua determinação parece ser de utilidade na identificação de eventos coronários (SBC, 2001; SIERKSMA e col., 2003).

Embora não se saiba o real da PCR, estudos imuno-histoquímicos demonstraram sua presença em tecidos inflamados, nos vasos ateroscleróticos e no miocárdio infartado. Tem sido demonstrado que a PCR aumenta a expressão de moléculas de adesão (ICAM-1, VCAM-1), liga-se a lipoproteínas plasmáticas e ativa o sistema complemento in vitro e in vivo, presente na maioria das células espumosas das placas ateroscleróticas (SANTOS e col., 2003). 
Uma meta-análise de estudos populacionais prospectivos comparou indivíduos no tercil mais baixo de valores de PCR com aqueles que estavam no tercil mais alto. Com uma boa consistência entre os estudos, foi observada uma odds de 2,0 (IC $95 \%=1,6-2,5)$ para eventos coronarianos no tercil mais alto. Estes estudos incluíram homens, mulheres e idosos. Estudos realizados com grandes populações como MONICA (Monitoring trends and determinants in Cardiovascular disease), Atherosclerosis Risk in Communities Study, Womens Health Study, Honolulu Heart Study e NHANES (National Health and Nutrition Examination) também foram representados. Em geral, a maioria dos estudos demonstrou uma relação entre valores de PCR e risco de incidência de doenças cardiovasculares (PEARSON e col., 2003).

MENDALL e col. (1996) estudaram 388 homens entre 50 e 69 anos de idade e demonstraram que a concentração sérica de PCR correlacionou-se com outros fatores de risco cardiovasculares (fatores lipídicos, hemostáticos e infecciosos, obesidade, tabagismo e idade) e que sua elevação estava fortemente associada à doença coronariana.

RIDKER e col. (1997) compararam 543 homens portadores de doença cardiovascular e 543 controles do Physician'Health Study (PHS), após seguimento de 8 anos, e mostraram que os níveis basais de PCR no $4^{\circ}$ quartil triplicavam o risco de ocorrência de infarto do miocárdio $(R R=2,9$, IC 95\%=1,8-4,6). Em 1998, os mesmos autores, analisaram esta mesma amostragem e observaram um aumento de 4 vezes no risco de desenvolver doença arterial periférica $(R R=4,1, \mathrm{IC} 95 \%=1,2-6,0)$ (RIDKER e col., 1998). 
Outros marcadores de risco cardiovascular como hiper-homocisteinemia (MANN e col. 1999; HAULRIK e col. 2002), hiper-fibrinogenemia, hiperreatividade plaquetária, resistência à insulina e os marcadores inflamatórios: selectinas E e P; moléculas de adesão ICAM-1; VCAM-1; TNF- $\alpha$; IL-6; também vêm sendo estudados (SILVA, 2004).

\subsection{Alimentação e dislipidemias}

Por meio de uma dieta adequada em quantidade e qualidade, o organismo adquire energia e os nutrientes necessários para o bom desempenho de suas funções e para a manutenção de um bom estado de saúde (MONDINI e MONTEIRO, 1994).

Experimentos e estudos observacionais têm apontado a dieta habitual como elemento fundamental de análise dos determinantes da susceptibilidade do aparecimento de ECNT (ZILVERSMIT, 1979; CONNOR e col., 1986; CONNOR e col., 1989; FORNÉS e col., 2000).

Entre os fatores de risco dietéticos para as dislipidemias e aterogênese podese citar o baixo consumo de substâncias antioxidantes, destacando-se a vitamina C, vitamina E, $\beta$-caroteno e outros carotenóides (VISIOLI, 2000; RAMALHO e col., 2003; TEPE e col., 2004), alguns minerais (principalmente os que constituem enzimas antioxidantes, como o selênio) e os compostos fenólicos (VISIOLI, 2000); o consumo elevado de cafeína (LANE e col., 1994); gorduras saturadas, ácidos graxos trans (WILLET e col., 1993; MOZAFFARIAN e col., 2006), colesterol e sódio (HE 
e WHELTON, 2002), contrastando com o baixo consumo de gorduras mono e poliinsaturadas (MARANGONI e GALLI, 2000) e de fibras alimentares (GREGORIO e col., 2001).

Estudos clínicos e epidemiológicos têm demonstrado que o consumo elevado de colesterol, gorduras saturadas e ácidos graxos trans têm papel importante na gênese das doenças cardiovasculares por aumentar as concentrações de lipídeos, principalmente de LDL (KANNEL, 1988; KATAN e col., 1995; HERRERA e col., 1996; HAYES, 1997; HAYES, 2001; MOZAFFARIAN e col., 2006). De forma contrária, o aumento do consumo de ácidos graxos monoinsaturados e poliinsaturados tem sido relacionado com a redução da concentração plasmática de lipoproteínas aterogênicas (LOTTENBERG, 1997).

As gorduras saturadas incluem os três principais ácidos graxos responsáveis pelo aumento do colesterol, os quais têm cadeia carbônica longa: ácido láurico, ácido mirístico e ácido palmítico (KRIS-ETHERTON e col., 1997; NELSON, 1998). As gorduras animais são as principais fontes de ácidos graxos saturados da dieta. Existem também óleos vegetais ricos em gorduras saturadas como o óleo de dendê, côco e de cacau (DZIEZAK, 1989). Já o colesterol dietético é encontrado somente em produtos de origem animal, e possui um menor efeito sobre a colesterolemia, quando comparado à gordura saturada (SBC, 2001).

O ácido oléico é o mais comum dos ácidos graxos monoinsaturados e se encontra na maioria das gorduras animais, incluindo aves, carne bovina, bem como 
em azeitonas, sementes e nozes. Os ácidos graxos poliinsaturados classificam-se, principalmente, nas séries ômega 3 e 6 . O ácido linoléico é o expoente mais importante da série (n-6) e está presente de forma abundante nos óleos vegetais como óleo de girassol, milho, soja e algodão (DZIEZAK, 1989; NELSON, 1998). O ácido $\alpha$-linolênico, representante da família $n-3$, é encontrado em sementes oleaginosas como canola, soja, linhaça e em peixes de água fria como arenque, sardinha, salmão e anchova (WILLET, 1994; FIGLIUOLO e CRAVEIRO, 1997; PARK e col., 1997).

Os ácidos graxos trans encontrados na dieta, originam-se por duas vias. Ocorrem naturalmente, em pequenas quantidades, nas carnes e no leite, pois são formados pelos ruminantes por meio de fermentação bacteriana (LICHTENSEIN e col., 2001). Além disto, encontram-se abundantemente na gordura vegetal hidrogenada, resultantes do processo industrial de hidrogenação catalítica, que se aplica aos óleos vegetais, líquidos à temperatura ambiente, com o objetivo de lhes conferir consistência semi-sólida a sólida.

\subsection{Potencial aterogênico dos alimentos}

A partir da observação dos resultados do estudo de Framingham (ANDERSON e col., 1987) e do clássico estudo dos "Sete Países" (KEYS, 1970) ficou definitivamente demonstrado o papel do colesterol e das gorduras saturadas como fatores de risco para doenças cardiovasculares e sua correlação com a aterosclerose. 
O potencial hiperlipidêmico e aterogênico dos alimentos está relacionado ao seu conteúdo de colesterol e gorduras saturadas, bem como ao total energético da dieta (ZILVERSMIT, 1979; CONNOR e col., 1986; CONNOR e col., 1989).

Estudos demonstraram que as gorduras saturadas e o colesterol da dieta suprimem a atividade hepática do receptor de LDL (receptor B/E), diminuindo a remoção de LDL do sangue, aumentando assim sua concentração sangüínea. De forma contrária, a diminuição do colesterol e gordura saturada provenientes da dieta aumenta a atividade do receptor de LDL das células do figado, aumenta a captação hepática de LDL, e diminui sua concentração no sangue (CONNOR e col., 1989; HERRERA e col., 1996; DIETSCHY, 1997).

Diante da importância dos níveis de colesterol no desenvolvimento das doenças cardiovasculares e sua relação com a dieta, diversos trabalhos foram realizados nas últimas décadas. Estudo realizado por KATO e col. (1973), em grupos populacionais de japoneses dos Estados Unidos, Havaí e Japão, avaliaram entre essas populações de mesma etnia, porém de meio sociocultural diverso, se havia diferenças quanto ao consumo de alimentos e desenvolvimento de doença coronariana. Os resultados demonstraram que a ocidentalização dos hábitos alimentares dos japoneses determinou o aparecimento de colesterolemia mais elevada e maior ocorrência, por exemplo, de doença isquêmica do coração. 
O estudo dos veteranos de Los Angeles, iniciado em 1959, avaliou, durante oito anos, 846 homens com idade média de 65 anos. Destes indivíduos, 424 receberam uma dieta rica em gordura poliinsaturada, contendo em média $365 \mathrm{mg}$ de colesterol por dia. Os 422 indivíduos restantes continuaram a receber uma dieta semelhante à habitualmente consumida, rica em gordura saturada e $653 \mathrm{mg}$ de colesterol por dia. A quantidade total de lipídeos de ambas as dietas era cerca de 40 $\%$ do valor calórico total. Ao final da pesquisa, verificou-se no grupo tratado, uma redução de $13 \%$ na colesterolemia e de $31 \%$ nos eventos coronarianos (GIANNINI, 1992; NOVAZZI, 1993).

O estudo de prevenção primária de Oslo, iniciado em 1973, avaliou 1232 homens entre 40 e 49 anos, durante cinco anos. Do grupo, 604 foram submetidos a uma dieta pobre em colesterol e gordura saturada e 628 permaneceram consumindo suas dietas habituais. No grupo tratado, houve redução de $13 \%$ do colesterol sérico, diminuição de $45 \%$ de eventos coronarianos, $41,4 \%$ de doenças cardiovasculares e $71 \%$ de morte súbita, quando comparados ao grupo sem intervenção dietética (LEREN, 1975; HIERMANN, 1981).

\subsection{Tratamento das dislipidemias}

Ao mesmo tempo em que se demonstrou uma relação direta entre níveis de colesterol com risco de mortalidade coronariana, estudos foram realizados para demonstrar que a terapêutica das dislipidemias reduziria a mortalidade geral (BARROS e MARTINEZ, 1995). 


\subsubsection{Tratamento dietético das dislipidemias}

Classicamente, a primeira conduta a ser adotada no tratamento das hiperlipidemias é a intervenção dietética, indicada isoladamente ou associada a medicamentos (POSNER e col., 1986, SANTOS, 1999; NCEP, 2001).

Para alcançar esse objetivo, os pacientes devem ser informados sobre a importância da dieta, a necessidade na mudança de estilo de vida e, principalmente, como proceder diante dessas situações, provavelmente utilizando técnicas adequadas de mudança de comportamento (NCEP, 2001; SBC, 2001).

A trigliceridemia pode ser reduzida pelo controle de carboidratos simples, bebidas alcoólicas e energia da dieta. A redução na ingestão de colesterol e gordura saturada pode ativar os receptores de LDL, aumentando o catabolismo dessas lipoproteínas e diminuindo sua concentração no sangue (SBC, 1996; SANTOS, 1999).

Segundo a American Heart Association (AHA, 2001) e o National Cholesterol Education Program (NCEP, 2001) o tratamento dietético da hipercolesterolemia deve ser feito de acordo com o seguinte quadro (Quadro 1). 
Quadro 1 - Recomendações dietéticas para o tratamento de hipercolesterolemia.

\begin{tabular}{|l|c|}
\hline \multicolumn{1}{|c|}{ Nutriente } & Ingestão Recomendada \\
\hline Gordura Total & $25 \mathrm{a} 35 \%$ das calorias totais \\
Ácidos Graxos saturados & $<7 \%$ das calorias totais \\
Ácidos graxos poliinsaturados & até $10 \%$ das calorias totais \\
Ácidos graxos monoinsaturados & até $20 \%$ das calorias totais \\
Carboidratos & $50 \mathrm{a} 60 \%$ das calorias totais \\
Proteínas & $10 \mathrm{a} 15 \%$ das calorias totais \\
Colesterol & $<200 \mathrm{mg} /$ dia \\
Fibras & 20 a $30 \mathrm{~g} /$ dia \\
Calorias & Para manter e atingir o peso ideal \\
\hline
\end{tabular}

Fonte: AHA (2001); NCEP (2001).

De maneira geral, o controle das dislipidemias depende do grau de aderência do paciente ao tratamento dietético (SBC, 1996). Para melhor adesão à dieta, esta deve se aproximar ao máximo possível da dieta habitual, devendo ser nutricionalmente adequada e agradável ao paladar (AHA, 2001).

No entanto, o que se observa nos tratamentos dietéticos tradicionais (Anexo I) é que o paciente recebe um impresso com "alimentos permitidos" e "alimentos proibidos", o que não estimula o seguimento da dieta, pois na maioria das vezes os alimentos proibidos são os de maior preferência do indivíduo (ZILVERSMIT, 1979).

Desta forma, uma ferramenta de intervenção dietética de fácil compreensão e que permita ao paciente gerenciar sua própria alimentação, sentindo-se um agente de mudança de seus próprios hábitos alimentares e tornando-se um aliado no tratamento, poderia levar a um melhor resultado em relação ao que se tem conseguido com os tratamentos dietéticos tradicionais. 


\subsubsection{Tratamento farmacológico das dislipidemias}

O objetivo do tratamento de pacientes com hipercolesterolemia é reduzir as concentrações plasmáticas de lipoproteínas aterogênicas. A primeira estratégia terapêutica para o tratamento é a orientação dietética, mudanças no estilo de vida e atividade física, após a exclusão de fatores secundários (NCEP, 2001; BERTOLINI e BAZOTTE, 2002).

Caso a terapia com dieta e outras mudanças de hábito não normalizem adequadamente os lipídeos plasmáticos, drogas hipolipemiantes passam a ser prescritas. Ressalta-se, no entanto, que indivíduos com doença coronariana estabelecida devem iniciar o tratamento das hiperlipidemias com o uso de medicamentos e dieta para alcançar as metas de redução das lipoproteínas aterogênicas (NCEP, 2001; BERTOLINI e BAZOTTE, 2002).

As drogas disponíveis para o tratamento das dislipidemias são: sequestrantes de ácidos biliares, estatinas, fibratos, ácido nicotínico e probucol (NOVAZZI, 1999). Embora muitos fármacos disponíveis reduzam os valores plasmáticos de LDL, as drogas com maior efeito atualmente são as estatinas, que atuam como inibidores da enzima HMG-Coa redutase (3-hidroxi-3-metilglutaril-Coa redutase) (BERTOLINI e BAZOTTE, 2002). As principais classes disponíveis são a lovastatina, pravastatina, sinvastatina, fluvastatina, cerivastatina e a atorvastatina (NOVAZZI, 1999). 
O estudo escandinavo 4 S (Scandinavian Sinvastatin Survival Study Group) realizado em 1994, com 4.444 indivíduos demonstrou, que a terapia hipolipidêmica é bastante eficaz na redução do risco de coronariopatias. Neste estudo, pacientes com história de angina ou infarto do miocárdio, receberam doses de 20 a $40 \mathrm{mg} / \mathrm{dia}$ de sinvastatina e a redução de colesterol diminuiu a taxa de mortalidade por coronariopatia em $42 \%$ num período de seis anos, como também reduziu em $30 \%$ a taxa de mortalidade geral e eventos cerebrovasculares (SCANDINAVIAN SINVASTATIN SURVIVAL STUDY GROUP, 1994).

Nos estudos PLAC I e II (Pravastatin Limitation of Atherosclerosis in the Coronary Arteries), pacientes recebendo doses de 20 a $40 \mathrm{mg} / \mathrm{dia}$ de pravastatina obtiveram uma redução de $60 \%$ nos eventos cardiovasculares (CROUSE e col., 1995; PITT e col., 1995). Resultados semelhantes foram observados no estudo KAPS (Kuopio Atherosclerosis Prevention Study), que após três anos de tratamento com pravastatina, obteve redução de $42 \%$ dos eventos cardiovasculares, elevação do nível de vitaminas plasmáticas e melhora da capacidade antioxidante geral da LDL (SALONEN e col., 1995).

SACKS e col. (1996) publicaram trabalho extremamente importante, no qual submeteram, por cinco anos, pacientes pós-infartados a $40 \mathrm{mg}$ de pravastatina, com colesterol médio menor de $240 \mathrm{mg} / \mathrm{dL}$ e LDL de $139 \mathrm{mg} / \mathrm{dL}$. Esses autores verificaram ao final do estudo, redução de $24 \%$ no risco de novo infarto, $19 \%$ da mortalidade total, $27 \%$ da necessidade de novos procedimentos de revascularização e de $28 \%$ dos acidentes cerebrovasculares. 
Efeitos adversos como distúrbios gastrointestinais leves, dores musculares e cefaléia podem acometer pacientes que utilizam estatinas. Elevações das transaminases e creatinofosfoquinase têm sido observadas em 1 a $2 \%$ dos pacientes que utilizam estes medicamentos (SANTOS, 1999). A miopatia tem uma freqüência geral baixa, acometendo aproximadamente $0,08 \%$ dos pacientes em uso de lovastatina e sinvastatina, podendo, entretanto, evoluir para rabdomiólise e insuficiência renal (SHULZ, 2006).

Portanto, apesar de se conhecer o perfil de segurança dessas drogas, os pacientes devem ser monitorados para evitar os efeitos adversos e as interações medicamentosas, além de continuarem com as mudanças em seu estilo de vida.

\section{9. Índice de colesterol}

O papel dos lipídeos nas hiperlipidemias e o potencial aterogênico dos alimentos são áreas de investigação que despertam grande interesse dos cientistas há décadas. FETCHER e col. (1967) planejaram uma tabela na qual computavam o efeito dos alimentos na taxa de colesterol sérico. Os valores baseavam-se em dados de uma equação de regressão, desenvolvida por KEYS (1965). Essa equação foi derivada de estudos em humanos, onde se verificava o efeito metabólico da ingestão de vários tipos de lipídeos (gordura saturada/colesterol).

A equação de KEYS foi recalculada por WHYTE e HAVENSTEIN (1976), a qual combinava a gordura saturada e a poliinsaturada, com o nível de colesterol dos 
alimentos (MATTSON e col., 1972). Isso foi feito, pois era necessário um maior peso para o componente colesterol na equação matemática.

Em 1979, essa última equação revisada foi usada por ZILVERSMIT que propôs o índice de colesterol dos alimentos pela fórmula:

$$
\mathrm{CI}=\mathbf{1 , 0 1}(\mathrm{S}-\mathbf{0 , 5 P})+\mathbf{0 , 0 5 C}
$$

Sendo:

$\mathrm{S}=$ quantidade de ácidos graxos saturados $(\mathrm{g}), \mathrm{P}=$ quantidade de ácidos graxos poliinsaturados $(\mathrm{g})$ e $\mathrm{C}=$ quantidade de colesterol $(\mathrm{mg})$.

Essa equação de regressão foi desenvolvida para mostrar o efeito absoluto das porções individuais do alimento no colesterol sérico (ZILVERSMIT, 1979; CONNOR e col., 1986; TORRES, 2000). Para esse sistema de dados, um baixo número de CI significa uma alta capacidade de reduzir o colesterol. O maior obstáculo para a utilização desse índice é que alimentos que possuem alto teor de ácidos graxos poliinsaturados podem apresentar índices negativos, e incorretamente, parecem ser melhores escolhas alimentares do que alimentos contendo menores teores de gordura em geral. 
Este sistema de índice, cria a impressão errada de que não é necessário limitar o uso de ácidos graxos poliinsaturados. Partindo deste princípio, parece razoável consumir uma quantidade alta de colesterol e gordura saturada (carne, queijo, sorvete), desde que a pessoa consuma uma quantidade alta de poliinsaturados para compensar o nível de saturado.

A equação de ZILVERSMIT foi usada para predizer a alteração que deveria ocorrer no colesterol sérico com uma mudança de padrão dietético quando se substituía a alimentação ocidental por uma alimentação pobre em gorduras, ambas com o mesmo teor de poliinsaturados. A expectativa de mudança no colesterol plasmático permaneceu igual, com o insaturado sendo incluído ou não na equação. Portanto, se a resposta à dieta não é afetada pelo teor de insaturado, não faz sentido incluir esse componente na equação, por ser redundante. Por outro lado, o colesterol e a gordura saturada eram componentes que influenciavam o nível de colesterol sérico. Desta maneira, CONNOR e col. (1986) propuseram alterar a equação para:

\section{$\mathrm{CSI}=(1,01 \times \mathrm{g}$ de gordura saturada $)+(0,05 \times \mathrm{mg}$ colesterol $)$}

Com base neste índice, TORRES (2000) desenvolveu uma tabela contendo o valor energético e de CSI de 187 alimentos e preparações normalmente consumidos pela população brasileira. A partir destes dados, ABREU e col. (2004) ampliaram esta listagem de alimentos e elaboraram o Sistema de Pontos para Controle de Colesterol e Gordura no Sangue (Anexo II), objetivando servir como instrumento de 
intervenção dietética para pacientes hipercolesterolêmicos, bem como prevenir as doenças relacionadas ao consumo excessivo de colesterol e gordura saturada.

Este instrumento é constituído por uma relação de 240 alimentos em medidas caseiras, que receberam pontuações para CSI. Possui formato de cartilha, contendo vinte e duas páginas, acompanhada de material explicativo, com linguagem simples e de fácil compreensão pelo qual, o indivíduo recebe instruções detalhadas para escolher os alimentos e determinar sua pontuação diária de CSI, por meio de tabelas simplificadas e de fácil utilização, sem proibição de nenhum alimento. Há, ainda, mensagens claras e objetivas em relação à necessidade de se manter o peso saudável, além dos passos a serem seguidos para uma alimentação equilibrada.

Para avaliar a eficácia deste instrumento de orientação alimentar, foi realizado por ABREU (2003) um estudo piloto de desenho experimental, com duração de três meses. Esse protocolo comparou dois grupos: o grupo estudo seguiu a dieta proposta pelo Sistema de Pontos e o controle foi orientado pela dieta tradicional para hiperlipidemias. Os resultados deste estudo demonstraram maior redução nas medidas de peso, IMC, circunferência abdominal, colesterol total e LDL nos pacientes que seguiram a dieta de pontos. 
2. JUSTIFICATIVA 


\section{JUSTIFICATIVA}

A primeira estratégia terapêutica para o tratamento de pacientes dislipidêmicos é a introdução de dieta, mudanças no estilo de vida e atividade física. Caso a terapia com dieta e outras mudanças de hábito não normalizem adequadamente os lipídeos plasmáticos, drogas hipolipemiantes devem ser prescritas.

As estatinas diminuem a mortalidade e morbidade em pacientes com doença cardiovascular e em indivíduos saudáveis em risco de desenvolverem cardiopatias. Embora se conheça os benefícios destes fármacos, seu uso prolongado pode trazer efeitos adversos como distúrbios gastrointestinais, cefaléia, dores musculares e danos hepáticos.

Existem poucas informações em nosso País sobre a interação das estatinas e o tratamento dietético. Assim, houve a necessidade de verificar o efeito de uma dieta com baixos índices de ácidos graxos saturados e colesterol, proposta pelo Sistema de Pontos para Controle de Colesterol e Gordura no Sangue, em relação aos indicadores antropométricos, controle dos lipídeos plasmáticos e marcadores de risco para doenças cardiovasculares em indivíduos coronarianos sob o uso de estatinas. 
3. OBJETIVOS 


\section{OBJETIVOS}

\subsection{Objetivo Geral}

Avaliar o efeito da dieta com baixo índice de colesterol e gordura saturada baseada no Sistema de Pontos para Controle de Colesterol e Gordura no Sangue, sobre os marcadores bioquímicos e antropométricos em indivíduos dislipidêmicos coronarianos sob o uso de sinvastatina.

\subsection{Objetivos Específicos}

- Verificar o consumo alimentar de indivíduos dislipidêmicos coronarianos sob o uso de sinvastatina;

- Monitorar os parâmetros lipídicos de colesterol total, LDL, HDL, VLDL e triglicérides de indivíduos dislipidêmicos coronarianos usuários de sinvastatina;

- Detectar o nível de proteína $\mathrm{C}$ reativa e auto-anticorpos anti-LDLox nos pacientes estudados. 


\section{METODOLOGIA}




\section{METODOLOGIA}

\subsection{Delineamento do estudo}

O delineamento desta pesquisa corresponde a um ensaio clínico randomizado controlado, do tipo prospectivo, com coleta de dados primários (PEREIRA, 1995; ESCOSTEGUY, 2003; FILHO e ROUQUAYRIOL, 2003).

\subsection{População e local de estudo}

A amostra de estudo foi constituída por indivíduos adultos de 20 a 65 anos de idade, de ambos os sexos, hiperlipidêmicos, portadores de doença coronariana, em uso de medicamentos hipolipemiantes (exclusivamente sinvastatina), voluntários, pacientes da Unidade de Coronariopatia Crônica, do Instituto do Coração do Hospital das Clínicas da Faculdade de Medicina da Universidade de São Paulo (InCor FMUSP), no município de São Paulo.

\subsection{Amostra}

O cálculo do tamanho da amostra foi feito com base no estudo de ABREU (2003) que verificou a redução dos níveis de colesterol de indivíduos hiperlipidêmicos com a utilização do Sistema de Pontos para Controle de Colesterol e Gordura no Sangue. O tamanho da amostra foi estimado em 18 indivíduos por grupo de estudo. Esse cálculo foi feito assumindo-se $\alpha=5 \%$ e $\beta=20 \%$, com desvio padrão da diferença de $101,4 \mathrm{mg} / \mathrm{dL}$ e a diferença mínima significativa de $50 \mathrm{mg} / \mathrm{dL}$. Utilizou-se o programa estatístico Power Analysis and Sample Size (PASS) versão 2002 for Windows. 


\subsection{Critérios de seleção e exclusão}

Foram selecionados para participar do estudo, todos os pacientes adultos, de ambos os sexos, portadores de doença coronariana e que estivessem fazendo uso de sinvastatina há pelo menos seis meses. Para o diagnóstico da doença coronariana aterosclerótica, foram considerados os seguintes critérios: avaliações clínicas e eletrocardiograma com sugestão de isquemia e teste ergométrico positivo e/ou cintilografia miocárdica positiva e/ou cinecoronariografia com obstrução coronária de pelo menos $50 \%$ em uma das artérias. Excluiu-se do estudo os pacientes que apresentaram os seguintes perfis:

- Analfabetos ou indivíduos que não conseguiam escrever - pela necessidade do Sistema de Pontos ser lido e entendido, além de ter que anotar a pontuação dos alimentos;

- Pessoas que relataram ser incapazes de fazer contas - pelo fato de ter que realizar operações de soma e multiplicação, para proceder à pontuação de ICS;

- Indivíduos impossibilitados de responder à entrevista e realizar a pontuação de ICS por serem portadores de problemas visuais, auditivos e problemas neurológicos;

- Pacientes portadores de diabetes mellitus $e$ intolerância à glicose, doenças hepáticas, renais, retocolite ulcerativa e hipotiroidismo por interferirem no metabolismo lipídico;

- Pacientes com um índice de massa corpórea $>30 \mathrm{~kg} / \mathrm{m}^{2}$; 
- Pacientes portadores de Insuficiência Cardíaca Congestiva grau II e III;

- Indivíduos em uso de medicação que interferisse nos lipídeos do plasma, como os anticoncepcionais, hormônios, corticóides ou anorexígenos, exceto a sinvastatina;

- Indivíduos que participaram de grupos de orientação de dieta para controle das hiperlipidemias antes da presente pesquisa;

- Pacientes que não compareceram a todas as consultas;

- Pacientes que relataram ter deixado de fazer uso de sinvastatina durante o estudo.

\subsection{Coleta de dados}

A coleta de dados do estudo foi realizada de julho de 2004 a junho de 2005, de segunda a sexta-feira, no Instituto do Coração do Hospital das Clínicas da Faculdade de Medicina da Universidade de São Paulo (InCor - FMUSP), no período das 7:00 às 13:00 horas. 


\subsection{Protocolo de Pesquisa}

Em levantamento realizado em 2000 prontuários da Unidade de Coronariopatia Crônica, foram identificados 56 pacientes que atendiam aos critérios de inclusão deste estudo. Foram então anotados os nomes e os telefones destes pacientes que foram contactados e se lhes apresentou os objetivos e procedimentos do estudo. Aqueles que concordaram em participar foram convidados a comparecer ao Instituto do Coração para dar início à pesquisa.

Após a assinatura de um termo de consentimento livre e esclarecido (Anexo III), cada paciente foi acompanhado em consulta individual por 12 semanas, sendo avaliado em três momentos ( $\mathrm{T}=0, \mathrm{~T}=45$ e $\mathrm{T}=90$ dias de estudo), com intervalo médio de 45 dias. Em cada momento, os pacientes foram acompanhados pela pesquisadora ao Laboratório de Análises Clínicas do Instituto do Coração para realizarem coleta de sangue (após jejum de 12-15 h) e após este procedimento foram feitas avaliações das medidas antropométricas e coletas de informações referentes à escolaridade, presença de comorbidades, uso de medicamentos e tabagismo (Anexo IV).

No momento basal $(\mathrm{T}=0)$, os pacientes foram distribuídos aleatoriamente em 2 grupos, de acordo com a ordem de inscrição na pesquisa. Dessa forma foi desenvolvido um estudo no qual foram acompanhados os seguintes grupos de pacientes: 
- Grupo controle: pacientes coronarianos fazendo uso de sinvastatina e orientados a seguir sua dieta habitual;

- Grupo estudo: pacientes coronarianos fazendo uso de sinvastatina e orientados a seguir uma dieta com baixo índice de colesterol e gordura saturada, proposta pelo Sistema de Pontos para Controle de Colesterol e Gordura no Sangue (Anexo II).

Estes dois grupos de estudo foram subdivididos em 4 subgrupos, de acordo com os valores de colesterol total verificados a partir da primeira análise bioquímica:

- Grupo controle: pacientes coronarianos fazendo uso de sinvastatina, orientados a seguir sua dieta habitual e com colesterol total > $200 \mathrm{mg} / \mathrm{dL}$ (DHCA);

- Grupo controle: pacientes coronarianos fazendo uso de sinvastatina, orientados a seguir sua dieta habitual e com colesterol total $<200 \mathrm{mg} / \mathrm{dL}$ (DHCB);

- Grupo estudo: pacientes coronarianos fazendo uso de sinvastatina, orientados a seguir a dieta proposta pelo Sistema de Pontos e com colesterol total $>200 \mathrm{mg} / \mathrm{dL}$ (DPCA);

- Grupo estudo: pacientes coronarianos fazendo uso de sinvastatina, orientados a seguir a dieta proposta pelo Sistema de Pontos e com colesterol total $<200 \mathrm{mg} / \mathrm{dL}$ (DPCB). 
A seguir, a Figura 3 apresenta o fluxo do protocolo de pesquisa.

Figura 3 - Delineamento do Estudo

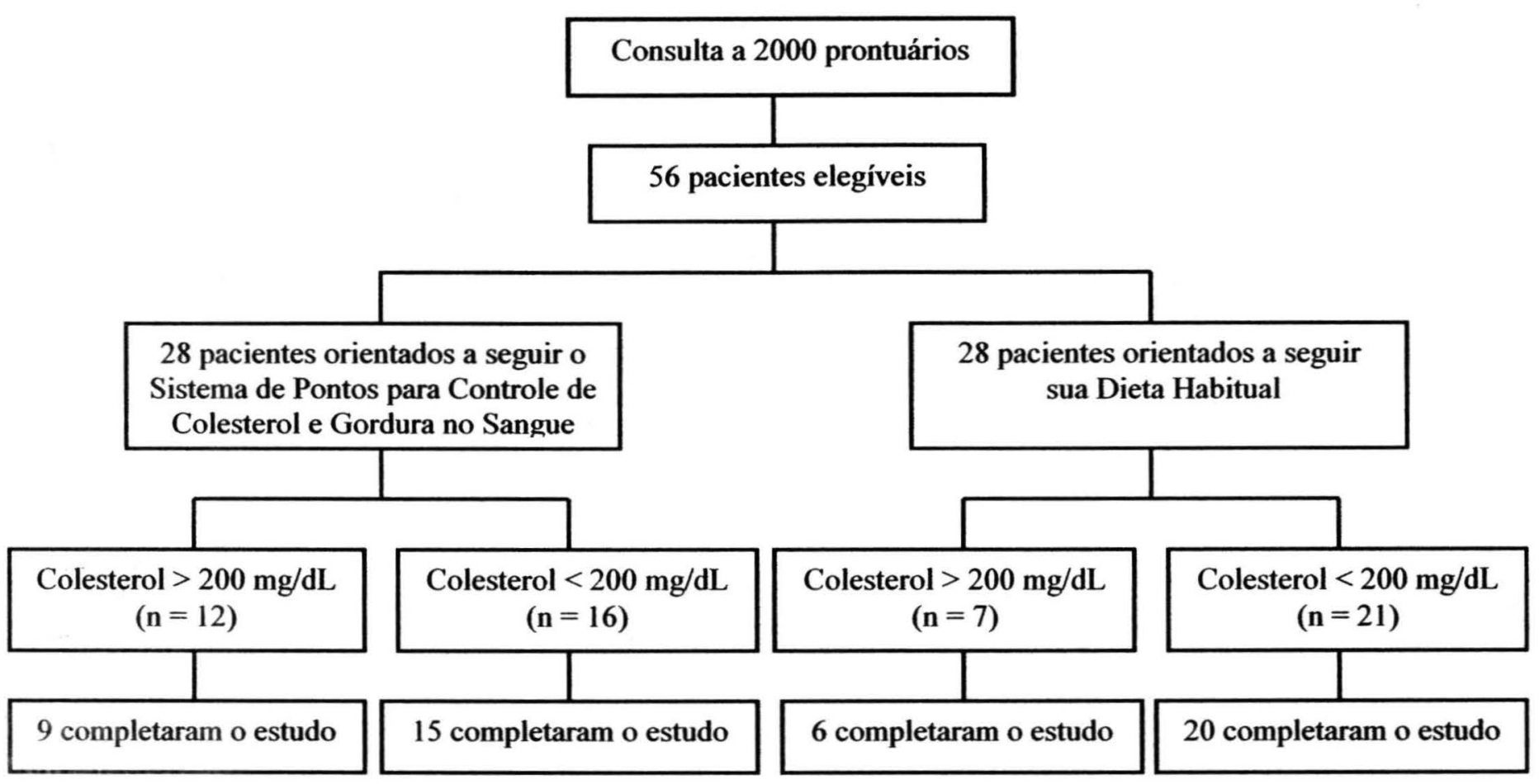

Em cada grupo dos 28 pacientes, escolheu-se de forma aleatória um subgrupo de 11 indivíduos, que também foram questionados quanto ao seu consumo alimentar durante a pesquisa. Desta forma, pôde-se verificar se os participantes que receberam a orientação nutricional (baseada no Sistema de Pontos, que preconiza principalmente a diminuição do consumo de ácidos graxos saturados e colesterol) modificaram sua ingestão alimentar, e obtiveram ao final do estudo, melhores resultados em relação aos marcadores antropométricos e bioquímicos, que o grupo que não recebeu o aconselhamento dietético. A avaliação de Auto-anticorpos Anti- 


\section{Metodologia}

LDLox no Plasma também foi realizada para este subgrupo por se tratar de um importante marcador do desenvolvimento da aterosclerose e doença cardiovascular.

Figura 4 - Delineamento do Estudo

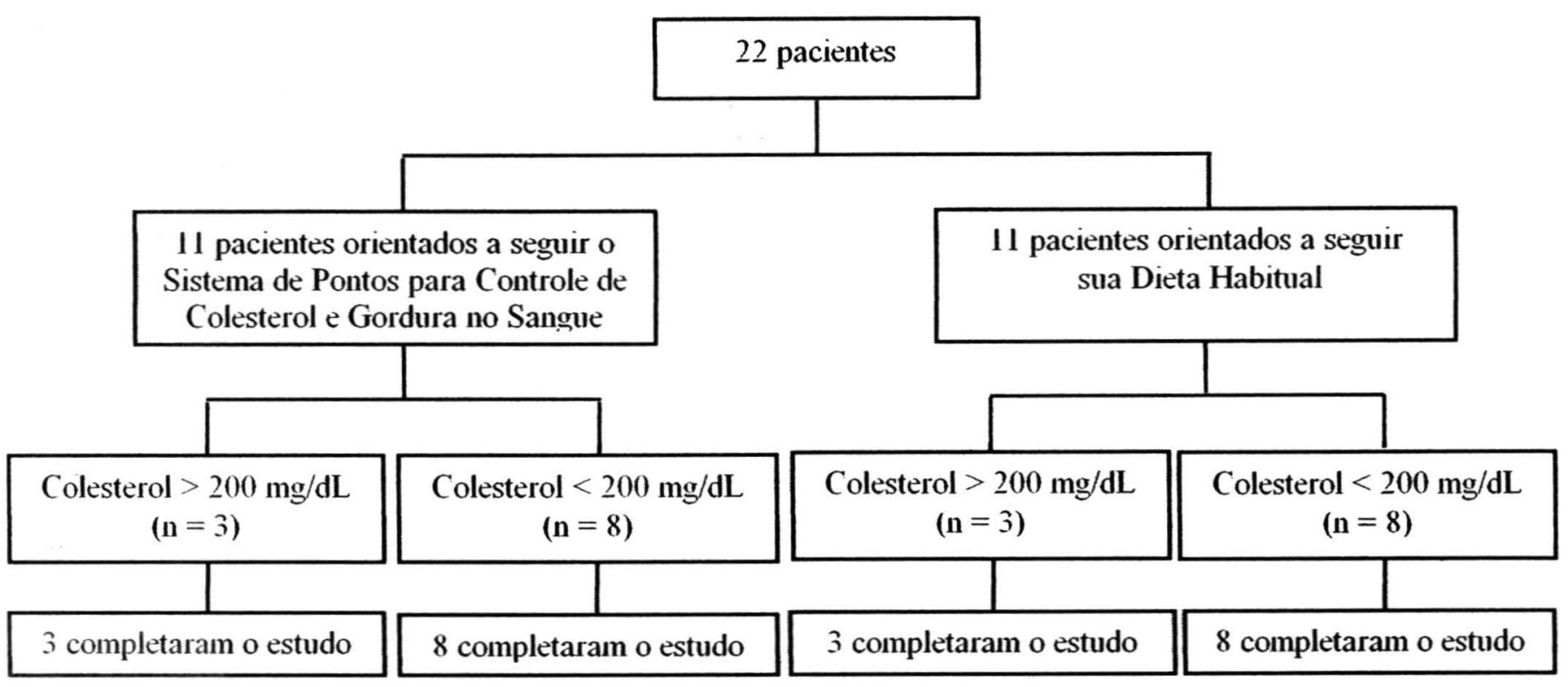

\subsection{Variáveis de estudo}

Para descrever as características da amostra estudada e proceder ao levantamento de dados relativos à pesquisa foram escolhidas as variáveis listadas abaixo, conforme descritas no Anexo IV: 


\subsubsection{Cor - Raça}

A raça do indivíduo foi classificada em branca, parda, preta, amarela ou indígena segundo o Instituto Brasileiro de Geografia e Estatística (IBGE, 2000).

\subsubsection{Escolaridade}

O nível de escolaridade foi calculado em anos completos de estudo e posteriormente agrupado segundo o IBGE (2000) em:

- $1-4$

- $5-8$

- $9-11$

- $12 \mathrm{ou}+$ anos

\subsubsection{Estado civil}

O estado civil dos participantes foi obtido durante a entrevista e classificado de acordo com o IBGE (2000) em casado(a), divorciado(a), viúvo(a) ou solteiro(a).

\subsubsection{Tabagismo}

O tabagismo foi verificado por meio da aplicação de um questionário que permitiu classificar o consumo atual ou prévio de tabaco pelos participantes do estudo (adaptado de VIEBIG, 2002). 


\subsubsection{Estado nutricional}

Para a avaliação do estado nutricional foi calculado o Índice de Massa Corporal (IMC) ou Índice de Quetelet (WHO, 1998). Este índice foi obtido por meio da seguinte fórmula:

$$
\text { IMC }=\text { Peso }(\mathrm{kg}) / \text { Estatura }^{2}(\mathrm{~m})
$$

Para realizar as medidas antropométricas de peso e estatura foram adotados os seguintes procedimentos:

a) Peso: Os entrevistados foram pesados com vestes leves (sem casaco ou paletó) e sem sapatos utilizando-se uma balança antropométrica de plataforma da marca FILIZOLA, ${ }^{\circledR}$ com capacidade de $150 \mathrm{~kg}$ e precisão de $100 \mathrm{~g}$.

b) Estatura corporal: A estatura dos entrevistados foi medida em metros, utilizando-se o estadiômetro acoplado à plataforma da balança FILIZOLA ${ }^{\circledR}$. Os indivíduos ficaram descalços e em posição ereta, olhando para frente de forma a manter o "plano de Frankfurt" (FRISANCHO, 1999). A leitura foi feita no 0,5 cm mais próximo, quando a haste horizontal da barra vertical de escala de altura tocasse na cabeça, sem, contudo, fazer pressão que mudasse sua posição. 
Os critérios que foram empregados para definir o estado nutricional de acordo com o índice de Massa Corporal dos indivíduos foram os propostos pela World Health Organization (WHO, 1998), conforme apresentado no Quadro 2.

Quadro 2 - Classificação do estado nutricional de adultos, segundo o Índice de Massa Corporal.

\begin{tabular}{|c|c|}
\hline IMC $\mathbf{~ k g} / \mathbf{m}^{\mathbf{2}}$ & Classificação \\
\hline$\leq 18,5$ & Baixo peso \\
$18,5-24,9$ & Normal \\
$\geq 25$ & Sobrepeso \\
$\geq 30$ & Obesidade \\
\hline
\end{tabular}

Fonte: WHO (1998)

O presente estudo analisou a circunferência abdominal dos indivíduos, que foi medida com uma fita métrica de fibra de vidro, inelástica, com o mínimo de vestimentas. A circunferência foi medida em centímetros à altura da cicatriz umbilical, em ortostase e ao final de uma expiração suave, com o indivíduo em pé e em posição ereta, com o abdome relaxado, braços ao lado do corpo e pés juntos (GROOT e STAVEREN, 1980).

Segundo as Diretrizes para Cardiologistas sobre Excesso de Peso e Doença Cardiovascular (SBC, 2002), uma circunferência abdominal superior a $94 \mathrm{~cm}$ para o sexo masculino e superior a $80 \mathrm{~cm}$ para o feminino, estão relacionados a um risco aumentado de complicações metabólicas e valores superiores a $102 \mathrm{~cm}$ nos homens e superior a 88 nas mulheres identificam um risco muito aumentado de desenvolver 
hipertensão arterial, dislipidemia, diabetes mellitus e doenças cardiovasculares (SBC, 2002).

Quadro 3 - Medida abdominal e risco para complicações metabólicas associadas à obesidade em caucasianos.

\begin{tabular}{|c|cc|}
\hline Sexo & Aumentado & Muito aumentado \\
\hline Homem & $>94$ & $>102$ \\
Mulher & $>80$ & $>88$ \\
\hline
\end{tabular}

Fonte: SBC (2002)

\subsubsection{Consumo Alimentar}

Informações sobre o consumo alimentar foram questionadas exclusivamente ao subgrupo de estudo e foram avaliadas em três momentos $(T=0, T=45$ e $T=90$ dias de estudo), por meio do Recordatório de 24 horas (R24h). O R24h consiste em definir e quantificar todos os alimentos e bebidas ingeridas durante um período de 24 horas anterior à entrevista (SERRA-MAJEM e BARBAS, 1995).

O R24h foi aplicado pela própria pesquisadora. Para cada tipo de alimento mencionado pelos indivíduos foram solicitadas informações adicionais sobre o tipo, o tamanho da porção, a quantidade consumida e os utensílios utilizados, sendo anotados em um formulário próprio (Anexo IV). 
Neste estudo para se obter um melhor registro das quantidades, utilizou-se um kit de utensílios e medidas caseiras, os quais foram mostrados aos indivíduos, quando tinham dúvidas a respeito da medida utilizada.

As medidas utilizadas foram anotadas em medidas caseiras e, posteriormente, transformadas em gramas, utilizando-se a tabela elaborada por PINHEIRO e col. (2000). O valor calórico total da dieta, os macronutrientes, ácidos graxos dietéticos, fibras, vitaminas e minerais foram calculados utilizando-se o Programa NDS Nutrition Data System - versão 35 (Nutrition Data System 2005 - Universidade de Minnessota). A partir dos dados de consumo alimentar determinou-se o índice de colesterol e gordura saturada (CSI), conforme metodologia estabelecida por CONNOR e col. (1986).

$$
\mathrm{CSI}=(1,01 \times \mathrm{g} \text { de gordura saturada })+(0,05 \times \mathrm{mg} \text { colesterol })
$$

Todos os nutrientes que apresentaram coeficiente de correlação (r) com a energia com valores próximos de um e significância de $\mathrm{p}<0,05$ foram ajustados. $O$ ajuste foi realizado pelo método residual proposto por WILLET e STAMPFER (1998), que tem o objetivo de controlar os fatores de confusão ocasionados pelo consumo total de energia. Utilizou-se o programa Statistical Package for the Social Sciences (SPSS) versão 13.0 (SPSS, 1999). 


\subsubsection{Avaliação do Perfil Lipídico}

As amostras de sangue foram colhidas pelo sistema "vacuteiner" seco para análise de lipídeos plasmáticos, após 12-15 horas de jejum. As concentrações de colesterol total e triglicérides foram determinadas por métodos colorimétricos enzimáticos; HDL, pelo ensaio colorimétrico enzimático homogêneo, por precipitação com sulfato de magnésio e sulfato de dextrano. Para estas dosagens bioquímicas foram utilizados kits enzimáticos da marca ROCHE (Roche Diagnostics, Indiana, USA) de modo automatizado, em equipamento Cobas Integra 700. As concentrações de LDL e VLDL foram determinadas por diferença, utilizando-se a equação de Friedewald * (SBC, 2001):

$$
\text { LDL-C }=\text { CT }- \text { HDL-C }- \text { TG/5 }
$$

* (válida se $\mathrm{TG}<400 \mathrm{mg} / \mathrm{dL}$ ).

O quadro a seguir apresenta os valores de referência de colesterol total e frações e triglicérides para indivíduos adultos com 20 anos ou mais, segundo a Sociedade Brasileira de Cardiologia (2001). 
Quadro 4 - Valores de referência de lipídeos séricos para indivíduos com 20 anos de idade ou mais.

\begin{tabular}{|c|cc|}
\hline Lipídeos & Valores & Categorias \\
\hline Colesterol total (mg/dL) & $<200$ & Ótimo \\
& $200-239$ & Limítrofe \\
& $\geq 240$ & Alto \\
LDL (mg/dL) & $<100$ & Ótimo \\
& $100-129$ & Desejável \\
& $130-159$ & Limítrofe \\
& $160-189$ & Alto \\
& $\geq 190$ & Muito Alto \\
& $<40$ & \\
HDL (mg/dL) & $>60$ & Baixo \\
& & Alto \\
& $<150$ & Ótimo \\
& $150-200$ & Limítrofe \\
Triglicérides (mg/dL) & $201-499$ & Alto \\
& $\geq 500$ & Muito alto \\
& &
\end{tabular}

Fonte: SBC (2001)

\subsubsection{Avaliação da Proteína C Reativa}

A proteína $\mathrm{C}$ reativa foi analisada por ensaio turbimétrico com intensificação da reação por partículas. As análises utilizaram kit da marca ROCHE (Roche Diagnostics, Indiana, USA) e foram realizadas de modo automatizado, em equipamento Cobas Integra 700. 
Os critérios utilizados para identificar risco cardiovascular foram os propostos por Schumann e Dati (1995):

Quadro 5 - Valores de proteína C reativa

\begin{tabular}{|l|l|}
\hline Valores & \\
\hline Adultos & $<5 \mathrm{mg} / 1$ \\
\hline
\end{tabular}

Fonte: Schumann e Dati (1995)

\subsubsection{Detecção de Auto-anticorpos Anti-LDLox no Plasma}

A determinação de auto-anticorpo anti-LDL-Cu ${ }^{+2}$ foi realizada exclusivamente nos pacientes do subgrupo pelo método ELISA baseado em DAMASCENO e col. (2002). Alíquotas de LDL-Cu ${ }^{+2}$ foram diluídas em solução tampão carbonato-bicarbonato de sódio $(0,1 \mathrm{M}, \mathrm{pH} 9,4)$ até a concentração final de $1,0 \mu \mathrm{g} /$ poço. Após o preparo das amostras, placas de 96 poços foram sensibilizadas e incubadas overnight a $4^{\circ} \mathrm{C}$ (EIA/RIA, Costar, Cambridge, MA, USA). Em seguida, o sobrenadante foi descartado, sendo os sítios livres bloqueados com $5 \%$ de leite desnatado (Molico, Nestlé, Araçatuba, SP, Brasil) diluído em solução tampão salina fosfato (PBS), $\mathrm{pH} \mathrm{7,4} \mathrm{cujas} \mathrm{proteases} \mathrm{haviam} \mathrm{sido} \mathrm{previamente} \mathrm{inativadas} \mathrm{pelo} \mathrm{calor}$ $\left(56^{\circ} \mathrm{C}\right)$.

As placas foram incubadas à temperatura ambiente por 2 horas e, em seguida, foram lavadas quatro vezes com PBS Tween (0,05\%) (PBS-T, Fluka Chemie AG, São Paulo, Brasil). Após esta etapa, amostras do plasma de pacientes hipercolesterolêmicos (1/400) foram diluídas em leite 1\% com PBS e incubadas por 
2 horas à temperatura ambiente. Em seguida, as placas foram lavadas quatro vezes com PBS Tween (0,05\%). Posteriormente adicionou-se 50,0 $\mu \mathrm{g}$ /poço do anticorpo policlonal anti-IgG humana conjugado com peroxidase (Rockland Immunochemicals for Research, Gilbertsville, PA, USA) diluído em leite 1\%-PBS, sendo as placas incubadas à temperatura ambiente por 1 hora e 30 minutos. Após este período, as placas foram lavadas quatro vezes, sendo adicionado $50 \mu \mathrm{g}$ de solução de substrato (12 ml de tampão citrato fosfato $\mathrm{PH} 4,5 / 250 \mu \mathrm{L}$ de TMB, $10 \mu \mathrm{L}$ de $\mathrm{H}_{2} \mathrm{O}_{2} / \mathrm{mL}$ ). A reação foi bloqueada com $50 \mu \mathrm{g}$ de $\mathrm{H}_{2} \mathrm{SO}_{4}$. A extensão da reação foi avaliada colorimetricamente usando um espectro no comprimento de onda de $450 \mathrm{~nm}$ (Spectra Count, Canberra Company, Meriden, CT). Os resultados foram determinados aplicando-se média das absorbâncias das amostras - background à equação de curvapadrão de IgG humana $(0,01-1,16 \mathrm{mg} / \mathrm{mL})$.

\subsection{Análise estatística}

Os dados foram digitados em planilhas e armazenados no programa EXCEL 2000 para Windows. A análise descritiva dos dados foi feita, de acordo com a natureza das variáveis envolvidas, através do cálculo de medidas resumo (média e desvio padrão), e elaboração de gráficos boxplot (BUSSAB, 1987) e tabelas de contingência (AGRESTI, 1990). 
O estudo da associação dos indivíduos segundo sexo e grupo de estudo, raça e grupo de estudo, estado civil e grupo de estudo, escolaridade e grupo de estudo, tabagismo e grupo de estudo, foram feitos por meio dos testes de Qui-quadrado de Pearson e teste Exato de Fischer (AGRESTI, 1990).

A análise das diferenças de médias das variáveis de interesse, segundo os grupos de estudo, foi realizada utilizando-se a análise de variância para medidas repetidas por meio do modelo linear generalizado (GLM). Foi feito o ajuste de Bonferroni para comparações múltiplas (NETER e col., 1986).

Todos os testes estatísticos empregados foram bilaterais e em todas as análises foi utilizado o nível de significância estatística de $\alpha=5 \%$ e $\beta=20 \%$. Todos os procedimentos foram realizados com o "software" Statistical Package for the Social Sciences (SPSS) versão 13.0 for Windows (SPSS, 1999).

\subsection{Aspectos éticos}

De acordo com a Resolução no 196 de 1996, do Conselho Nacional de Saúde, por se tratar de pesquisa envolvendo seres humanos, há a necessidade de aprovação do Comitê de Ética da Faculdade de Saúde Pública da USP ou da entidade onde será realizada a pesquisa (CONSELHO NACIONAL DE SAÚDE, 1996). 
A pesquisa foi autorizada pelo Comitê de Ética da Faculdade de Saúde Pública da Universidade de São Paulo (USP) por meio do documento Of. COEP/219/03 (Anexo V). Desta forma, foi elaborado um termo de consentimento livre e esclarecido para ser assinado pelos participantes da pesquisa (Anexo III).

Os indivíduos foram argüidos sobre a disponibilidade em participar da pesquisa, após serem informados do objetivo do estudo e dos procedimentos a serem adotados, além do anonimato e confidencialidade dos dados, bem como da possibilidade de desistir do estudo a qualquer momento, sem apresentar motivos ou sofrer qualquer constrangimento. Foram ainda informados que teriam plena liberdade de aceitar ou não, ficando cientes de que a negativa de adesão não lhes traria nenhum prejuízo.

Os indivíduos que aceitaram em participar do estudo assinaram o termo de consentimento livre e esclarecido, perante o compromisso de que os resultados do estudo lhes seriam transmitidos. 


\section{RESULTADOS}

\subsection{Características da população em estudo}

Dos 56 pacientes que foram selecionados para a pesquisa, 4 não compareceram a todas as consultas, 1 faleceu e 1 relatou ter deixado de usar a sinvastatina ao longo do estudo. Os resultados, portanto são baseados em uma amostra de 50 indivíduos. Destes, 20 pertenciam ao grupo de pacientes DHCB; 6 faziam parte do DHCA; 15 eram do grupo DPCB e 9 do DPCA.

Embora o tamanho da amostra de estudo tenha sido estimada em 18 indivíduos por grupo, houve grande dificuldade na triagem dos pacientes, alguns dos quais tiveram receio de se comprometer com a pesquisa e depois não conseguir terminá-la; outros, por não estarem dispostos a participar de retornos e exames constantes e, principalmente, pela problemática de encontrar pacientes que atendessem aos critérios de inclusão do estudo.

Outra dificuldade da pesquisa, foi encontrar pacientes que após o uso de sinvastatina por seis meses, apresentassem colesterol total $>200 \mathrm{mg} / \mathrm{dL}$ na primeira dosagem bioquímica, razão pela qual os grupos DHCA e DPCA não atingiram o número de indivíduos estipulados para o estudo. 
Em relação ao sexo dos participantes, $44,0 \%(n=22)$ eram do sexo feminino e $56,0 \%(n=28)$ do masculino. Verificou-se que não houve associação estatisticamente significativa entre o sexo dos pacientes e os grupos de estudo $(\mathrm{p}=0,802)$.

A idade média dos entrevistados foi de 55,76 anos (6,21 anos), sendo a idade mínima e máxima 39 e 65 anos, respectivamente (Tabela 1).

Tabela 1 - Medidas-resumo da idade (anos) dos indivíduos, segundo grupo de estudo. São Paulo, 2007.

\begin{tabular}{cccccc}
\hline & \multicolumn{5}{c}{ Medidas-resumo - Idade (anos) } \\
\cline { 2 - 6 } Grupos de estudo & N* $^{*}$ & Média & Mínimo & Máximo & Desvio-padrão \\
\hline DHCB & 20 & 55,80 & 39,00 & 65,00 & 6,80 \\
DHCA & 6 & 57,33 & 53,00 & 64,00 & 3,61 \\
DPCB & 15 & 54,33 & 39,00 & 62,00 & 6,81 \\
DPCA & 9 & 57,00 & 50,00 & 65,00 & 5,50 \\
\hline
\end{tabular}

* Número de indivíduos

A caracterização dos indivíduos por grupos de estudo, foi descrita por meio de tabela de contingência, como se segue. 
Tabela 2 - Características sócio-demográficas dos indivíduos, segundo grupos de estudo. São Paulo, 2007.

\begin{tabular}{|c|c|c|c|c|c|c|c|c|c|c|}
\hline \multirow{3}{*}{ Variáveis } & \multicolumn{8}{|c|}{ Grupos de estudo } & \multirow{2}{*}{\multicolumn{2}{|c|}{ Total }} \\
\hline & \multicolumn{2}{|c|}{ DHCB } & \multicolumn{2}{|c|}{ DHCA } & \multicolumn{2}{|c|}{ DPCB } & \multicolumn{2}{|c|}{ DPCA } & & \\
\hline & $\mathbf{N}^{*}$ & $\%$ & $N^{*}$ & $\%$ & $\mathbf{N}^{*}$ & $\%$ & $\mathbf{N}^{\star}$ & $\%$ & $\mathbf{N}^{*}$ & $\%$ \\
\hline Sexo & & & & & & & & & & \\
\hline Feminino & 7 & 35,0 & 4 & 66,7 & 5 & 33,3 & 6 & 66,7 & 22 & 44,0 \\
\hline Masculino & 13 & 65,0 & 2 & 33,3 & 10 & 66,6 & 3 & 33,3 & 28 & 56,0 \\
\hline \multicolumn{11}{|l|}{ Raça } \\
\hline Branco & 17 & 85,0 & 5 & 83,3 & 12 & 80,0 & 7 & 77,8 & 41 & 82,0 \\
\hline Pardo & 2 & 10,0 & - & - & 3 & 20,0 & 1 & 11,1 & 6 & 12,0 \\
\hline Negro & 1 & 5,0 & 1 & 16,7 & - & - & 1 & 11,1 & 3 & 6,0 \\
\hline \multicolumn{11}{|l|}{ Estado civil } \\
\hline Solteiro & 4 & 20,0 & 1 & 16,7 & 2 & 13,3 & 2 & 22,2 & 9 & 18,0 \\
\hline Casado & 16 & 80,0 & 5 & 83,3 & 12 & 80,0 & 6 & 66,7 & 39 & 78,0 \\
\hline Viúvo & - & - & - & - & 1 & 6,7 & 1 & 11,1 & 2 & 4,0 \\
\hline \multicolumn{11}{|l|}{ Escolaridade } \\
\hline $1-4$ & 7 & 35,0 & 4 & 66,7 & 7 & 46,7 & 7 & 77,8 & 25 & 50,0 \\
\hline $5-8$ & 6 & 30,0 & 1 & 16,7 & 4 & 26,7 & 1 & 11,1 & 12 & 24,0 \\
\hline $9-11$ & 5 & 25,0 & - & - & 3 & 20,0 & 1 & 11,1 & 9 & 18,0 \\
\hline 12 ou + & 2 & 10,0 & 1 & 16,7 & 1 & 6,7 & - & - & 4 & 8,0 \\
\hline \multicolumn{11}{|l|}{ Tabagismo } \\
\hline Sim & 4 & 20,0 & 2 & 33,3 & 4 & 26,7 & 2 & 22,2 & 12 & 24,0 \\
\hline Não & 16 & 80,0 & 4 & 66,7 & 11 & 73,3 & 7 & 77,8 & 38 & 76,0 \\
\hline \multicolumn{11}{|l|}{ Ex - tabagista } \\
\hline Sim & 7 & 43,8 & 3 & 75,0 & 5 & 45,5 & 4 & 57,1 & 19 & 50,0 \\
\hline Não & 9 & 56,3 & 1 & 25,0 & 6 & 54,5 & 3 & 42,9 & 19 & 50,0 \\
\hline
\end{tabular}

*Número de indivíduos

Pode-se observar na Tabela 2 que a maioria $(82,0 \%)$ dos indivíduos avaliados era da raça branca e casados $(78,0 \%)$. As análises estatísticas demonstraram que não existe associação entre a raça e os grupos de estudo $(\mathrm{p}=0,547)$ e o estado civil e grupo $(\mathrm{p}=0,419)$. 
Em relação à escolaridade, houve o predomínio de indivíduos com até 4 anos de estudo (50,0\%), seguidos por indivíduos com até 8 anos de instrução $(24,0 \%)$. Verificou-se que $18,0 \%(n=5)$ das pessoas tinham até 11 anos de estudo e apenas $8,0 \%(n=2)$ mais de 12 anos. A comparação entre os grupos estudados, com o nível de escolaridade, mostrou que todos apresentaram a mesma distribuição de escolaridade $(\mathrm{p}=0,665)$.

A maioria dos entrevistados $(76,0 \%)$ não era fumante no momento da coleta de dados da pesquisa, mas metade relatou ser ex-fumante. Não foi observada associação estatística entre tabagismo e grupo $(\mathrm{p}=0,874)$.

Em relação ao estado nutricional constatou-se que 12,0\% (n=6) dos indivíduos foram classificados como eutróficos no início da pesquisa (T0) e 88,0\% $(n=44)$ apresentaram sobrepeso de acordo com os critérios descritos na metodologia do presente estudo (Tabela 3).

Tabela 3 - Distribuição dos indivíduos segundo estado nutricional e grupos de estudo. São Paulo, 2007.

\begin{tabular}{|c|c|c|c|c|c|c|c|c|c|c|}
\hline \multirow{3}{*}{ IMC } & \multicolumn{8}{|c|}{ Grupos de estudo } & \multicolumn{2}{|c|}{ Total } \\
\hline & \multicolumn{2}{|c|}{ DHCB } & \multicolumn{2}{|c|}{ DHCA } & \multicolumn{2}{|c|}{ DPCB } & \multicolumn{2}{|c|}{ DPCA } & & \\
\hline & $\mathbf{N}$ & $\%$ & $\mathbf{N}$ & $\%$ & $\mathbf{N}$ & $\%$ & $\mathbf{N}$ & $\%$ & $\mathbf{N}$ & $\%$ \\
\hline Normal & 2 & 10,0 & 1 & 16,7 & - & - & 3 & 33,3 & 6 & 12,0 \\
\hline Sobrepeso & 18 & 90,0 & 5 & 83,3 & 15 & 100,0 & 6 & 66,7 & 44 & 88,0 \\
\hline Total & 20 & 100,0 & 6 & 100,0 & 15 & 100,0 & 9 & 100,0 & 50 & 100,0 \\
\hline
\end{tabular}


Figura 5 - Boxplot do Índice de Massa Corporal (IMC) dos indivíduos, segundo grupo de estudo. São Paulo, 2007.

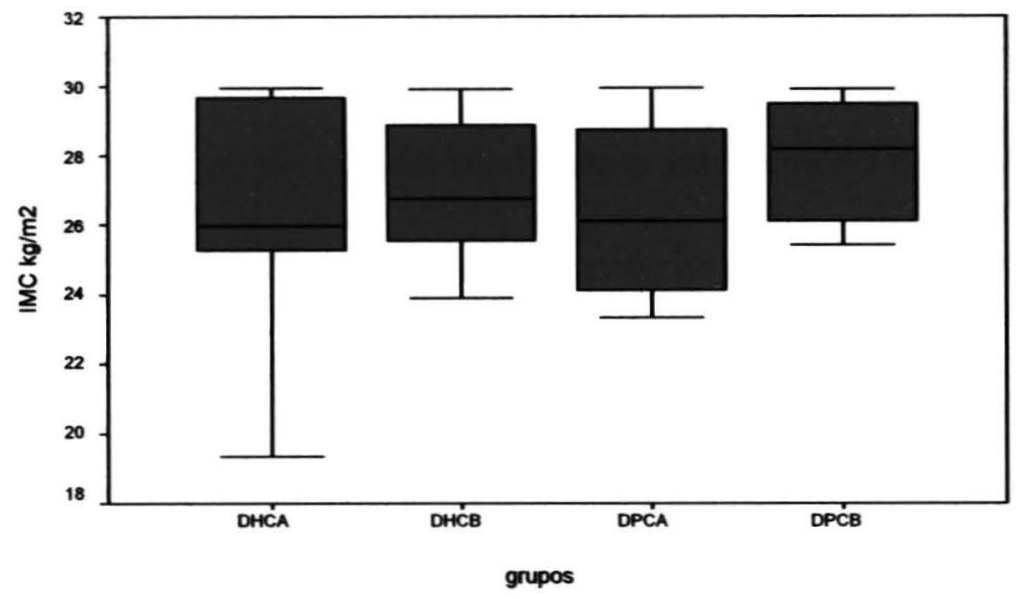

Quanto à circunferência abdominal, 32,0\% $(\mathrm{n}=16)$, dos participantes do estudo foram considerados como de alto risco para o desenvolvimento de complicações metabólicas, $34,0 \%(n=17)$ foram classificados como indivíduos de risco e $34,0 \%(n=17)$ dos pacientes tinham os valores de circunferência abdominal adequados às referências propostas pela SBC (2002), no início do estudo.

Os dados descritivos da população estudada em relação a antropometria, consumo alimentar e análises bioquímicas em cada um dos momentos de estudo $(\mathrm{T}=0, \mathrm{~T}=45$ e $\mathrm{T}=90)$ podem ser conferidos detalhadamente no Anexo VI. 


\subsection{Avaliação do efeito da dieta proposta pelo Sistema de Pontos para Controle de Colesterol e Gordura no Sangue}

Em decorrência à fase descritiva, procedeu-se a avaliação do desempenho dos grupos de estudo mediante a intervenção nutricional sobre o consumo alimentar, os indicadores antropométricos e marcadores bioquímicos dos indivíduos dislipidêmicos.

\subsubsection{Consumo Alimentar}

As médias dos valores de macronutrientes e energia observadas nos indivíduos após o estudo são apresentadas na Tabela 4.

Tabela 4 - Valor energético e de macronutrientes, segundo grupos de estudo ao final da pesquisa. São Paulo, 2007.

\begin{tabular}{cccccccc}
\hline & \multicolumn{7}{c}{ Grupos de Estudo } \\
\cline { 2 - 7 } Variáveis & DPCB & DHCB & $\mathbf{p}^{*}$ & DPCA & DHCA & $\mathrm{p}^{*}$ \\
\hline Energia (Kcal) & 1525,99 & 1596,54 & $\mathrm{p}=0,011$ & 1054,19 & 991,05 & $\mathrm{p}=0,516$ \\
Carboidratos (g) & 175,19 & 165,33 & $\mathrm{p}<0,001$ & 166,34 & 162,37 & $\mathrm{p}>0,999$ \\
Proteínas (g) & 78,96 & 70,73 & $\mathrm{p}<0,001$ & 70,46 & 76,35 & $\mathrm{p}=0,006$ \\
Lipídios (g) & 44,01 & 52,26 & $\mathrm{p}<0,001$ & 51,09 & 50,08 & $\mathrm{p}>0,999$ \\
Fibras Solúveis (g) & 2,68 & 2,64 & $\mathrm{p}>0,999$ & 2,24 & 1,99 & $\mathrm{p}=0,019$ \\
Fibras Insolúveis (g) & 10,06 & 9,35 & $\mathrm{p}<0,001$ & 10,82 & 6,01 & $\mathrm{p}<0,001$ \\
\hline $\begin{array}{l}\text { Resultados apresentados sob a forma de média marginal, resultante da variabilidade dos } \\
\text { valores obtidos nos tempos basal, T=45 dias de intervenção e T=90 dias de intervenção * }\end{array}$ \\
$\begin{array}{l}\text { Diferença entre os grupos foi estabelecida utilizando-se a análise de variância de medidas repetidas, } \\
\text { modelo linear generalizado (GLM) com teste de Bonferroni ajustado. }\end{array}$
\end{tabular}


Pôde-se observar que a ingestão alimentar com base no consumo energético $(p=0,011)$ e de lipídios $(p<0,001)$ foi estatisticamente menor no grupo DPCB, quando comparado ao DHCB. Verificou-se ainda que o grupo DPCB apresentou consumo maior de carboidratos, proteínas e fibras insolúveis que o DHCB $(\mathrm{p}<0,001)$.

Ao longo do estudo, o grupo DPCA apresentou um consumo menor de proteínas $(\mathrm{p}=0,006)$ e maior de fibras insolúveis $(\mathrm{p}<0,001)$ e solúveis $(\mathrm{p}=0,019)$, quando comparado ao grupo DHCA. O consumo de energia, carboidratos e lipídios não apresentou diferença significativa entre estes grupos.

Tabela 5 - Variáveis lipídicas, segundo grupos de estudo. São Paulo, 2007.

\begin{tabular}{|c|c|c|c|c|c|c|}
\hline \multirow[b]{2}{*}{ Variáveis } & \multicolumn{6}{|c|}{ Grupos de Estudo } \\
\hline & DPCB & DHCB & $\mathbf{p}^{*}$ & DPCA & DHCA & $\mathbf{p}^{*}$ \\
\hline Saturados (g) & 12,51 & 16,32 & $\mathrm{p}<0,001$ & 13,87 & 15,05 & $\mathrm{p}=0,023$ \\
\hline Monoinsaturados (g) & 15,15 & 18,58 & $\mathrm{p}<0,001$ & 17,92 & 17,65 & $p>0,999$ \\
\hline Polinsaturados (g) & 12,26 & 12,24 & $p>0,999$ & 14,27 & 12,95 & $\mathrm{p}<0,001$ \\
\hline Ômega 3 (g) & 1,13 & 1,34 & $\mathrm{p}<0,001$ & 1,69 & 1,20 & $\mathrm{p}<0,001$ \\
\hline Ômega 6 (g) & 10,49 & 10,60 & $p>0,999$ & 12,48 & 11,18 & $\mathrm{p}<0,001$ \\
\hline Colesterol (mg) & 185,91 & 221,62 & $\mathrm{p}<0,001$ & 167,95 & 192,74 & $\mathrm{p}=0,086$ \\
\hline Trans (g) & 2,58 & 2,98 & $p=0,003$ & 3,27 & 3,29 & $p>0,999$ \\
\hline CSI & 21,87 & 26,60 & $\mathrm{p}<0,001$ & 22,66 & 24,90 & $\mathrm{p}=0,003$ \\
\hline
\end{tabular}


De acordo com as variáveis demonstradas na Tabela 5 , verificou-se que o grupo DPCB apresentou um consumo menor de ácidos graxos saturados $(\mathrm{p}<0,001)$, colesterol $(\mathrm{p}<0,001)$, ácidos graxos trans $(\mathrm{p}=0,003)$ e CSI $(\mathrm{p}<0,001)$ que o DHCB.

No decorrer da análise foi observado que o grupo DPCA apresentou um consumo significantemente maior de ácidos graxos polinsaturados, ômega 3 e ômega $6(\mathrm{p}<0,001)$ e menor de ácidos graxos saturados $(\mathrm{p}=0,023)$ e CSI $(\mathrm{p}=0,003)$, quando comparado ao grupo DHCA.

Tabela 6 - Consumo de vitaminas antioxidantes, segundo grupos de estudo. São Paulo, 2007.

\begin{tabular}{|c|c|c|c|c|c|c|}
\hline \multirow[b]{2}{*}{ Variáveis } & \multicolumn{6}{|c|}{ Grupos de Estudo } \\
\hline & DPCB & DHCB & $\mathbf{p}^{*}$ & DPCA & DHCA & $\mathbf{p}^{*}$ \\
\hline Vitamina C (mg) & 59,67 & 56,94 & $p>0,999$ & 50,30 & 34,77 & $\mathrm{p}=0,001$ \\
\hline Vitamina A ( $\mu \mathrm{g})$ & 172,90 & 170,29 & $p>0,999$ & 160,32 & 207,90 & $\mathrm{p}<0,001$ \\
\hline Vitamina E (mg) & 4,15 & 4,07 & $\mathrm{p}=0,513$ & 4,36 & 3,29 & $\mathrm{p}<0,001$ \\
\hline
\end{tabular}

A Tabela 6 demonstra que o consumo de vitaminas antioxidantes nos grupos DPCB e DHCB foi estatisticamente semelhante. No entanto, ao longo dos três meses de estudo foi detectado que o grupo DPCA apresentou ingestão significantemente maior de vitaminas $\mathrm{C}(\mathrm{p}=0,001)$ e $\mathrm{E}(\mathrm{p}<0,001)$ que os pacientes do DHCA. 


\subsubsection{Estado nutricional}

A Tabela 7 apresenta as médias das variáveis antropométricas dos indivíduos ao final do estudo. A análise do comportamento do IMC revelou que as médias desta variável foram estatisticamente semelhantes para todos os grupos de estudo. Em relação à circunferência abdominal, observou-se redução estatisticamente significativa no grupo DPCB, quando comparada ao DHCB $(p<0,001)$. Não se observou alteração de circunferência abdominal, quando os grupos DPCA e DHCA foram comparados $(\mathrm{p}>0,999)$.

Tabela 7 - Variáveis antropométricas, segundo grupos de estudo. São Paulo, 2007.

\begin{tabular}{ccccccc}
\hline & \multicolumn{7}{c}{ Grupos de Estudo } \\
\cline { 2 - 7 } Variáveis & DPCB & DHCB & $\mathbf{p}^{*}$ & DPCA & DHCA & $\mathbf{p}^{*}$ \\
\hline IMC $\left(\mathbf{k g} / \mathbf{m}^{2}\right)$ & 27,25 & 27,03 & $\mathrm{p}=0,732$ & 26,12 & 26,16 & $\mathrm{p}=0,053$ \\
CA $(\mathbf{c m})$ & 92,24 & 94,46 & $\mathrm{p}<0,001$ & 89,77 & 90,55 & $\mathrm{p}>0,999$
\end{tabular}

Resultados apresentados sob a forma de média marginal, resultante da variabilidade dos valores obtidos nos tempos basal, $\mathrm{T}=45$ dias de intervenção e $\mathrm{T}=90$ dias de intervenção * Diferença entre os grupos foi estabelecida utilizando-se a análise de variância de medidas repetidas, modelo linear generalizado (GLM) com teste de Bonferroni ajustado. 


\subsubsection{Indicadores Bioquímicos}

A Tabela 8 apresenta as variáveis de perfil lipídico dos indivíduos dislipidêmicos ao final dos três meses de estudo.

Tabela 8 - Variáveis de perfil lipídico, segundo grupos de estudo. São Paulo, 2007.

\begin{tabular}{|c|c|c|c|c|c|c|}
\hline \multirow[b]{2}{*}{ Variáveis } & \multicolumn{6}{|c|}{ Grupos de Estudo } \\
\hline & DPCB & DHCB & $\mathbf{p}^{*}$ & DPCA & DHCA & $\mathbf{p}^{*}$ \\
\hline Colesterol (mg/dL) & 163,06 & 171,13 & $\mathrm{p}<0,001$ & 227,46 & 228,27 & $\mathrm{p}>0,999$ \\
\hline HDL (mg/dL) & 44,56 & 44,81 & $p>0,999$ & 52,29 & 47,71 & $\mathrm{p}<0,001$ \\
\hline LDL (mg/dL) & 89,19 & 99,59 & $\mathrm{p}<0,001$ & 142,60 & 138,05 & $\mathrm{p}=0,001$ \\
\hline VLDL (mg/dL) & 29,03 & 26,72 & $\mathrm{p}<0,001$ & 32,07 & 41,69 & $\mathrm{p}<0,001$ \\
\hline Triglicérides (mg/dL) & 146,02 & 133,53 & $\mathrm{p}<0,001$ & 160,09 & 208,53 & $\mathrm{p}<0,001$ \\
\hline
\end{tabular}

Durante o desenvolvimento do estudo, foi detectado que o grupo DPCB apresentou uma média significativamente menor de colesterol total e LDL, quando comparado ao grupo DHCB $(p<0,001)$. Em relação ao $\mathrm{HDL}$ não se observou diferença estatisticamente significativa entre os grupos DPCB e DHCB $(p>0,999)$.

Quanto aos triglicérides, observou-se ao longo do tempo, média maior no grupo DPCB, quando comparado ao DHCB $(\mathrm{p}<0,001)$. Neste estudo, os valores de VLDL, foram avaliados a partir das concentrações de triglicérides. Desta forma, as 
análises comparativas para o comportamento da VLDL apresentaram resultados semelhantes aos de triglicérides.

Quando os grupos DPCA e DHCA foram comparados, pôde-se verificar aumento significativo de HDL $(\mathrm{p}<0,001)$ e redução estatisticamente significativa de triglicérides e VLDL nos indivíduos que seguiram a dieta de pontos associada à sinvastatina $(\mathrm{p}<0,001)$.

Tabela 9 - Média das variáveis inflamatórias, segundo grupos de estudo. São Paulo, 2007.

\begin{tabular}{ccccccc}
\hline & \multicolumn{5}{c}{ Grupos de Estudo } \\
\cline { 2 - 6 } Variáveis & DPCB & DHCB & $\mathbf{p}^{*}$ & DPCA & DHCA & $\mathbf{p}^{*}$ \\
\hline PCR (mg/L) & 3,84 & 4,73 & $\mathbf{p}<0,001$ & 3,21 & 6,41 & $\mathrm{p}<0,001$ \\
anti-LDLox (mg/mL) & 175,48 & 89,78 & $\mathrm{p}<0,001$ & 139,00 & 93,16 & $\mathrm{p}<0,001$ \\
\hline $\begin{array}{l}\text { Resultados apresentados sob a forma de média marginal, resultante da variabilidade dos } \\
\text { valores obtidos nos tempos basal, T=45 dias de intervenção e T=90 dias de intervenção * } \\
\text { Diferença entre os grupos foi estabelecida utilizando-se a análise de variância de medidas repetidas, } \\
\text { modelo linear generalizado (GLM) com teste de Bonferroni ajustado. }\end{array}$
\end{tabular}

A avaliação feita para a PCR apresentou médias menores deste indicador inflamatório no grupo orientado a seguir a dieta de pontos, quando se comparou os grupos DHCB e DPCB ( $p<0,001)$. Tal efeito também foi observado ao se comparar os grupos DHCA e DPCA ( $<<0,001)$.

Em relação aos auto-anticorpos anti-LDLox os resultados demonstraram que ao final da pesquisa tanto o grupo DPCB, quanto o DPCA apresentaram média 
significantemente maior deste indicador, quando comparados ao DHCB e DHCA respectivamente $(\mathrm{p}<0,001)$. 
6. DISCUSSÃO 


\section{DISCUSSÃO}

Os resultados deste estudo reportam para uma série de comentários, que serão discutidos a seguir. Em decorrência dos diversos parâmetros avaliados, fez-se uma discussão em tópicos agrupando o conjunto de variáveis que respondem aos objetivos do estudo.

\subsection{Características da população em estudo}

Houve predominância de homens neste estudo, sendo $56,0 \%(\mathrm{n}=28)$ dos participantes do sexo masculino e $44,0 \%(n=22)$ do sexo feminino. Apesar de se tratar de um ensaio clínico randomizado controlado, havia voluntariedade na participação, e nesse ambulatório, os homens tiveram maior adesão ao estudo, do que as mulheres.

A média de idade dos participantes foi de 55,76 (6,21) anos, sendo a idade mínima e máxima 39 e 65 anos, respectivamente. Devido ao tipo de estudo realizado, em que os participantes necessariamente deveriam ser portadores de doença coronariana e ter alteração de perfil lipídico, era de se esperar uma população com idade mais avançada.

Em relação à distribuição dos indivíduos por raça, a população inclusa no estudo seguiu a mesma distribuição descrita pelos dados do último censo (IBGE, 2000) com predominância da raça branca, seguida pela parda e negra. 
Em relação à escolaridade, houve predomínio de indivíduos com até 4 anos de estudo (50,0\%). Tal fato pode ser justificado pela baixa condição sócio-econômica que os pacientes da Unidade de Coronariopatia Crônica, do Instituto do Coração do Hospital das Clínicas da Faculdade de Medicina da Universidade de São Paulo, de modo geral, apresentam.

Com relação ao tabagismo, observou-se que a maioria dos entrevistados $(76,0 \%)$ não era fumante no momento da coleta de dados da pesquisa. Estudo realizado pela Sociedade de Cardiologia do Estado de São Paulo em 1999 verificou que as taxas de prevalência de tabagismo foram de $17 \%$ após avaliação de aproximadamente 20 mil indivíduos em 19 cidades do estado. Segundo dados do Ministério da Saúde (2003) aproximadamente 33\% da população brasileira fuma e a maioria de fumantes tem, entre 20 e 49 anos de idade. A baixa prevalência de fumantes em nosso estudo deve-se, provavelmente, ao trabalho intenso de conscientização para o abandono do hábito, que vem sendo desenvolvido pelos profissionais de saúde que atuam no InCor - FMUSP. 


\subsection{Avaliação do efeito da dieta proposta pelo Sistema de Pontos sobre o estado nutricional}

Em 1997 a obesidade foi reconhecida pela Organização Mundial de Saúde como doença universal com importantes repercussões para a Saúde Pública (WHO, 1998). A obesidade está associada ao incremento da mortalidade por inúmeras doenças crônicas, particularmente pela doença cardiovascular (MONTAYE e col., 2000). Sua importância como fator de risco independente para a doença arterial coronariana (DAC) foi demonstrada com a divulgação do estudo de Framingham quando ficou evidenciado que o ganho de peso durante a idade adulta aumenta o risco de DAC em ambos os sexos, independente da presença de outros fatores de risco (HUBERT e col., 1983).

Além de contribuir de forma isolada para a DAC, a obesidade é fortemente correlacionada aos fatores de risco considerados primários para essa doença, destacando-se sua associação à hipertensão arterial sistêmica (HAS), diabetes mellitus e dislipidemias (KANNEL, 1998).

MARTINS e col. (1989), em pesquisas realizadas no município de São Paulo, caracterizaram níveis lipêmicos e a presença de outros fatores de risco para doenças cardiovasculares como obesidade, hipertensão arterial, tabagismo, etilismo, antecedentes diabéticos e uso de contraceptivos orais. Demostrou-se que a obesidade isolada ou associada a níveis lipêmicos elevados, apresentou-se como um dos fatores de risco mais freqüentes em todas as faixas etárias e em ambos os sexos. Verificou-se 
também que a obesidade, isolada ou associada à hipertensão e/ou alcoolismo, foi o fator de risco mais relevante.

No presente estudo, dos 50 indivíduos avaliados, constatou-se que $12,0 \%$ $(n=6)$ estavam eutróficos no início da pesquisa e $88,0 \%(n=44)$ apresentaram sobrepeso de acordo com os critérios propostos pela WHO (1998). É necessário destacar que embora os pacientes com um índice de massa corpórea $\geq 30 \mathrm{~kg} / \mathrm{m}^{2}$ tenham sido excluídos da pesquisa, a maioria dos indivíduos estudados apresentou excesso de peso (IMC $\geq 25 \mathrm{~kg} / \mathrm{m}^{2}$ ). Tal fato pode ter sido um dos fatores que contribuiu para o desenvolvimento de dislipidemias e doença coronariana nestes pacientes.

O estudo realizado por COLOMBO e col. (2003) no município de Campinas, com 43 pacientes portadores de coronariopatia, demonstrou, assim como em nosso estudo, que o sobrepeso afetou a maioria dos pacientes estudados $(51,1 \%)$, sendo $48,4 \%$ entre os homens e $60,0 \%$ entre as mulheres.

Ao analisar o comportamento do IMC dos indivíduos ao longo do período de estudo, verificou-se que as médias desta variável foram estatisticamente semelhantes para os grupos que foram orientados a seguir a dieta de pontos e para aqueles que continuaram com a sua dieta habitual $(\mathrm{p}>0,050)$.

Deve-se destacar que os pacientes orientados a seguir a dieta proposta pelo Sistema de Pontos, receberam recomendações em relação à escolha de uma 
alimentação equilibrada e sobre a necessidade de manter um peso saudável, sem, no entanto, serem submetidos a dietas específicas de restrição energética, visando a perda de peso corpóreo. Desta forma, os indivíduos foram estimulados a continuar com o tratamento, para reeducarem seus hábitos alimentares e alcançar o IMC ideal.

É importante ressaltar ainda a relação existente entre o padrão de distribuição de gordura corporal e o desenvolvimento e/ou progressão da DAC. O padrão de distribuição de gordura do tipo masculina, chamada obesidade andróide (predomínio de gordura no abdômen e na parte superior do corpo), está associada a significativas complicações metabólicas, que se correlacionam com o desenvolvimento da DAC (DEPRES e col., 1990; FREEDMAN e col., 1995).

É comprovado atualmente que o excesso de gordura depositada na região abdominal é um forte preditor para a doença cardiovascular e diabetes melittus tipo 2. Tal associação pode ser parcialmente explicada pelo fato do excesso de acúmulo de gordura visceral relacionar-se, de forma independente à hipertensão arterial, intolerância à glicose, resistência à insulina e à dislipidemia (DEPRES e col., 1990).

Desta forma, além do IMC, a avaliação da distribuição de gordura corporal pode ajudar a identificar pessoas com maior risco para doenças cardiovasculares. No presente trabalho, uma grande proporção de indivíduos $(32,0 \%)$, tinha a circunferência abdominal muito aumentada no início da pesquisa, sendo considerados como de alto risco metabólico e $34,0 \%(n=17)$ foram classificados como pacientes de risco de acordo com as referências propostas pela SBC (2002). 
Assim como em nosso estudo, valores elevados de circunferência abdominal foram encontrados por COLOMBO e col. (2003), ao se avaliar pacientes coronarianos. Destes, $21,0 \%$ dos indivíduos foram considerados como de alto risco para o desenvolvimento de complicações metabólicas e $6,0 \%$ foram classificados como pacientes de risco. CARROL e col. (2000) em estudo desenvolvido junto a pacientes com doença coronariana de um serviço de reabilitação cardíaca relatou que níveis elevados de CA em homens e mulheres com DAC estão associados com o aumento no risco metabólico, independente do uso de terapêutica cardioprotetora. Os dados mostraram ainda aumento no risco de hipertrigliceridemia em homens com CA $\geq 94 \mathrm{~cm}$ e em mulheres com $\mathrm{CA} \geq 88 \mathrm{~cm}$. Homens com CA acima de $102 \mathrm{~cm}$ exibiram baixos valores de HDL, elevados valores de triglicérides e hipertensão diastólica.

Ao avaliar o efeito da dieta proposta pelo Sistema de Pontos, verificou-se que ao longo do estudo, o grupo de pacientes DPCB obteve redução significativa $(\mathrm{p}<0,001)$ da circunferência abdominal, quando comparado ao grupo DHCB. Assim, pôde-se considerar que a dieta proposta pelo sistema de pontos mostrou-se eficiente para a redução da CA neste grupo de estudo.

A obesidade, portanto, se traduz em importante condição clínica que requer uma abordagem efetiva, especialmente no que se refere à prevenção primária e secundária da coronariopatia, onde a abordagem dos fatores de risco relaciona-se com o desenho de intervenções educacionais que possibilite ao sujeito a adoção de comportamentos positivos em relação à saúde. 


\subsection{Avaliação do efeito da dieta proposta pelo Sistema de Pontos sobre o perfil lipídico}

Diversos estudos clínicos e epidemiológicos têm demonstrado que a redução do colesterol total e, principalmente, da fração LDL tem papel fundamental na redução da mortalidade por problemas cardiovasculares, na diminuição dos principais eventos coronarianos e infarto em indivíduos de alto risco ou com doença cardiovascular estabelecida (NCEP, 2001).

De acordo com o National Cholesterol Education Program (NCEP, 2001), indivíduos de alto risco ou portadores de doença cardiovascular, na maioria das vezes necessitam de tratamento medicamentoso, associado às mudanças do estilo de vida (MEV) para alcançar as metas de redução de perfil lipídico. Recomenda-se que mesmo quando os hipolipemiantes são prescritos, atenção especial às MEV sejam sempre mantidas e reforçadas (NCEP, 2001).

Os estudos têm demonstrado ainda, que dietas restritivas em ácidos graxos saturados e colesterol diminuem as concentrações plasmáticas de colesterol total e LDL, mesmo em pacientes hipercolesterolêmicos tratados com inibidores da HMGCoA redutase (COBB e col., 1991; CLIFTON e col., 1992; CHISHOLM e col., 1994). Ademais, a substituição de ácidos graxos trans por insaturados (poli e mono) tem sido enfatizada pela maioria dos estudos de prevenção e tratamento das doenças cardiovasculares (REAVEN e col., 1993; WILLET e col., 1993; STONE, 1996; HAYES, 2001; MOZAFFARIAN e col., 2006). 
Os resultados apresentados em nosso estudo corroboram os dados relatados pela literatura. As análises do consumo alimentar dos pacientes demonstraram que o grupo DPCB consumiu quantidades significativamente menores de ácidos graxos saturados, colesterol, CSI e trans, quando comparado ao DHCB. Este dado sugere que os indivíduos que adotaram a dieta de pontos, restringiram o consumo de lipídios e obtiveram ao final do estudo, menores concentrações plasmáticas de colesterol total e LDL, que o grupo tratado apenas com a sinvastatina.

Estudo realizado no município de Boston (EUA) por SCHAEFER e col. (2001), com 47 indivíduos coronarianos, de ambos os sexos, com idade média de 61,9 anos, em uso de hipolipemiantes, e com média basal de CT $(178 \pm 29)$ e LDL $(102 \pm 27)$, semelhantes as verificadas nos grupos DPCB e DHCB do presente estudo, demonstrou que uma dieta restritiva em lipídios, também resultou em redução adicional de CT e LDL, quando comparada aos indivíduos com uso exclusivo de estatinas.

A comparação estatística entre os grupos DPCB e DHCB apresentou respostas semelhantes à medida de HDL e maiores concentrações de VLDL e triglicérides, no grupo que foi orientado a seguir a dieta de pontos. $\mathrm{O}$ que se pôde observar foi que as concentrações basais médias destas lipoproteínas, em ambos os grupos estavam dentro dos limites desejáveis de acordo com a Sociedade Brasileira de Cardiologia (2001), sendo mantidas durante o estudo. 
Quando se comparou o consumo alimentar dos grupos DPCA e DHCA, ambos com CT $\geq 200 \mathrm{mg} / \mathrm{dL}$ no início do estudo, pôde-se verificar que o grupo que associou o tratamento dietético ao medicamentoso, substituiu o consumo de ácidos graxos saturados e CSI, pelos poliinsaturados incluindo os das séries ômega 3 e 6 .

A diminuição do consumo de ácidos graxos saturados na dieta, associada ao aumento de poliinsaturados, principalmente os dos grupos n-3 e n-6, que têm sido extensamente investigados pelas suas propriedades antiinflamatórias e cardioprotetoras (GARCIA-CLOSAS e col., 1993; PARK e col., 1997; STONE, 1997, MARANGONI e GALLI, 2000; MADSEN e col., 2003), pode ter contribuído para a redução dos valores de VLDL e triglicérides e para o aumento significativo de HDL no grupo que seguiu a dieta proposta pelo Sistema de Pontos aliada ao tratamento medicamentoso e que tinha colesterol total $>200,0 \mathrm{mg} / \mathrm{dL}$.

Também se observou um consumo maior de fibras (insolúveis e solúveis) no grupo DPCA, quando comparado ao DHCA $(\mathrm{p}<0,001)$, sugerindo que estes pacientes adotaram as orientações propostas pelo Sistema de Pontos, que estimula o consumo de frutas, hortaliças e grãos, alimentos ricos em fibras e com baixa pontuação de CSI. Os benefícios sobre o perfil lipídico relacionado ao consumo de fibras (principalmente solúveis), têm sido amplamente estudados. De acordo com uma meta-análise conduzida por BROWN e col. (1999), o consumo diário de $20 \mathrm{~g}$ de aveia (correspondente a $3,4 \mathrm{~g}$ de fibras insolúveis e $0,7 \mathrm{~g}$ de fibras solúveis), demonstrou reduzir as concentrações de colesterol total em cerca de $1 \mathrm{mg} / \mathrm{dL}$. 
JULA e col. (2002) também se propuseram a avaliar o efeito da dieta em indivíduos hiperlipidêmicos usuários de estatinas. Ao pesquisar 120 homens hipercolesterolêmicos (CT $\geq 232 \mathrm{mg} / \mathrm{dL}$ ), do município de Turku (Finlândia), os pesquisadores verificaram que o tratamento dietético isolado, o uso de sinvastatina isoladamente e a combinação de sinvastatina e uma dieta com baixos teores de lipídios, reduziram o LDL colesterol em 10,8\%, 20,8\% e 41,0\% respectivamente. Similarmente ao presente estudo, houve um aumento de HDL nos indivíduos que associaram o tratamento dietético à sinvastatina.

Dados semelhantes foram encontrados por CHISHOLM e col. (1994) ao avaliarem 19 indivíduos hipercolesterolêmicos tratados com sinvastatina, de um Hospital Público de Dunedin (Nova Zelândia). Este estudo verificou uma redução significativa de colesterol total e de LDL nos indivíduos que seguiram uma dieta reduzida em lipídios, quando comparados àqueles que foram orientados a consumir uma dieta rica em gorduras.

Estudo realizado por HUNNINGHAKE e col. (1993) também apresentou redução de $5,0 \%, 27,0 \%$ e $32,0 \%$, respectivamente, na LDL de pacientes tratados com a dieta proposta pelo National Cholesterol Education Program Step II, lovastatina e a combinação da dieta e do hipolipemiante. 


\subsection{Avaliação do efeito da dieta proposta pelo Sistema de Pontos sobre marcadores inflamatórios}

A modificação oxidativa da fração LDL tem sido considerada um evento chave no processo biológico de iniciação e desenvolvimento da lesão aterosclerótica (TSIMIKAS e col., 2001; BARTER e col., 2004; FERNANDES e col., 2004; FERNVIK e col., 2004; FAVIOU, 2005). Desta forma, uma alta taxa de LDL-ox é, potencialmente, um dos mais recentes fatores de risco cardiovascular a serem identificados.

A hipótese de que a LDL-ox é fundamental para o desenvolvimento da aterogênese, foi sugerida quando foi observado que a formação de células espumosas não se devia à captação das $\mathrm{LDL}$ nativas por macrófagos, via LDL receptores $\mathrm{B} / \mathrm{E}$ (STEINBERG e col., 1989; TSIMIKAS e WITZTUM, 2001). De forma contrária, a captação da LDL-ox pelos macrófagos, levava a formação de células espumosas, mediada por um grupo de receptores chamados scavengers (SR) (BROWN e col., 1980; ABDALLA e col., 1994; REARDON e col., 2004; BINDER e col., 2005).

Esse mecanismo estimula o sistema imune e induz à produção de anticorpos anti-LDLox (PIARULLI e col., 2005). Diversos estudos em humanos e experimentos com animais têm verificado altas taxas de LDL-ox, assim como seus anticorpos em lesões ateroscleróticas (PRATICO e col., 2001; TSIMIKAS e WITZTUM, 2001; SILASTE e col., 2004). Nesse sentido, tem sido sugerido que a quantidade de auto- 
anticorpos anti-LDLox no plasma tem correlação positiva com a doença aterosclerótica, tornando seu monitoramento um importante marcador biológico desta enfermidade (AHMED e col., 1999; FAVIOU e col., 2005; PIARULLI e col., 2005).

Sabe-se que a formação de auto-anticorpos anti-LDLox é dependente da susceptibilidade individual de base genética e de outros fatores, dentre os quais: a concentração de antioxidantes e dos ácidos graxos insaturados na LDL, de hábitos alimentares, fumo, e também da idade e sexo (TINAHONES e col., 2005).

O conteúdo de antioxidantes da partícula de LDL é crucial para a sua proteção. Estudos in vitro mostraram que a oxidação da LDL somente se inicia após os radicais livres terem depletado o conteúdo de antioxidantes celular. In vivo, é provável, que a magnitude do processo oxidativo e, mesmo, a ocorrência ou não de oxidação da LDL dependa do balanço entre a intensidade da agressão oxidativa e a capacidade das defesas antioxidantes (BALTOUNI, 1997).

A hipótese de que a peroxidação lipídica desempenha papel importante na patogênese da aterosclerose despertou crescente entusiasmo sobre o uso de antioxidantes como agentes antiaterogênicos (SILVA e col., 1995; RAO, 2002). As substâncias antioxidantes mais utilizadas com o objetivo de prevenir ou reduzir o desenvolvimento da doença aterosclerótica têm sido as vitaminas $\mathrm{C}$ e $\mathrm{E}$, os carotenóides e flavonóides (SBC, 2001). 
Os resultados demonstrados em nosso estudo indicam que embora tenha sido verificado um menor consumo de ácidos graxos saturados, trans e colesterol no grupo DPCB, quando comparado ao $\mathrm{DHCB}$, não houve diferença significativa em relação ao consumo de vitaminas antioxidantes $(p>0,050)$. No entanto, observou-se que os pacientes do grupo DPCA apresentaram uma ingestão significativamente maior de vitaminas C e E, do que os do grupo DHCA $(p<0,001)$.

Os grupos tratados apenas com a sinvastatina (DHCA e DHCB) tiveram menor concentração de auto-anticorpos anti-LDLox ao final do estudo, do que os grupos que associaram o tratamento medicamentoso a dieta proposta pelo Sistema de Pontos. Esta aparente discrepância pode ser explicada pela possibilidade de que em certas circunstâncias, a diminuição dos níveis de auto-anticorpos anti-LDLox não reflete a redução da oxidação desta lipoproteína, mas indica um aumento no consumo de auto-anticorpos devido a sua associação à lesões ateroscleróticas precoces, reduzindo desta forma os níveis de auto-anticorpos anti-LDLox livres para serem detectados nos ensaios biológicos (TOIKKA e col., 2000).

Quanto à proteína $\mathrm{C}$ reativa, sabe-se que altas concentrações desse marcador inflamatório são preditivas de morbidade e mortalidade por doenças cardiovasculares (HORNE e col., 2000; MADSEN e col., 2003). RIDKER e col. (1998) reportaram que a avaliação de perfil lipídico associada à PCR fornece um bom prognóstico na identificação de risco cardiovascular. 
Estudos in vitro que avaliaram a vascularização celular demonstraram que a PCR aumenta a secreção de MCP-1 e induz a expressão dos fatores VCAM-1 e ICAM-1 (BARTER e col., 2004). Pesquisas têm demonstrado que uma dieta com baixos valores de lipídios e rica em antioxidantes possui propriedades antiinflamatórias (MADSEN e col., 2003). Os resultados apresentados em nosso estudo confirmam estes dados, pois indicaram que os dois grupos de pacientes que associaram a dieta de pontos ao tratamento medicamentoso, tiveram uma maior redução de PCR ao final da pesquisa.

Por fim, há que se considerar as limitações e dificuldades encontradas durante o desenvolvimento deste estudo.

Estudos recentes mostram que a maioria dos pacientes com DCV infelizmente não atinge as metas do tratamento por diversas razões, como o alto custo das medicações, falta de aconselhamento pelos profissionais de saúde e, principalmente, pela dificuldade em modificar seu estilo de vida (dieta, abandono do tabagismo e prática de atividade física).

O presente estudo se propôs a avaliar o efeito da dieta de pontos sobre os marcadores bioquímicos $\mathrm{e}$ antropométricos de indivíduos dislipidêmicos coronarianos, sob o uso de sinvastatina. Ainda que, a pesquisa tenha encontrado resultados consistentes para algumas variáveis de estudo e se saiba que o tratamento dietético associado ao medicamentoso é de suma importância para os portadores de 
doença cardiovascular, convém ressaltar que a modificação de hábitos alimentares não é processo simples.

As alterações no hábito alimentar dos indivíduos podem implicar em aumento de habilidade e tempo disponível para o preparo de alimentos. Fatores ambientais, culturais e sociais também podem constituir obstáculos importantes para mudanças de comportamento alimentar.

Além destes fatores, deve-se pontuar que em nosso estudo os pacientes avaliados não apresentaram alto nível socioeconômico, o que leva a considerar que alguns desses indivíduos tiveram dificuldades em substituir alimentos de seu consumo habitual por frutas, verduras, legumes e grãos integrais, pois são produtos de alto custo. O estudo de NEUMANN (2000) no município de São Paulo e o de SICHIERI (1998) no Rio de Janeiro demonstraram que quando as comparações entre o consumo alimentar dos indivíduos são feitas em relação à renda, hortaliças e frutas são alimentos mais consumidos entre os indivíduos de alta renda e escolaridade.

Além disso, preparações e alimentos ricos em gorduras (frituras, carnes gordas, embutidos), devido a sua alta palatabilidade, fazem parte da preferência alimentar da maioria dos indivíduos. No estudo de NEUMANN (2000) os indivíduos com menor renda e escolaridade referiram consumir diariamente carne de boi, de porco, frango, embutidos, ovos, frituras, pizzas e lanches, banha e refrigerantes. 
Assim torna-se um desafio para o profissional de saúde conscientizar a população em relação à associação dieta/saúde e promover mudanças desejáveis em seu padrão alimentar que possam ser efetivamente incorporadas em seu contexto familiar e social, garantindo o aporte suficiente e adequado de nutrientes e adesão a nova dieta, principalmente entre aqueles que estão nas camadas mais pobres e com menor nível de instrução. 
7. CONCLUSÕES 


\section{CONCLUSÕES}

Os resultados obtidos pelo presente estudo permitem concluir que:

- Os pacientes do grupo DPCB consumiram ao longo do estudo, quantidades significantemente menores de lipídios, ácidos graxos saturados, trans, colesterol e CSI quando comparados aos do grupo DHCB;

- Os indivíduos do grupo DPCA, consumiram menores quantidades de ácidos graxos saturados e CSI e maiores quantidades de fibras, ácidos graxos polinsaturados, ômega 3, ômega 6 e vitaminas $\mathrm{C}$ e E;

- A dieta com baixo índice de colesterol e gordura saturada baseada no Sistema de Pontos associada ao uso da sinvastatina resultou em uma média menor de circunferência abdominal, colesterol total, LDL e proteína $\mathrm{C}$ reativa ao final da pesquisa no grupo DPCB quando comparado ao DHCB;

- O Sistema de Pontos associado à sinvastatina resultou em menor média de VLDL, triglicérides e proteína $\mathrm{C}$ reativa e aumento de HDL no grupo DPCA quando confrontado com aquele tratado exclusivamente pela utilização de estatinas (DHCA);

- Os grupos tratados apenas com a sinvastatina (DHCA e DHCB) tiveram menores concentrações de auto-anticorpos anti-LDLox que os grupos que associaram o tratamento medicamentoso à dieta proposta pelo Sistema de Pontos. 
Estes fatores denotam a importância da intervenção nutricional como terapêutica das dislipidemias em pacientes coronarianos, mesmo quando estes são tratados com sinvastatina.

Ademais, embora as estatinas sejam eficazes e seguras no tratamento das hipercolesterolemias, efeitos colaterais podem acometer pacientes que as utilizam e, nestes casos, dietas com baixos teores de lipídios poderiam auxiliá-los a utilizar menores doses destes medicamentos. 


\section{REFERÊNCIAS}




\section{REFERÊNCIAS}

Abdalla DSP. Estresse oxidativo e alimentação. In: Tirapegui J. Nutrição: Fundamentos e aspectos atuais. São Paulo: Atheneu; 2001; p. 179-200.

Abdalla DSP, Costa-Ros LFBP, Monteiro HP, Campos A, Curi R. Human macrophage metabolism of low density lipoprotein oxidized by stimulated neutrophils and ferritin. Atherosclerosis. 1994; 107:157-163.

Abreu ES. Elaboração e avaliação da eficácia do Sistema de Pontos de um instrumento de orientação alimentar como ferramenta para intervenções dietéticas em indivíduos hiperlipidêmicos. São Paulo; 2003. [Tese de doutorado Faculdade de Saúde Pública]

Abreu ES, Nacif MAL, Torres EAFS. Sistema de pontos para controle de colesterol e gordura no sangue. São Paulo: Metha; 2004, 69 p.

Agresti A. Categorical data analysis. New York: Wiley Interscience; 1990.

Ahmed E, Trifunovic J, Stegmayr B, Hallmans G, Lefvert AK. Autoantibodies against oxidatively modified ldl do not constitue a risk factor for stroke. Stroke. 1999; 30: 2541-2546.

American Heart Association, 2001 [on line]. Available from http://www.americanheartassociation.com [2002 marc 12].

Anderson KM, Castelli WP, Levy D. Cholesterol and mortality 30 year follow up from Framingham study. JAMA. 1987; 257:2176-80. 
Araújo FB, Barbosa DS, Hsin CY, Maranhão RC, Abdalla DSP. Evaluation of oxidative stress in patients with hyperlipidemia. Atherosclerosis. 1995; 117: 61-71.

Araújo EAC. Diferenciais dos fatores de risco cardiovascular nas populações migrantes e não migrantes de Minas Gerais. São Paulo; 2002. [Tese de doutorado - Faculdade de Saúde Pública].

Barros MAV, Martinez TLR. Dislipidemias nas mulheres. Aspectos fisiológicos e terapêuticos. Arq Bras Cardiol. 1995; 65 (3): 283-288.

Barros MRAC, Bertolami MC, Abdalla DSP, Ferreira WP. Identification of mildly oxidized low-density lipoprotein (electronegative LDL) and its auto-antibodies IgG in children and adolescents hypercholesterolemic offsprings. Atherosclerosis. 2006; 184:103-107.

Barter PJ, Nicholls S, Rye KA, Anantharamaiah GM, Navab M, Fogelman AM. Antiinflammatory properties of HDL. Circ Res. 2004; 95; 764-772. .

Batlouni M. Hipótese oxidativa da aterosclerose e emprego de antioxidantes na doença arterial coronária. Arq Bras Cardiol.1997; 68 (1): 56-63.

Bertolami MC. Dislipidemias e alterações endoteliais. Arq Bras Cardiol. 1995; 65 (3): 267-271.

Bertolini GL, Bazotte RB. Fármacos Hipolipemiantes. In: Curi R, Pompéia C, Miyasaka CK, Procópio. Entendendo a gordura: Manole; 2002. p.491-505.

Binder CJ, Shaw PX, Chang MK, Boullier A, Hartvigsen K, Horkko S, Miller YI, Woelkers DA, Corr M, Witztum JL. The role of natural antibodies in atherogenesis. J Lip Res. 2005; 46: 1353-1361. 
Bittencourt Júnior PIH, Senna SM Ácidos graxos e Aterosclerose. In: Curi R, Pompéia C, Miyasaka CK, Procópio. Entendendo a gordura: Manole; 2002. p. 539554.

Bjorntorp P. Obesity and the risk of cardiovascular disease. Annal Clin Res. 1995; 17:3-9.

Brown MS, Masu SK, Falck JR, Ho YK, Goldstein JL. The scavenger cell pathway for lipoprotein degradation: specificity of the binding site that mediates the uptake of negatively charged LDL by macrophages. J Supramol Struct. 1980;13: 67-81.

Brown L, Rosner B, Willett WW, Sacks FM. Cholesterol-lowering effects of dietary fiber: a meta-analysis. Am J Clin Nutr. 1999;69:30-42.

Bussab WO, Morettin PA. Estatística básica, São Paulo: Atual; 1987. p.321.

Carrol S, Cooke CB, Butterly RJ, Moxon JWD, Moxon JWA, Dudfield M. Waist circumference in the assessment of obesity and associated risk factor in coronary artery disease. Coronary Health Care. 2000; 4 (4): 179-86.

Cervato AM, Mazzilli RN, Martins IS, Marucci MF. Dieta habitual e fatores de risco para doenças cardiovasculares. Rev Saúde Pública. 1997; 31 (3): 227-35.

Chang YH, Abdalla DSP, Sevanian A. Characterization of cholesterol oxidation products formed by oxidative modification of low density protein. Free Radical Biology \& Medicine. 1997; 23 (2): 202-214.

Chisholm A, Sutherland W, Ball M. The effect of dietary fat content on plasma noncholesterol sterol concentration in patients with familiar hypercholesterolemia treated with simvastatin. Metabolism. 1994; 43 (3): 310-314. 
Clifton PM, Wight MB, Nestel PJ. Is fat restriction with HMGCoA reductase inhibitor treatment ? Atherosclerosis. 1992; 93:59-70.

Cobb MM, Teitelbaum HS, Breslow JL. Lovastatin efficacy in reducing low-density lipoprotein cholesterol levels on high-vs low fat diets. JAMA. 1991; 265: 997-1001.

Colombo RCR, Aguillar OM, Gallani MCBJ, Gobatto CA. Caracterização da obesidade em pacientes com infarto do miocárdio. Rev Latino-am Enfermagem. 2003; 11 (4): 461-467.

Connor SL, Gustafson JR, Artaud-Wild SM, Favell, DP, Classick-Kohn CJ, Hatcher LF, Connor WE. The cholesterol/saturated-fat index: an indication of hipercolesterolemic and atherogenic potential of food. Lancet. 1986; (May): 122932.

Connor SL, Gustafson JR, Artaud-Wild SM, Favell, DP, Classick-Kohn CJ, Hatcher LF, Connor WE. The cholesterol/saturated-fat index for coronary prevention: Background, use, and a comprehensive table of foods. J Am Diet Assoc. 1989; 89:807-16.

Conselho Nacional de Saúde. Regulamentação de pesquisas envolvendo seres humanos. Resolução n¹96/96. Brasília (DF); 1996.

Crouse JR, Byington RP, Bond MG. Pravastatine, lipids, and atherosclerosis in the carotid arteries (PLAC II). Am J Cardiol. 1995; 75: 455-459.

D'Agostino RB, Grundy S, Sullivan LM, Wilson P. Validation of the Framingham heart disease prediction scores: results of a multiple ethnic groups investigation. JAMA. 2001;286:180-7. 
Damasceno NRT, Goto H, Rodrigues FMD, Dias CTS, Okawabata FS, Abdalla DSP, Gidlund M. Soy Protein Isolate Reduces the Oxidizability of LDL and the generation of oxidized LDL autoantibodies in rabbits with diet-induced atherosclerosis. J Nutr. 2000; 130: 2641-2647.

Damasceno NRT, Apolinário E, Oliveira JMA, Fernandes I, Abdalla DSP. Biomarker LDL's oxidative modification in vivo. RBAC. 2002; 34 (3): 115-120.

Davi G, Guagnano MT, Ciabattoni G, Basili S, Falco A, Marinopiccoli M, Nutini M, Sensi S, Patrono C. Platelet activation in obese women. JAMA. 2002; 288 (16): 2008-2014.

Depres JP, Moorjani S, Lupien PJ, Tremblay A, Nadeau A, Bouchard C. Regional distribution of body fat, plasma lipoproteins, and cardiovascular disease. Arteriosclerosis. 1990; 10 (4); 497-511.

Dietschy JM. Theoretical considerations of what regulates low-density-lipoprotein and high-density-lipoprotein cholesterol. Am J Clin Nutr. 1997; 65 (Suppl): 1581-9.

Drewnowski A, Popkin BM. The nutrition transition: new trends in the global diet. Nutr Rev. 1997; 55 (2): 31-43.

Dziezak JD. Preservatives: antioxidants. The ultimate answer to oxidation. Food Technol. 1989; 9: 94-103.

Ehara S, Ueda M, Naruko T. Elevated levels of oxidized low density lipoprotein show a positive relationship with the severity acute coronary syndromes. Circulation. 2001;103: 1955.

Escosteguy C. Estudos de intervenção. In: Medronho RA. Epidemiologia. Atheneu; 2003. p. 151-160. 
Esposito K, Pontillo A, Di Palo C, Giugliano G, Masella M, Marfella R, Giugliano D. Effect of weight loss and lifestyle changes on vascular inflammatory markers in obese women. JAMA. 2003; 289 (14): 1799-1804.

Faviou E, Vourli G, Nounopoulos C, Zachari A, Dionyssiou-Asteriou A. Circulating oxidized low density lipoprotein, autoantibodies against them and homocysteine serum levels in diagnosis and estimation of severity of coronary artery disease. Free Radical Research. 2005; 39 (4): 419-429.

Fernvik EC, Ketelhuth DFJ, Russo M, Gidlund M. The autoantibody repertory against copper-or macrofage-modified LDL differs in normolipidemics and hypercholesterolemic patients. J Clin Immunology. 2004; 24 (2): 170-176.

Fernandes, JL, Orford JL, Garcia C, Coelho OR, Gidlund M, Blotta MHSL. Differences in human antioxidized LDL autoantibodies in patients with stable and unstable angina. J Autoimmunity. 2004; 23: 345-352.

Fetcher ES, Foster N, Anderson JT, Grande F, Keys A. Quantitative estimation of diets to control serum cholesterol. Am J Clin Nutr. 1967; 20: 475-92.

Figliuolo R, Craveiro AA. Conceitos sobre as propriedades farmacológicas e terapêuticas dos ácidos graxos poliinsaturados da série ômega-3. International Meeting on Oils Technology, Campinas - S.P, 1991.

Filho NA, Rouquayrol MZ. Elementos de metodologia epidemiológica. In: Rouquayrol MZ, Filho NA. Epidemiologia e Saúde. MEDSI; 2003. p.147-177.

Fornés NS. Padrões alimentares e suas relações com os lipídios séricos em população da área metropolitana de São Paulo. São Paulo; 1998. [Tese de doutorado - Faculdade de Saúde Pública]. 
Fornés NS, Martins IS, Hernan M, Velásquez-Meléndez, Ascherio A. Frequência de consumo alimentar e níveis séricos de lipoproteínas na população de Cotia, SP, Brazil. Rev Saúde Pública. 2000; 34 (4): 380-7.

Freedman DS, Williamson DF, Croft JC, Ballew C, Byers T. Relation of body fat distribution to ischemic heart disease. Am J Epidemiol. 1995; 42 (1): 53-62.

Frisancho AR. Anthropometric standards for the assessment of growth and nutritional status. Ann Arbor: University of Michigan; 1999.

Garcia-Closas, R, Serra-Majem L, Segura R. Fish consupmption, n-3 fatty acids and the Mediterranean diet. Eur J Clin Nutr. 1993; 47 (Suppl 1): S85-S90.

Getz GS. Immune function in atherogenesis. J Lipid Res. 2005; 46 (1): 1-10.

Giannini SD. Prevenção da coronariopatia. In: Quintão ECR. Colesterol e aterosclerose. Rio de Janeiro: Qualitymark Ltda; 1992. p.45-60.

Gregorio SR, Areas, MA, Reues FGR. Fibras alimentares e doença cardiovascular. Dietary fibers and cardiovascular disease. Nutrire: Rev Soc Bras Alim Nutr. 2001; 22: 109-120.

Groot L, Staveren WV. Working plan and manual of operation - anthropometry Nutrition and the elderly a concerted action on nutrition health. In: European Community Euro-nut Netherlands, november 1980.

Haulrik N, Toubro S, Dyerberg J, Stender S, Skow AR, Astrup A. Effect of protein and methionine intakes on plasma homocysteine concentrations: a 6-mo randomized controlled trial in overweight subjects. Am J Clin Nutr. 2002; 76:1202-6. 
Hayes HK. Dietary Fat and Coronary Heart Disease. In: Bendich A e Deckelbaum RJ Preventive Nutrition: The comprehensive guide for health professionals. Totowa; 1997.

Hayes KC. n-6 versus n-3 fatty acid modulation of lipoprotein metabolism. Arq Bras Cardiol. 2001; 77 (3): 1-44.

He J, Whelton PK. Comentary: Salt intake, hypertension and risk of cardiovascular disease: an important public health challenge. Inter J Epidemiol. 2002; 31: 327-331.

Herrera NR, Arauz GA, Rojas MN, Rosello Araya M. Factores aterogenicos de la dieta de la populación costarricense, 1991. Arch Latinoam Nutr. 1996: 46 (1): 27 32.

Hiermann I, Byre KV, Holme I, Leren P. Effect of diet and smoking intervention on the incidence of coronary heart disease. Report from the Oslo study of a randomized trial in health men. Lancet. 1981; 2: 1303.

Hirata MH, Hirata RDC. Transporte de ácidos graxos no plasma. In: Curi R, Pompéia C, Miyasaka CK, Procópio. Entendendo a gordura: Manole; 2002. p.5973.

Horne BD, Muhlestein JB, Carlquist JF, Bair TL, Madsen TE, Hart NI, Anderson JL. Statin therapy, lipd levels, C-reative protein and the survival of patients with angiographically severe coronary artery disease. J Am Coll Cardiol. 2000; 36 (6): 1774-1780.

Hubert HB, Feinleib M, MacNamara PT, Castell WP. Obesity as an independent risk factor for cardiovascular disease: a 26 years follow-up of participants in the Framingham Heart Study. Circulation. 1983; 67 (5): 968-77. 
Hunninghake DB, Stein EA, Dujovne CA. The efficacy of an intensive dietary therapy alone or combined with lovastatin in outpatients with hypercholesterolemia. N Eng J Med. 1993; 328: 1213-1219.

IBGE. 2000 [on line]. Disponível em URL < http//:www.ibge.gov.br $>[5$ de dezembro de 2001].

Jenkins DJA, Kendall CWC, Marchie A, Faulkner DA, Wong JMW, Souza R, Emam A, Parker TL, Vidgen E, Lapsley KG, Trautwein EA, Josse RG, Leiter LA, Connelly PW. Effects of a dietary portfolio of cholesterol-lowering foods vs. lovastatin on serum lipids and C-reactive protein. JAMA. 2003; 290 (4): 502-510.

Jula A, Marniemi J, Huupponen R, Virtanen A, Rastas M, Ronnemaa. Effects of diet and sinvastatin on serum lipids, insulin, and antioxidants in hypercholesterolemic men. JAMA. 2202; 287 (5): 598-533.

Junior JBS, Gomes FBC, Cezário AC, Moura L. Doenças e agravos não transmissíveis. In: Rouquayrol MZ, Filho NA. Epidemiologia e Saúde. MEDSI; 2003. p.289-312.

Kannel WB. Una perspectiva sobre los factores de riesgo de las enfermedades cardiovasculares. In: Org Pan de La Salud (publicación científica, 155). El desafio de la epidemiologia - Problemas y lecturas seleccionadas. Washington; 1988.

Katan MB, Zock PI, Mensink RP. Dietary oil serum lipoproteins and coronary heart disease. Am J Clin Nutr. 1995; 26: 403-17.

Kato H, Tillotson J, Nichaman MZ, Rhoads GG, Hamilton HB. Epidemiologics studies of coronary heart disease and stroke in Japanese men living in Japan, Hawaii and California. Am J Epidemiol. 1973; 97 (6): 372-385. 
Keys A, Anderson JT, Grande F. Serum cholesterol response to changes in the diet. IV. Particular saturated fatty in the diet. Metabolism. 1965; 14: 776-87.

Keys A. Coronary heart disease in seven countries. Circulation. 1970; 41 (suppl 1): 162-183.

Koenig W, Sund M, Frohlich M, Lowel H, Hutchinson WL, Pepys MB. Refinement of the association of serum C-reactive protein concentration and coronary heart disease risk by correction for within-subject variation over time. The MONICA Augsburg Studies, 1984 and 1987. Am J Epidemiol. 2003; 158:357-364.

Kris-Etherton P, Yu S: Individual fatty acids on plasma lipids and lipoproteins: human studies. Am J Clin Nutr. 1997; 65 (Suppl): 162S-44S.

Lane JD, Pieper CF, Barefoot JC, Williams RB, Siegler NC. Caffeine and cholesterol: interactions with hostility. Phychosom Med. 1994; 56 (3): 260-6.

Laurenti R. Epidemiologia das doenças cardiovasculares no Brasil. Arq Bras Cardiol.1982; 18 (4): 243-248.

Laurenti R, Buchalla CM. Os mitos a respeito das doenças cardiovasculares. Arq Bras Cardiol. 2001; 76 (2): 99-104.

Leren P, Askevold EM, Foss OP. The Oslo Study. Cardiovascular disease in young and middle aged Oslo men. Acta Med Scand. 1975; 1 (Suppl): 588.

Lessa I. $\mathrm{O}$ adulto brasileiro e as doenças da modernidade. Epidemiologia das doenças crônicas não transmissíveis. São Paulo: Hucitec;1998.

Lessa I. Doenças crônicas transmissíveis no Brasil: um desafio para a complexa tarefa da vigilância. Ciência \& Saúde Coletiva. 2004; 9 (4): 931-943. 
Lichtenstein AH, Jauhiainen M, McGladdery S, Ausman LM, Jalbert SM, VilellaBach M, Ehnholm C, Frohlich J, Schaefer EJ. Impact of hydrogenated fat on highdensity lipoprotein subfractions and metabolism. J Lipid Res. 2001; 42 (4): 597-604.

Lima JC. As dislipidemias e suas avaliações laboratoriais. Rev Bras Hipertens. 1999; 6 (2): 133-137.

Lolio CA. Mortalidade por doenças do aparelho circulatório em capitais de regiões metropolitanas do Brasil, 1979-1989. São Paulo; 1994. [Tese de Livre Docência - Faculdade de Saúde Pública da USP].

Lottenberg AMP. Influência do grau de saturação dos ácidos graxos da dieta e do estado alimentar sobre a esterificação do colesterol e sua transferência entre lipoproteínas no plasma. São Paulo; 1997. [Tese de Doutorado - Faculdade de Ciências Farmacêuticas da USP].

Lotufo PA. Epidemiologia das doenças cardiovasculares no Brasil: histórico, situação atual e proposta de modelo teórico. Rev Soc Cardiol Estado de São Paulo. 1996; 6 (5):541-547.

Lotufo PA. Mortalidade por doenças do coração no Brasil. Comparação com outros países. Arq Bras Cardiol.1998; 70 (5): 321 - 325.

Lotufo PA, Lolio CA. Tendências de Evolução da mortalidade por doenças cardiovasculares: o caso do Estado de São Paulo. In: Monteiro CA. Velhos e Novos Males da Saúde do Brasil - A evolução do País e de suas Doenças. São Paulo: HUCITEC NUPENS/USP; 1995. p.279-287.

Macambira R, Poli DM, Canosa HG, Moura JE, Volpe R, Martins VL, Lucena, WA. Aterosclerose - Fatores de risco e fatores de risco. JBM. 2001; 81: 64-68. 
Madsen T, Christensen JH, Blom M, Schmidt EB. The effect of dietary n-3 fatty acids on serum concentrations of C-reactive protein: a dose-response study. $\mathbf{B r} \mathbf{J}$ Nutr. 2003; 89:517-522.

Mann NJ, Li D, Sinclair AJ, Dudman NPB, Guo XW, Elsworth GR, Wilson AK, Kelly FD. The effect of diet on plasma homocysteine concentrations in healthy male subjects. Eur J Clin Nutr. 1999; 53: 895-899.

Mansur AP, Favaratu D, Souza MFM. Tendência da mortalidade por doenças circulatórias no Brasil de 1979 a 1996. Arq Bras Cardiol. 2001; 76:497-503.

Marangoni F, Galli C. Dietary fats of European countries in the Mediterranean area. World Rev Nutr Diet. 2000; 87: 78-89.

Martins IS, Gomes AD, Pasini U. Niveis lipêmicos e alguns fatores de risco de doenças cardiovasculares em população no município de São Paulo, SP (Brasil). Rev Saúde Pública. 1989; 23 (1): 26-38.

Matsudo VKR. Measuring nutrition status, physical activity, and fitness, with special emphasis on populations at nutritional risk. Nutr Rev. 1996; 54 (4): S79-S96

Matsudo V, Matsudo S, Araujo T, Andrade D, Andrade E, Oliveira LC, Braggion G. Nível de atividade física da população do estado de São Paulo: análise de acordo com o gênero, idade, nível socioeconômico, distribuição geográfica e de conhecimento. Rev Bras Ciên e Mov. 2002a; 10 (4): 41-50.

Matsudo V, Matsudo S, Andrade D, Araujo T, Andrade E, Oliveira LC, Braggion G. Promotion of physical in a developing country: The Agita São Paulo experience. Public Health Nutr. 2002b; 5 (1A): 253-261.

Mattson FH, Erickson BA, Klingman AM. Effect of dietary cholesterol on serum cholesterol in men. Am J Clin Nutr. 1972; 25: 589-94. 
Medeiros F. Dislipidemias. In: Farret JF. Nutrição e doenças cardiovasculares: prevenção primária e secundária. São Paulo: Atheneu, 2005. p. 37-54, 2005.

Mendall MA, Patel P, Ballam L, Strachan D, Nortfield TC. C-reactive protein and its relation to cardiovascular risk factor: a population based cross-sectional study. $\mathbf{B r}$ Med J. 1996; 312: 1061-1065.

Ministério da Saúde. Secretaria Nacional de Ações Básicas de Saúde. Divisão Nacional de Epidemiologia. Doenças cardiovasculares no Brasil - Sistema Único de Saúde - SUS. Brasília: Centro de documentação do Ministério da Saúde; 1993.

Ministério da Saúde. Fundação Nacional Saúde. Vigilância Epidemiológica. Vigilância e Monitoramento de doenças e agravos não trasnmissíveis. Disponível em URL http://www.funasa.gov.br/epi/intransmi/epi ntrasmi_00htm [2003 jul20].

Mondini L, Monteiro CA. Mudanças no padrão da alimentação da população urbana brasileira (1962-1988). Rev Saúde Pública. 1994; 28: 433-9.

Montaye M, Bacquer DD, Backer DG, Amouyel P. Overweight and obesity: a major challenge for coronary heart disease secondary prevention in clinical practice in Europe. Eur Heart J. 2000; 21 (10): 808-13.

Monteiro CA, Mondini L, Souza ALM, Popkin BM. The nutrition transition in Brasil. Eur J Clin Nutr. 1995; 49: 105-113.

Monteiro CA, Mondini L, Costa RBL Mudanças na composição e adequação nutricional da dieta familiar nas áreas metropolitanas do Brasil (1988-996). Rev Saúde Pública. 2000; 34 (3): 251-8.

Mozaffarian D, Katan M, Ascherio A, Stampfer MJ, Willet WC. Trans fatty acids and cardiovascular disease. N Engl J Med. 2006; 354: 1601-1613. 
National Cholesterol Education Program. Executive Summary of the Third Report of the National Cholesterol Education Program (NCEP) Expert Panel on detection, evaluation, and treatment of high blood cholesterol in adults (Adult Treatment Panel III). JAMA. 2001; 285 (19): 2486-2497.

Navab M, Berliner JÁ, Watson $\mathrm{AD}$, The Yin and Yang of oxidation in the development of the fatty streak. A review based on the 1994 George Lyman Duff Memorial Lecture. Arterioscler Thromb Vasc Biol. 1996; 16:831-842.

Nelson GJ. Dietary fat, trans fatty acids, and risk of coronary heart disease. Nutr Rev. 1998; 56 (8): 250-252.

Neter J, Hunter MH, Nachtsheim CJ, Wasserman W. Applied linear statistical models. $4^{\mathrm{a}}$ ed. Boston: Irwin; 1986. p.1408.

Neumann AILCP. Consumo de alimentos de risco e proteção para doenças cardiovasculares entre funcionários públicos estaduais do município de São Paulo. São Paulo; 2000. [Dissertação de Mestrado - Faculdade de Saúde Pública].

Novazzi JP. Dislipidemias. Rev Bras Med. 1999; 56 (7): 647-655.

Nutrition Data System. NCC Food and Nutrient Database Version 35, 2005. Regent of the University of Minnesota.

Oliveira HCF, Quintão ECR. Colesterol e Aterogênese. In: Quintão ECR. Colesterol e Aterosclerose. Rio de Janeiro: Qualitymark Ltda; 1992. p.45-60.

Park YK, Koo MH, Carvalho PO . Recentes progressos dos alimentos funcionais. Bol SBCTA. 1997; 31 (2): 200 - 206. 
Pearson TA, Mensah GA, Alexander RW, Anderson JL, Cannon RO, Criqui M, Fadl YY, Fortmann SP, Hong Y, Myers GL, Rifai N, Smith SC, Taubert K, Tracy RP, Vinicor F. Markers of inflammation and Cardiovascular Disease - Application to clinical and public health practice. A statement for healthcare professionals from the center for disease control and prevention and the American Heart Association. Circulation. 2003; 107: 499-511.

Pereira MG. Epidemiologia: Teoria e Prática. Rio de Janeiro: Guanabara Koogan, 1995.

Piarulli F, Lapolla A, Sartore G, Rossetti c, Bax G, Noale M, Minicuci N, Fiori C, Marchioro L, Manzato E, Fedele D. autoantibodies against oxidized LDLs and atherosclerosis in type 2 diabetes. Diabetes Care. 2005; 28(3): 653-657.

Pinheiro ABV, Lacerda AEM, Benzecry EH, Gomes MC, Costa VM. Tabela para Avaliação de Consumo Alimentar em Medidas Caseiras. $4^{\circ}$ ed. São Paulo: Ed. Atheneu.; 2000.

Pitt B, Mancini GBJ, Ellis SG, Rosman HS, Park JS, McGovern ME. Pravastatin limitation of atherosclerosis in the coronary arteries (PLAC I): reduction in atherosclerosis progression and clinical events. J Am Coll Cardiol. 1995; 26: 1133 1139.

Power Analysis and Sample Size (PASS) for Windows, 2002.

Portal VL, Moriguchi EH, Vieira JLC, Schio S, Mastalir ET, Buffé F, Bortolini EB, Bruch RS, Rodrigues R. Comparação do efeito de dois inibidores da HMGCoA Redutase sobre a suscetibilidade da LDL à oxidação. Arq Bras Cardiol. 2003; 80 (2):150-155. 
Posner BM, DeRusso PA, Norquist SL, Erick MA. Preventive nutrition intervention in coronary heart disease: Risk assessment and formulating dietary goals. J Am Diet Assoc. 1986; 86 (10): 1395-1400.

Pratico D, Tangirala RK, Horkko S, Witzum JL, Palinski W, FitzGerald G. Circulating autoantibodies to oxidized cardiolipin correlate with isoprostane F2 - VI levels and the extent of atherosclerosis in ApoE-deficient mice: modulation by vitamin E. Blood. 2001; 97 (2): 459-464.

Pyorala K. Dietary cholesterol en relation to plasma cholesterol and coronary heart disease. Am J Clin Nutr. 1987; 45: 1176-84.

Rader DJ, Wilson JM. Gene Therapy for Lipid Disorders. In: Haber, E. (ed.) Molecular Cardiovascular Medicine. Scientific American, New York. 97-114, 1995.

Ramalho RA, Accioly E, Silva LM. Doenças cardiovasculares: Efeito antioxidante das vitaminas A, C e E. Rev Metab Nutr. 2003; 7 (1): 6-9.

Rao AV. Lycopene, Tomatoes, and the prevention of coronary heart disease. Experimental Biology and Medicine. 2002; 227:908-913.

Reardon CA, Miller ER, Blachowiczz L, Lukens J, Binder CJ, Witzumm JL, Getz GS. Autoantibodies to OxLDL fail to alter the clearance of injected OxLDL in apolipoprotein E-deficient Mice. J Lip Res. 2004; 45: 1347-1354.

Reaven P, Parthasaraty S, Grasse BJ, Miller E, Steinberg D, Witztum L. Effects of oleate-rich and linoleate rich diet on the susceptibility of low density lipoprotein to oxidative modification in middy hypercholesterolemic subjects. J Clin Invest. 1993; 91: 668-676. 
Ridker, PM, Cushman M, Stampfer MJ, Tracy RP, Henneckens CH. Inflammation, aspirin, and the risk of cardiovascular disease in apparently health men. $\mathbf{N}$ Engl $\mathbf{J}$ Med. 1997; 336: 973-979.

Ridker, PM, Cushman M, Stampfer MJ. Plasma concentration of C-reactive protein and risk of developing peripheral vascular disease. Circulation. 1998; 97: 425-428.

Ridker, PM, Glynn RJ, Hennekens. C-reactive protein adds to the predictive value of total and HDL cholesterol in determining the risk of first myocardial infarction. Circulation. 1998; 97: 2007-11.

Sacks FM, Pfeffer MA, Moye LA. The effect of pravastatin on coronary events after myocardial infarction in patients with coronary heart disease. N Eng J Med. 1996; 335: 1001-9.

Salonen R, Nyyssonen K, Porkkala-Sararaho E. The Kuopio Atherosclerosis Prevention Study (KAPS): effect of pravastatin treatment on lipids, oxidation, resistance of lipoproteins, and atherosclerotic progression. Am J Cardiol. 1995; 76: 34C-39C.

Santos JE. Terapêutica das hiperlipidemias: como e por quê ? Rev Bras Hipertens. 1999; 6 (2): $158-62$.

Santos RD, Maranhão RC. Classificação e aspectos clínicos das dislipidemias. Rev Bras Med. 1998; 55: 12-16.

Santos WB, Mesquita ET, Vieira RMR, Olej B, Coutinho M, Avezum A. Proteína-Creativa e doença cardiovascular. As bases da evidência científica. Arq Bras Cardiol. 2003; 80 (4): 452-6. 
Scandinavian Sinvastatin Survival Study Group - Randomized trial of cholesterol lowering in 4444 patients with coronary heart disease: The Scandinavian Sinvastatin Survival Study (4S). Lancet. 1994; 344:1383-1389.

Schaefer EJ, Augustin JL, McNamara JR, Seman LJ, Bourdet KL, Meydani MM, Holay Sanday. Am J Cardiol. 2001; 87: 1000-1003.

Schumann G, Dati F. Vorläufige Referenzbereiche für 14 Proteine im Serum (für Erwachsene) nach Standardisierung immunchemischer Methoden unter Bezug auf das internationale Referenzmaterial CRM 470. Lab Med 1995;19:401-403.

Serra-Majem LI, Barbas LR. Recordatorio de 24 horas. In: Majem LIS, Bartrina JÁ, Verdú MJ. Nutrición y Salud Pública - Métodos, bases científicas y aplicaciones. Barcelona: Masson; 1995.p.113 - 9.

Shulzs I. Tratamento das dislipidemias - Como e quando indicar a combinação de Medicamentos Hipolipemiantes. Arq Bras Endocrinol Metab. 2006; 50 (2): 344359.

Sichieri R. Epidemiologia da obesidade. Rio de Janeiro: EdUERJ; 1998.

Sierksma A, Van Der Gaag, Kluft C, Hendriks HFJ. Moderate alcohol consumption reduces plasma $\mathrm{C}$-reactive protein and fibrinogen levels; a randomized, dietcontrolled intervention study. Eur J Clin Nutr. 2002; 56: 1130-1136.

Silaste ML, Rantala M, Alfthan G, Aro A, Witztum JL, Kesaniemi YA, Horkkp S. Changes in dietary fat intake alter plasma levels of oxidized low-density lipoprotein and lipoprotein (a). Arterioscler Thromb Vasc Biol. 2004; 24:498-503.

Silva EL, Chang YH, Moriel P, Miara J, Barbosa DS, Araújo FB, Abdalla, DSP. Lipoprotein oxidation: implications to atherogenesis. Free Radical Res Latin America. 1995;47 (5/6): 376-384. 
Silva NAS. Saúde cardiovascular na era tecnológica. Arq Bras Cardiol. 2004; 83 (6): 453-455.

Sociedade Brasileira de Cardiologia. $2^{\circ}$ Consenso Brasileiro sobre Dislipidemias Avaliação -Detecção-Tratamento. Arq Bras Cardiol. 1996; 67: 109-29.

Sociedade Brasileira de Cardiologia. III Diretrizes Brasileiras Sobre Dislipidemias e Diretriz de Prevenção da Aterosclerose do Departamento de Aterosclerose da Sociedade Brasileira de Cardiologia. Arq Bras Cardiol. 2001; 77 (Suppl): 1-48.

Sociedade Brasileira de Cardiologia. Diretrizes para Cardiologistas sobre excesso de peso e doença cardiovascular dos Departamentos de Aterosclerose, Cardiologia Clínica e Funcor da Sociedade Brasileira de Cardiologia. Arq Bras Cardiol. 2002; 78 (SupplI): 1-13.

Stein EA, Myers GL. Lipids, lipoproteins and apolipoproteins. In: Tietz Textbook of Clinical Chemistry. Burtis, C.A.; Ashwood, E.R. Second edition. Pennsylvania, 1994,1002-1093.

Steinberg D, Pathsarathy S. Carew TE. Beyond Cholesterol: Modifications of lowlipoprotein increases its atherogenicity. New Eng J Med. 1989; 320: 915-924.

Stone NJ. Lipid Management: Current diet and drug treatment options. Am J Med. 1996; 101 (Suppl 4A): 40S-49S.

Stone NJ. Fish consumption, fish oil, lipids, and coronary heart disease. Am J Clin Nutr. 1997; 65: 1083-6.

Statistical Package for the Social Sciences (SPSS) for Windows, Release 13.0.1, Standard Version, 1999. 
Tepe B, Sokmen M; Akpulat A, Sokmen A. In vitro antioxidant actives of the methanol extracts of five Allium species from Turkey. Food Chem. 2005; 92:89-92

Tinahones FJ, Gómez-Zumaquero JM, Garrido-Sánchez L, García-Fuentes E., RojoMartínez G, Esteva I, Adana MSR., Cardona F, Soriguer F. Influence of age and sex on levels of anti-oxidized LDL antibodies and anti-LDL immune complexes in the general population. J Lipid Res. 2005, 46: 452-457.

Tsimikas S, Palinski W, Witztum JL. Circulating autoantibodies to oxidized LDL correlate with arterial accumulation and depletion of oxidized LDL in LDL receptordeficient mice. Arterioscler Thromb Vasc Biol. 2001; 21:95-100.

Tsimikas S, Witztum JL. Measuring circulating oxidized low-density lipoprotein to evaluate coronary risk. Circulation. 2001; 103:1930-1932.

Toikka JO, Ahotupa M, Haapanen A, Viikari JSA, Hartiala JJ, Raitakari OT. Increased arterial intima-media thickness and in vivo LDL oxidation in young men with borderline hypertension. Hypertension. 2000; 36: 923-933.

Torres EAFS. Teor de lipídeos em alimentos e sua importância na nutrição. São Paulo; 2000. [Tese de Livre Docência - Faculdade de Saúde Pública da USP].

Viebig RF. Desenho de um questionário de Freqüência Alimentar para a população da região metropolitana de São Paulo. São Paulo; 2002. [Dissertação de Mestrado - Faculdade de Saúde Pública da USP].

Visioli F. Antioxidants in Mediterranean diet. World Rev Nutr Diet. 2000; 87:4355.

Whyte HM, Havenstein N. A perspective view of dieting to lower the blood cholesterol. Am J Clin Nutr. 1976; 29: 784-90. 
Willett WC, Stampfer MJ, Manson JE, Colditz GA, Speizer FE, Rosner BA, Sampson LA, Hennekens CH. Intake of trans fatty acids and risk of coronary heart disease among women. Lancet. 1993; 341: 581-585.

Willet WC. Diet and health: what should we eat ? Science. 1994; 264:532-7.

Willett WC, Stampfer MJ. Implication of total energy intake for epidemiologic analyses. In: Willett WC. Nutritional epidemiology. $2^{\text {nd }}$ ed. New York: Oxford University Press, 1998 (Monographs in epidemiology and biostatistics,30).

World Health Organization. Obesity - preventing a managing the global epidemic. Report. Geneva; 1998 (Report of a WHO Consultation on Obesity).

Xavier HT, Abdalla DSP, Martinez TLR, Ramires JAF, Gagliardi ART. Efeitos da lipoproteína LDL-oxidada sobre a proliferação e a motilidade espontânea in vitro de células endoteliais de artérias coronárias humanas. Arq Bras Cardiol. 2004; 83 (6): 488-492.

Zilversmit DB. Cholesterol index in foods. J Am Diet Assoc. 1979; 74:562-65. 
ANEXOS 


\title{
DIETA TRADICIONAL PARA PORTADORES DE DISLIPIDEMIAS
}

\author{
ORIENTACÃO DIETÉTICA
}

\section{ALIMENTOS PROIBIDOS}

manteiga, coalhada, iogurte e leite integral e margarina;

queijos gordos (mussarela, prato, gorgonzola, cheddar, catupiry, provolone, etc); torresmo, toucinho, bacon, lingüiça, salsicha, mortadela, presunto, apresuntado; carne de porco ou carne de animais com gordura aparente; miúdos ou vísceras, bife de figado; côco, leite de côco, sorvete, chocolate; maionese, chantily, leite condensado, creme de leite; banha, sardinha em lata, camarão; bolachas, croissant, torradas prontas.

\section{ISO MODERADO}

arroz, milho, aveia, trigo;

mandioca, batata, mandioca, mandioquinha, batata-doce, massas, cará, inhame, beterraba; pães (francês/italiano/sírio/light); fubá, sagu, farinhas em geral; feijão, ervilha, lentilha, soja, tremoço, grão-de-bico; frituras com óleo vegetal ou azeite; halvarinas (Becel/Doriana Light), frutos oleaginosos (amendoim, nozes, castanhas)

frutas (3 unidades/dia)

carne magra (vaca, frango sem pele), peixes, peito de peru, peito de chester, atum ao natural.

\section{ALIMENTOS PERMITIDOS}

leite desnatado;

coalhada ou iogurte desnatado;

ricota, queijo fresco magro, queijo cottage;

legumes e verduras 


\section{Sistema de Pontos para Controle de Colesterol e Gordura no Sangue}

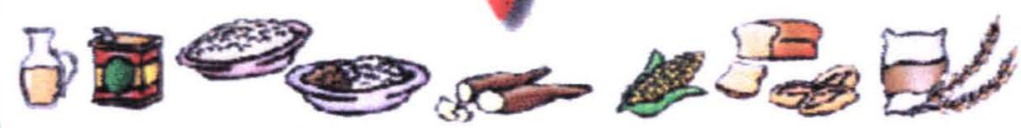

-

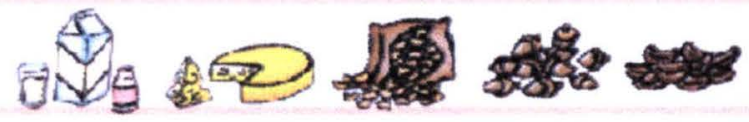
2015

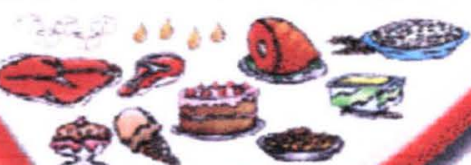

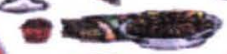

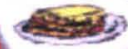

Ajude o sen Coraciano a viver Mais e Melhor 


\title{
SISTEMA DE PONTOS PARA CONTROLE DE COLESTEROL E GORDURA NO SANGUE
}

\author{
Edeli Simioni de Abreu
} Márcia A. L. Nacif

Elizabeth A. F. S. Torres

São Paulo 2002 
Índice

Apresentação

Representação Gráfica da Alimentação Saudável.

Passos para uma

Alimentação Saudável

Como Contar os Pontos .......... 04

Atenção . . . . . . . . . . . . . 07

Lista de Pontos

dos Alimentos ................ 08

Modelo . . . . . . . . . . . . . . . . . . . 21

Referências Bibliograficas . . . . . . 22 


\section{Apresentação}

A alimentação saudável tem papel fundamental na prevenção de doenças e na redução e manutenção dos níveis de colesterol no sangue. Sabe-se que uma dieta com elevados indices de colesterol e gordura saturada agrava esses riscos. Assim, fica fácil deduzir que o consumo de alimentos com reduzido teor de gordura saturada e pobres em colesterol é importante na redução dos níveis de colesterol sangüineos.

O que fica difícil medir é o potencial de aumentar o colesterol que cada alimento possui. Para facilitar esse entendimento foi desenvolvido um Índice de colesterol/gordura saturada - ICS, que pode ser utilizado para comparar diferentes alimentos e preparações, por meio de pontuações.

Controlar o peso é outro fator que diminui os riscos para o aumento de colesterol $\mathrm{e}$, conseqüentemente, previne o aparecimento de doenças do coração, diabetes, hipertensão arterial, entre outras. Porém, isso não é tarefa fácil, mas com um pouco de boa vontade, é possivel atingir o objetivo, sem fazer grandes sacrifícios. O que é necessário é aprender a escolher os alimentos certos.

Para começar, devemos banir a idéia de "fazer regime", que está associada a fazer sacrifício durante um tempo e depois abandonar, voltando, muitas vezes, à estaca zero. O correto é adotar um plano dietético, ou seja, uma forma de se alimentar hoje, nos próximos dias e sempre.

Para auxiliar na promoção de um melhor estado nutricional e no estabelecimento de hábitos alimentares adequados, foi desenvolvido o presente Sistema de Pontos, de fácil compreensão e manejo, que pode ser calculado pelo próprio individuo que aprenderá a elaborar sua dieta através de pontuaçōes de ICS, além de uma representação gráfica da alimentação saudảvel. 


\section{Representação Gráfica da Alimentação Saudável}

\section{Uma ferramenta para controle e prevenção de colesterol elevado e gordura no sangue.}

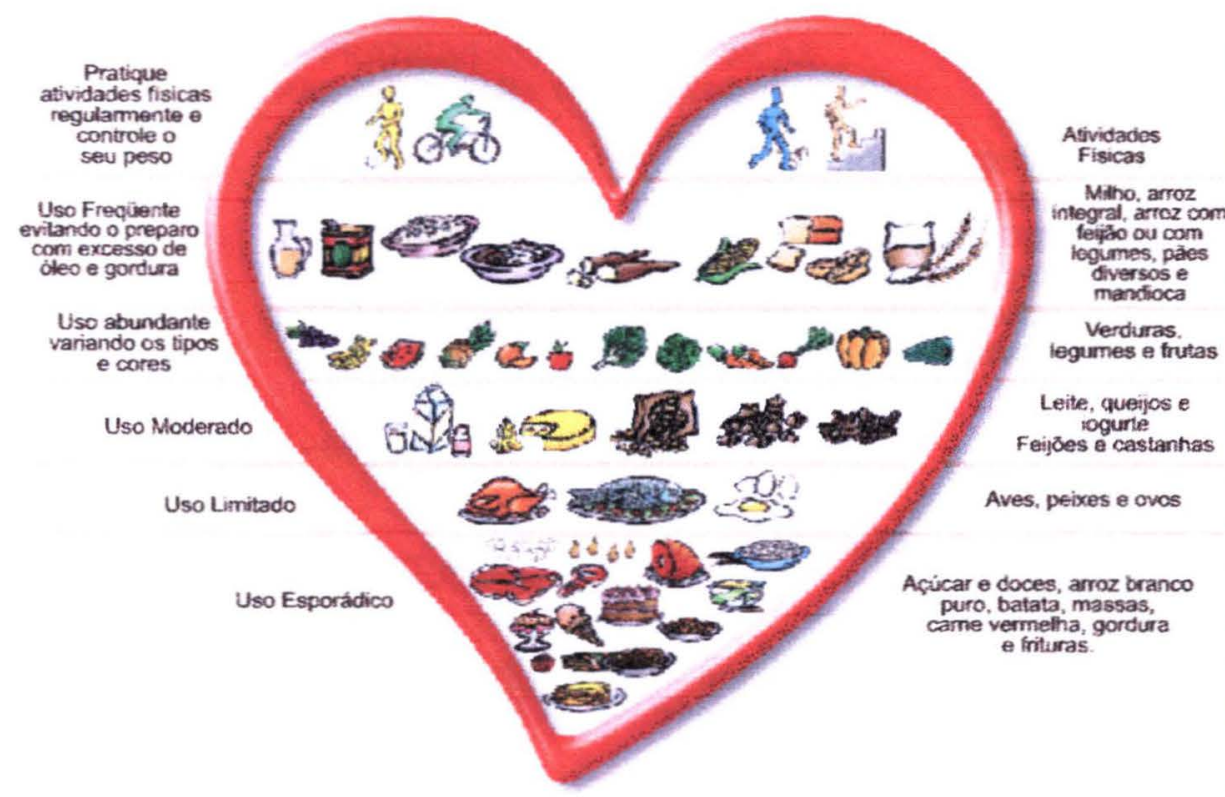

ESCOLHA UMA ALIMENTAÇÃO SAUDÁVEL 
1 - CONSUMIR UMA ALIMENTAÇÃO VARIADA

2 - BASEAR A ALIMENTAÇÃO NO CONSUMO DE ALIMENTOS DERIVADOS DE GRĂOS E RAIZES, LEGUMES, VERDURAS E FRUTAS

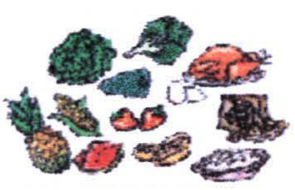

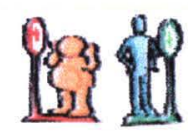

4 - PRATICAR ATIVIDADES FÍSICAS REGULARMENTE E COM ORIENTAÇĀO
3 - EVITAR A OBESIDADE, MANTENDO O PESO CORPORAL DESEJÁVEL

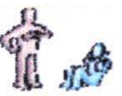

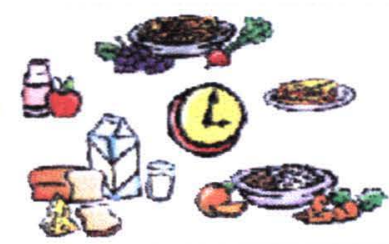

5 - SELECIONAR UMA DIETA COM BAIXA QUANTIDADE DE GORDURA, COLESTEROL E GORDURA SATURADA 6 - FRACIONAR A DIETA, FAZENDO TRÉS REFEIÇÖES E DOIS LANCHES ENTRE ELAS, ESCOLHENDO ALIMENTOS SAUDÁVEIS

7 - EVITAR O CONSUMO DE FRITURAS

8 - CONSUMIR PRODUTOS DE ORIGEM ANIMAL MODERADAMENTE

9 - PREFERIR AS CARNES MAGRAS E RETIRAR GORDURAS VISIVEIS

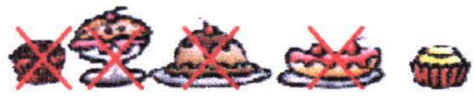

10 - CONSUMIR ACYÚCAR E DOCES COM MODERAÇÃO

11 - REDUZIR O CONSUMO DE SAL

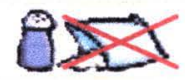

12 - LIMITAR O CONSUMO DE ÁLCOOL, SE INGERIR, FAÇA-O COM MODERAÇĀO

13 - NÃO ESQUECER DE CONSUMIR ÁGUA, POIS É ESSENCIAL À SAÚdE 


\section{Como Contar os Pontos}

Esse é o seu guia de alimentos. Utilize-o para fazer escolhas convenientes onde quer que você estiver.

No que se baseia esse sistema de pontos?

Não há proibição de nenhum alimento: uma pessoa com excesso de colesterol não tem que se isolar do mundo ou comer pratos especiais.

Propicia uma variedade de alimentos para escolher:

uma dieta com alimentos permitidos e proibidos é

monótona. Esse sistema permite que cada um

module sua alimentação sem eliminar os alimentos preferidos.

Permite que se tenha uma vida alimentar normal: dá para comer bem.

Em pouco tempos

aprende-se a conhecer o valor e a equivalência dos alimentos, não sendo mais necessário anotá-los, e, isso vale para o resto da vida.

Quantos pontos de ICS (Índice de Colesterol e Gordura Saturada) que se pode consumir por dia para baixar o colesterol?

É só procurar na próxima tabela (tabela 1) os pontos de ICS que estão liberados para a sua dieta de acordo com sexo e idade.

\section{Tabela 1: Quantidade máxima de ICS segundo sexo.}

ICs por dia

Sexo

Masculino

Feminino
Até 55 anos

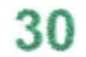

25
Acima de $\mathbf{5 5}$ anos 


\title{
Como Contar os Pontos
}

\author{
E é necessário anotar os \\ pontos de tudo que se come?
}

Anotar os pontos leva a melhores resultados. Após algum tempo, é possivel deixar de anotar porque o método e os principios já foram assimilados. Mas até isso acontecer, anote

os seus pontos, consultando as listas de pontos

(a partir da página 08), em ordem crescente de ICS, de acordo com as porções que você ingerir.

Exemplo : se você consumir 4 colheres de sopa de arroz, salada de alface temperada com azeite e 1 bife, anote e conte os pontos da seguinte forma:

\begin{tabular}{|c|c|c|c|}
\hline Alimento & $\begin{array}{l}\text { Quantidade } \\
\text { de Porģbes }\end{array}$ & $\begin{array}{l}\text { Pontuacădo de } \\
\text { ICS por porģä }\end{array}$ & $\begin{array}{l}\text { Pontuaçás } \\
\text { total de ICS }\end{array}$ \\
\hline Arroz & 2 & 1 & 2 \\
\hline Alface & 1 & 0 & 0 \\
\hline Azeite & 1 & 1 & 1 \\
\hline Bife & 1 & 12 & 12 \\
\hline Total & & & 15 \\
\hline
\end{tabular}

Tente e você vai ver que não é difícil ter uma alimentação saudável sem banir os alimentos preferidos.

\section{Onde anotar os pontos?}

Na página 21 você vai encontrar um modelo que pode ser copiado em um caderno ou outro tipo de papel em que você deve anotar os pontos e guardar para mostrar ao seu médico.

\section{Procure manter o seu peso saudável:}

De acordo com a sua altura, pode-se verificar o seu peso saudável minimo e máximo, apresentados na Tabela 2. 


\section{Como Contar os Pontos}

Tabela 2: Peso saudável segundo altura

Peso saudável

corporal em Kg

$\begin{array}{ccc}\text { Altura }(\mathrm{cm}) & \text { Minimo } & \text { Máximo } \\ \mathbf{1 4 0} & 39,2 & 40,0 \\ \mathbf{1 4 2} & 40,3 & 50,4 \\ \mathbf{1 4 4} & 41,5 & 51,8 \\ \mathbf{1 4 6} & 42,6 & 53,3 \\ \mathbf{1 4 8} & 43,5 & 54,8 \\ \mathbf{1 5 0} & 45,0 & 56,3 \\ \mathbf{1 5 2} & \mathbf{4 6 , 2} & 57,8 \\ \mathbf{1 5 4} & 47,4 & 59,3 \\ \mathbf{1 5 6} & 48,7 & 60,8 \\ \mathbf{1 5 8} & 49,9 & 62,4 \\ \mathbf{1 6 0} & 51,2 & 64,0 \\ \mathbf{1 6 2} & 52,5 & 65,6 \\ \mathbf{1 6 4} & 53,8 & 67,2 \\ \mathbf{1 6 6} & 55,1 & 68,9 \\ \mathbf{1 6 8} & 56,4 & 70,6 \\ \mathbf{1 7 0} & 57,8 & 72,3 \\ \mathbf{1 7 2} & 59,2 & 74,0 \\ \mathbf{1 7 4} & 60,6 & 75,7 \\ \mathbf{1 7 6} & 62,0 & 77,4 \\ \mathbf{1 7 8} & 63,4 & 79,2 \\ \mathbf{1 8 0} & 64,8 & 81,0 \\ \mathbf{1 8 2} & 66,2 & 82,8 \\ \mathbf{1 8 4} & 67,7 & 84,6 \\ \mathbf{1 8 6} & 69,2 & 86,5 \\ \mathbf{1 8 8} & 70,7 & 88,4 \\ \mathbf{1 9 0} & 72,2 & 90,3 \\ \mathbf{1 9 2} & 73,7 & 92,2 \\ \mathbf{1 9 4} & 75,3 & 94,1 \\ \mathbf{1 9 6} & 76,8 & 96,0 \\ \mathbf{1 9 8} & 78,4 & 98,0 \\ \mathbf{2 0 0} & 80,0 & 100,0\end{array}$

EXPERIMENTE! VALE A PENA TER UMA ALIMENTAÇĀO SAUdÁVEL COMENDO DE TUDO!! 


\section{Atenção}
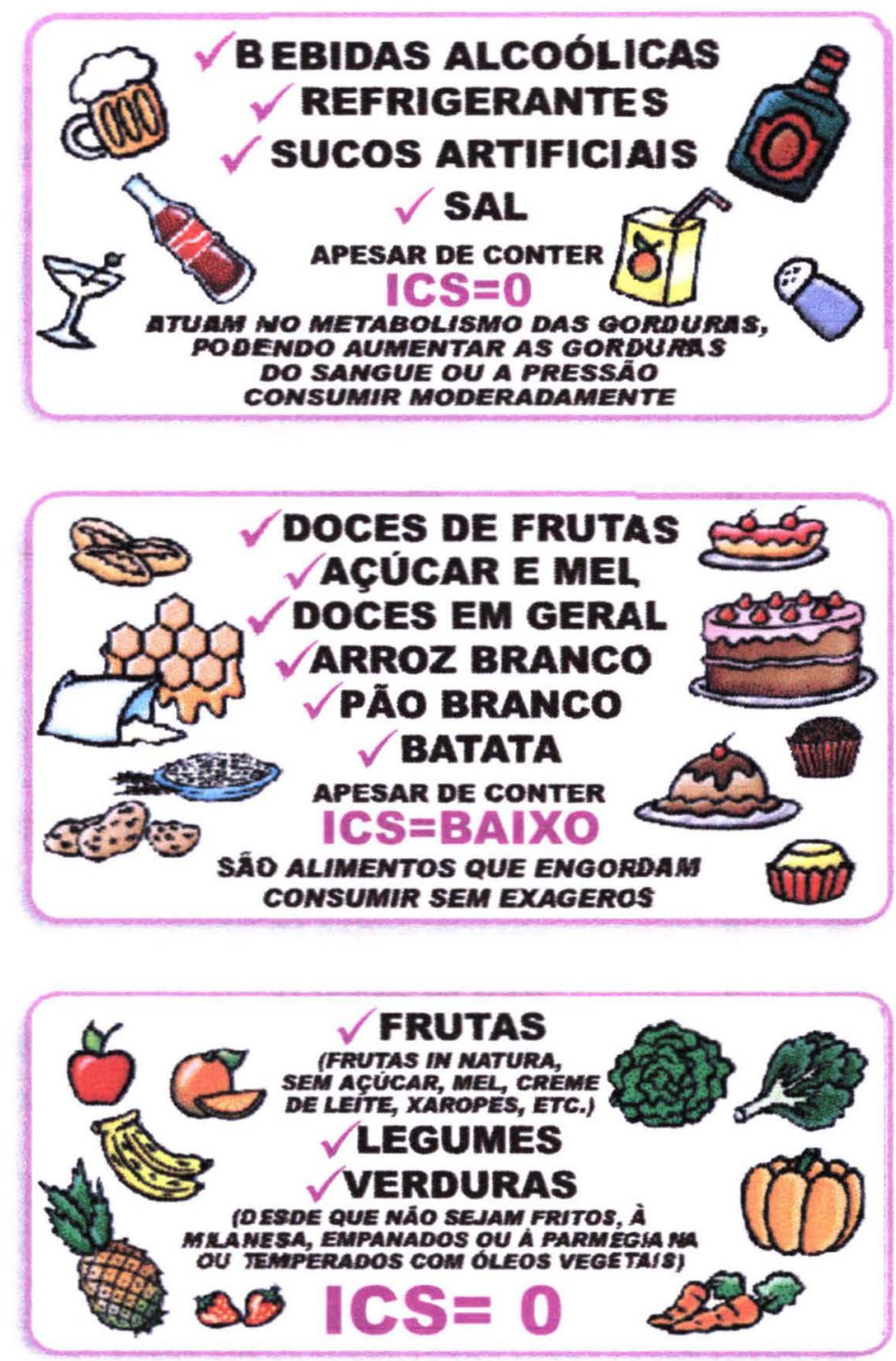


\section{Lista de Pontos dos Alimentos}

0 pontos

\begin{tabular}{|c|c|c|}
\hline Alimento & Porçāo & por Porçăo \\
\hline \multirow[t]{2}{*}{ Açúcar mascavo/refinado } & 01 colher de sopa & 0 \\
\hline & 01 colher de chá & 0 \\
\hline Água de coco & 01 copo de requeijão & 0 \\
\hline Aveia & 01 colher de sopa & o \\
\hline Azeitona & 01 unidade & $\mathbf{0}$ \\
\hline Balas /balas diet & 01 unidade & 0 \\
\hline Café com açúcarl sem açúcar & 01 xícara de café & 0 \\
\hline Caldo de cana & 01 copo de requeijajo & o \\
\hline Catchup & 01 colher de sopa & 0 \\
\hline \multirow[t]{2}{*}{ Cereal matinal } & 01 xícara de chá & 0 \\
\hline & 01 colher de sopa & $\mathbf{0}$ \\
\hline Chá com açúcar/ sem açúcar & 01 copo de requeijāo & $\mathbf{0}$ \\
\hline Chiclete /diet & 01 unidade & 0 \\
\hline Doces de frutas & 01 colher de sopa & 0 \\
\hline Farelo de trigo & 01 colher de sopa & 0 \\
\hline Farinha de mandioca & 01 colher de sopa & 0 \\
\hline Farinha de milho & 01 colher de sopa & $\mathbf{0}$ \\
\hline Frutas em calda & 01 unidade & 0 \\
\hline Fubá & 01 colher de sopa & o \\
\hline Gatorade & 01 copo de requeijäo & o \\
\hline Gelatina/gelatina diet & 01 pote & 0 \\
\hline Geléia/geléia diet & 01 colher de sopa & 0 \\
\hline
\end{tabular}




\section{Lista de Pontos dos Alimentos}

0 pontos

\begin{tabular}{|l|l|l|}
\hline \multicolumn{1}{|c|}{ Alimento } & \multicolumn{1}{c|}{ Porção } & $\begin{array}{c}\text { ICS } \\
\text { Gorçăo }\end{array}$ \\
\hline Gräo de bico cozido & 01 fatia fina & 0 \\
\hline Groselha com águaldiet & 01 colher de servir & 0 \\
\hline logurte desnatado & 01 copo de requeijäo & 0 \\
\hline logurte diet ou light & 01 pote & 0 \\
\hline Kani Kama & 01 pote & 0 \\
\hline Leite de soja & 05 unidades & 0 \\
\hline Leite desnatado & 01 copo de requeijão & 0 \\
\hline Leite em pó desnatado & 01 copo de requeijão & 0 \\
\hline Leite fermentado - Yakult & 02 colheres de sopa & 0 \\
\hline Mel & 01 pote & 0 \\
\hline Mostarda & 01 colher de sopa & 0 \\
\hline Ovo cozido (clara) & 01 colher de sopa & 0 \\
\hline Queijo de soja & 01 unidade & 0 \\
\hline Refrigerante/ diet ou light & 01 fatia & 0 \\
\hline Salada de frutas & 01 copo & 0 \\
\hline Soja cozida & 01 xícara de chá & 0 \\
\hline Sucos de frutas & 01 colher de servir & 0 \\
\hline Sushi & 01 copo de requeijão & 0 \\
\hline Suspiro & 01 unidade & 0 \\
\hline Trigo & 01 unidade & 0 \\
\hline Vinagre & 01 colher de sopa & 0 \\
\hline & 01 colher de sopa & 0 \\
\hline
\end{tabular}




\section{Lista de Pontos dos Alimentos}

1 ponto

\begin{tabular}{|c|c|c|}
\hline Alimento & Porçâa & por Porç̧ăo \\
\hline Apresuntado & 01 fatia & 1 \\
\hline \multirow[t]{2}{*}{ Arroz à grega } & 01 colher de servir /escumadeira & 1 \\
\hline & 02 colheres de sopa & 1 \\
\hline \multirow[t]{2}{*}{ Arroz integral cozido } & 01 colher de servir /escumadeira & 1 \\
\hline & 02 colheres de sopa & 1 \\
\hline \multirow[t]{2}{*}{ Arroz branco cozido } & 01 colher de servirlescumadeira & 1 \\
\hline & 02 colheres de sopa & 1 \\
\hline Azeite de oliva & 01 colher de sopa & 1 \\
\hline Atum em lata & 01 colher de sopa & 1 \\
\hline Barra de cereais & 01 unidade & 1 \\
\hline \multirow[t]{2}{*}{ Batata cozida } & 01 colher de servir & 1 \\
\hline & 01 unidade & 1 \\
\hline \multirow[t]{2}{*}{ Batata doce cozida } & 01 colher de servir & 1 \\
\hline & 01 unidade & 1 \\
\hline Batata doce frita & 01 colher de servir & 1 \\
\hline Batata frita & 01 colher de servir /escumadeira & 1 \\
\hline Batata frita ("chips") & 01 colher de servir & 1 \\
\hline Batata frita (palha) & 01 colher de servir & 1 \\
\hline Berinjela à milanesa & 01 fatia & 1 \\
\hline Bis & 01 unidade & 1 \\
\hline Biscoito de maisena & 04 unidades & 1 \\
\hline Biscoito de polvilho & 05 unidades & 1 \\
\hline Blanquet de peru & 02 fatias & 1 \\
\hline
\end{tabular}




\section{Lista de Pontos dos Alimentos}

\section{1 ponto}

\begin{tabular}{|l|l|l|}
\hline \multicolumn{1}{|c|}{ Alimento } & \multicolumn{1}{|c|}{ Porção } & ICs \\
\hline Porçăo
\end{tabular}




\section{Lista de Pontos dos Alimentos}

\section{1 ponto}

Alimento

Nugget de frango

Óleos canola/ girassol/ milho/ soja

Paçoca

Pão de forma (todos os tipos)

Pão francês

Pão de hambúrguerihot dog

Pão tipo bisnaguinha

Pé de frango

Peito de peru defumado

Polenta com molho

Polenta frita

Presunto

Purê de batata

Queijo petit suisse-danoninho

Quiabo frito

Rosbife

Salada de maionese

Salame

Sopa de feijão com macarräo

Sopa de legumes/ legumes cimacarrão

Sorvete diet ou light

Torradas (pão francês)
Porçâo

ICS

por Porção

02 unidades

1

01 colher de sopa

1

01 unidade 1

02 fatias 1

01 unidade 1

01 unidade 1

02 unidades 1

01 unidade 1

02 fatias finas 1

01 colher de servir 1

01 fatia 1

01 fatia fina 1

01 colher de servir 1

01 pote 1

04 colheres de sopa 1

01 fatia fina

01 colher de servir 1

01 fatia fina 1

01 concha 1

01 concha 1

01 bola 1

05 fatias/unidades 


\section{Lista de Pontos dos Alimentos}

\section{2 pontos}

\begin{tabular}{|c|c|c|}
\hline Alimento & Porção & $\begin{array}{l}\text { ICS } \\
\text { por Porçáo }\end{array}$ \\
\hline Banana frita & 01 unidade & 2 \\
\hline Bombom & 01 unidade & 2 \\
\hline Abacate & 1 fatia média & 2 \\
\hline Açai & 01 copo & 2 \\
\hline Amendoim torrado & 01 colher de sopa & 2 \\
\hline Arroz doce & 01 pote & 2 \\
\hline Caldo verde & 01 concha & 2 \\
\hline Canja & 01 concha & 2 \\
\hline Castanhas & 01 colher de sopa & 2 \\
\hline Creme de leite light & 01 colher de sopa & 2 \\
\hline Flan & 01 pote & 2 \\
\hline logurte de frutas & 01 pote & 2 \\
\hline logurte de frutas para beber & 01 pote & 2 \\
\hline Leite integral semi desnatado & 01 copo de requeijão & 2 \\
\hline Leite tipo C & 01 copo de requeijão & 2 \\
\hline Macarrão c/ molho de carne & 01 colher de servir/pegador & 2 \\
\hline Maionese & 01 colher de sopa & 2 \\
\hline Marisco cozido com casca & 01 pires & 2 \\
\hline McFritas & 01 unidade pequena & 2 \\
\hline Mortadela & 01 fatia fina & 2 \\
\hline Nozes & 01 colher de sopa & 2 \\
\hline Pão caseiro & 01 fatia & 2 \\
\hline
\end{tabular}




\section{Lista de Pontos dos Alimentos}

\section{2 pontos}

\begin{tabular}{|c|c|c|}
\hline Alimento & Porçăa & por ICS \\
\hline Pipoca & 01 xicara de chá & 2 \\
\hline Queijo fresco light & 01 fatia grande & 2 \\
\hline Queijo parmesão & 01 colher de sopa & 2 \\
\hline Salgados fritos & 01 unidade média & 2 \\
\hline Salsichão & 01 fatia fina & 2 \\
\hline Sopas tipo creme & 01 concha & 2 \\
\hline Tomate seco & 01 colher de sopa & 2 \\
\hline
\end{tabular}

\section{3 pontos}

\begin{tabular}{|l|l|l|}
\hline \multicolumn{1}{|c|}{ Alimento } & \multicolumn{1}{c|}{$\begin{array}{c}\text { Pcs } \\
\text { porçä́o }\end{array}$} \\
\hline Almôndega (bovina) & 01 unidade & 3 \\
\hline Bacalhau ao forno & 01 pires & 3 \\
\hline Carne moida refogada & 01 colher de sopa & 3 \\
\hline Esfiha de carne & 01 unidade & 3 \\
\hline Ovo de codorna & 01 unidade & 3 \\
\hline Queijo mussarela & 01 fatia pequena & 3 \\
\hline Requeijão light & 01 colher de sopa & 3 \\
\hline Sardinha & 01 unidade & 3 \\
\hline Sopa de legumes cl carne & 01 concha & 3 \\
\hline Sashimi & 01 porção & 3 \\
\hline Sorvete com leite & 01 bola & 3 \\
\hline Vitamina de leite com frutas & 01 copo de requeijão & 3 \\
\hline
\end{tabular}




\section{Lista de Pontos dos Alimentos}

\section{4 pontos}

\begin{tabular}{|l|l|c|}
\hline \multicolumn{1}{|c|}{ Alimento } & \multicolumn{1}{c|}{ Porção } & por Porção \\
\hline Bolo comum & 01 fatia & 4 \\
\hline Bolo diet & 01 fatia & 4 \\
\hline Carne seca & 01 colher de sopa & 4 \\
\hline Cream cheese light & 01 colher de sopa & 4 \\
\hline Frango refogado & 01 pedaço & 4 \\
\hline logurte com mel & 01 pote & 4 \\
\hline Manteiga & $1 / 2$ colher de sopa & 4 \\
\hline & 1 ponta de faca & 4 \\
\hline McFritas & 01 unidade média & 4 \\
\hline Nhoque c/molho & 01 colher de servir & 4 \\
\hline Pão de queijo & 01 unidade & 4 \\
\hline Queijo de minas & 01 fatia grande & 4 \\
\hline Queijo prato & 01 fatia pequena & 4 \\
\hline Queijo provolone & 01 fatia pequena & 4 \\
\hline Ricota & 01 fatia grande & 4 \\
\hline Salgados assados & 01 unidade média & 4 \\
\hline Torta de maçã ou banana & 01 unidade & 4 \\
\hline Yakisoba & 01 porção & 4 \\
\hline
\end{tabular}




\section{Lista de Pontos dos Alimentos}

5 pontos

\begin{tabular}{|c|c|c|}
\hline Alimento & Porção & $\begin{array}{l}\text { ICS } \\
\text { por Porçâo }\end{array}$ \\
\hline Bucho & 1 porção & 5 \\
\hline Chantilly & 01 colher de sopa & 5 \\
\hline Carne assada/ de panela/cozida & 01 pedaço & 5 \\
\hline Creme de leite & 01 colher de sopa & 5 \\
\hline Esfiha de queijo & 01 unidade & 5 \\
\hline Frango (carne branca) grelh. & 01 filé pequeno & 5 \\
\hline Gordura vegetal hidrogenada & 01 colher de sopa & 5 \\
\hline McFritas & 01 unidade grande & 5 \\
\hline Moela & 01 pedaço & 5 \\
\hline Panqueca & 01 unidade & 5 \\
\hline Patê & 01 colher de sopa & 5 \\
\hline Peixe assado/cozido/grelhado & 01 filé pequeno & 5 \\
\hline Polenguinho & 01 unidade & 5 \\
\hline Porco (pernil) assado & 01 fatia & 5 \\
\hline Requeijão & 01 colher de sopa & 5 \\
\hline Salsicha cozida & 01 unidade & 5 \\
\hline Torta salgada & 01 fatia & 5 \\
\hline \multicolumn{3}{|c|}{6 pontos } \\
\hline Alimento & Porẹăo & $\begin{array}{l}\text { ICS } \\
\text { por Porçăo }\end{array}$ \\
\hline Bolo de aniversário & 01 fatia & 6 \\
\hline Canelone & 01 unidade & 6 \\
\hline Catupiry & 01 colher de sopa & 6 \\
\hline Chocolate & 01 unidade pequena & 6 \\
\hline
\end{tabular}




\section{Lista de Pontos dos Alimentos}

6 pontos

\begin{tabular}{|c|c|c|}
\hline Alimento & Porção & por Porçăo \\
\hline Chocolate diet & 01 unidade pequena & 6 \\
\hline Coalhada & 01 copo & 6 \\
\hline Hambúrguer & 01 unidade & 6 \\
\hline logurte natural & 01 pote & 6 \\
\hline Leite em pó integral & 02 colheres de sopa & 6 \\
\hline Leite tipo B & 01 copo de requeijäo & 6 \\
\hline Milk shake & 01 unidade pequena & 6 \\
\hline Pastel & 01 unidade & 6 \\
\hline Pizza & 01 pedaço & 6 \\
\hline Porco (lombo) assado & 01 fatia & 6 \\
\hline Quibe frito & 01 unidade & 6 \\
\hline Quindim & 01 unidade & 6 \\
\hline Sonho & 01 unidade & 6 \\
\hline \multicolumn{3}{|c|}{7 pontos } \\
\hline Alimento & Porçăo & por Porşão \\
\hline Bacon & 01 fatia fina & 7 \\
\hline Banha de porco & 01 colher de sopa & 7 \\
\hline Cocada & 01 unidade & 7 \\
\hline Cream cheese & 01 colher de sopa & 7 \\
\hline Feijoada & 01 concha & 7 \\
\hline Lingüiça & 01 gomo & 7 \\
\hline Panetone & 01 fatia & 7 \\
\hline Peixe frito & 01 filé pequeno & 7 \\
\hline
\end{tabular}




\section{Lista de Pontos dos Alimentos}

8 pontos

\begin{tabular}{|c|c|c|}
\hline Alimento & Porçāo & por Porçăa \\
\hline Chouriço & 01 porção & 8 \\
\hline Capelete & 01 colher de servir & 8 \\
\hline Frango frito & 01 pedaço & 8 \\
\hline McChicken & 01 unidade & 8 \\
\hline Ravióli & 01 colher de servir & 8 \\
\hline Rondelli & 01 pedaço & 8 \\
\hline Strogonoff & 1 concha & 8 \\
\hline Suflês & 01 fatia & 8 \\
\hline
\end{tabular}

Alimento

Carne de vaca (magra) grelh.

Frango à milanesa

Músculo

Salgadinhos chips

Torresmo

Tortas doces

Toucinho defumado
Porção

ICS

\begin{tabular}{lr}
01 bife pequeno & 9 \\
01 filé & 9 \\
\hline 01 porção & 9 \\
01 pacote & 9 \\
01 unidade & 9 \\
01 fatia & 9 \\
01 fatia fina & 9
\end{tabular}




\section{Lista de Pontos dos Alimentos}

\section{1 pontos}

\begin{tabular}{|c|c|c|}
\hline Alimento & Porçăo & por Porçâa \\
\hline Camarão refogado & 01 pires & 11 \\
\hline Lasanha & 01 pedaço & 11 \\
\hline Ovo cozido (gema) & 01 unidade & 11 \\
\hline Ovo cozido (inteiro) & 01 unidade & 11 \\
\hline Peru & 01 porção & 11 \\
\hline Pudim & 01 fatia & 11 \\
\hline
\end{tabular}

12 pontos

\begin{tabular}{|l|l|c|}
\hline \multicolumn{1}{|c|}{ Alimento } & \multicolumn{1}{|c|}{ Porção } & $\begin{array}{c}\text { ICS } \\
\text { Porçăo }\end{array}$ \\
\hline Bife & 01 bife & 12 \\
\hline Bisteca de porco & 01 bife & 12 \\
\hline Camarão frito & 10 unidades grandes & 12 \\
\hline Lagosta cozida & 01 unidade & 12 \\
\hline Lula frita & 01 pires & 12 \\
\hline Ovo frito & 01 unidade & 12 \\
\hline Peixe empanado & 01 filé pequeno & 12 \\
\hline
\end{tabular}

\section{4 pontos}

\begin{tabular}{|l|l|c|}
\hline \multicolumn{1}{|c|}{ Alimento } & \multicolumn{1}{|c|}{ Porçăo } & \multicolumn{1}{|l|}{$\begin{array}{c}\text { ICS } \\
\text { posçăo }\end{array}$} \\
\hline Carne de vaca (gorda) grelh. & 01 bife & 14 \\
\hline Pavê & 01 pedaço & 14 \\
\hline
\end{tabular}




\section{Lista de Pontos dos Alimentos}

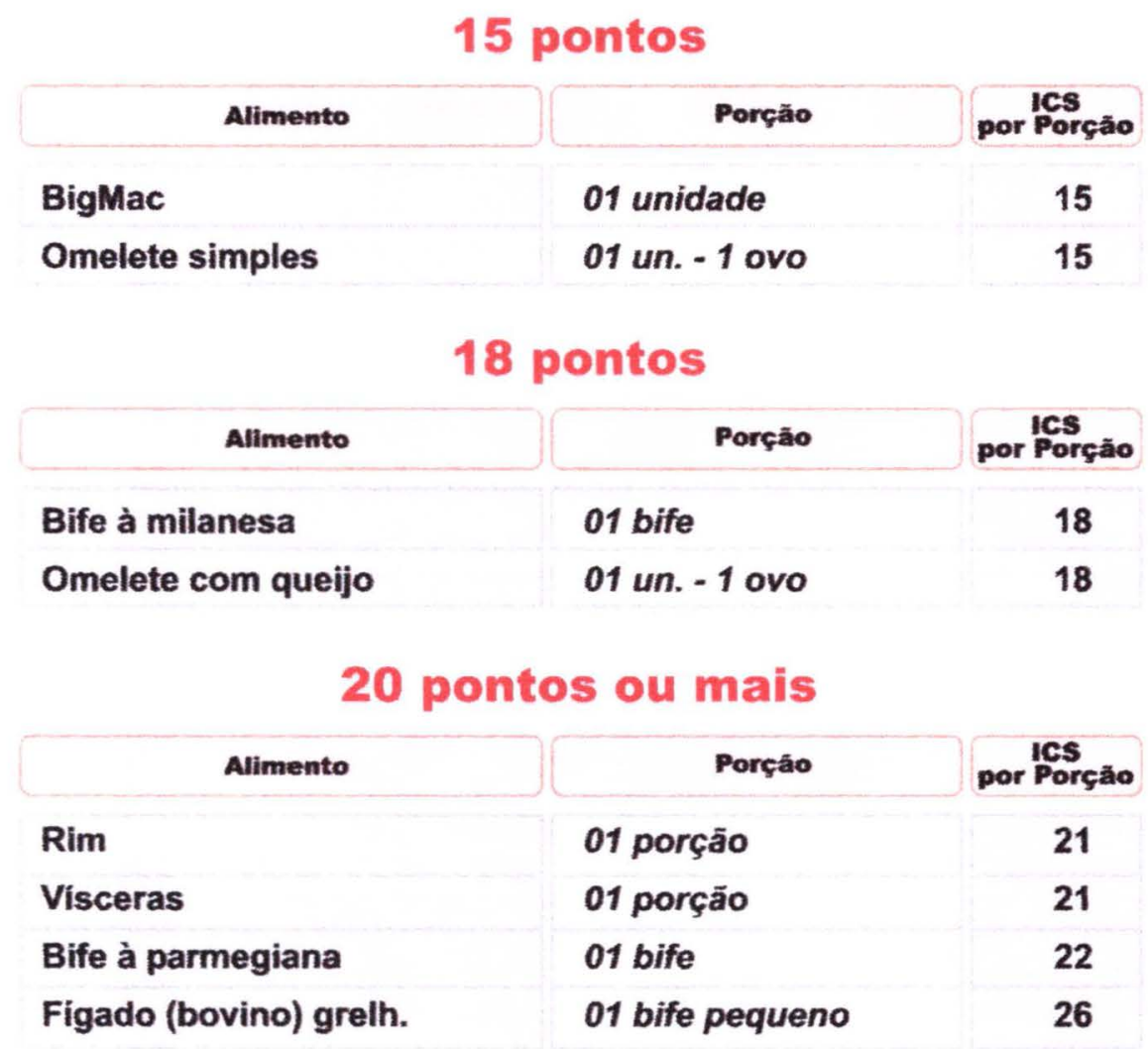


Modelo

ANOTE SEUS PONTOS

PERÍODO: 01 DIA

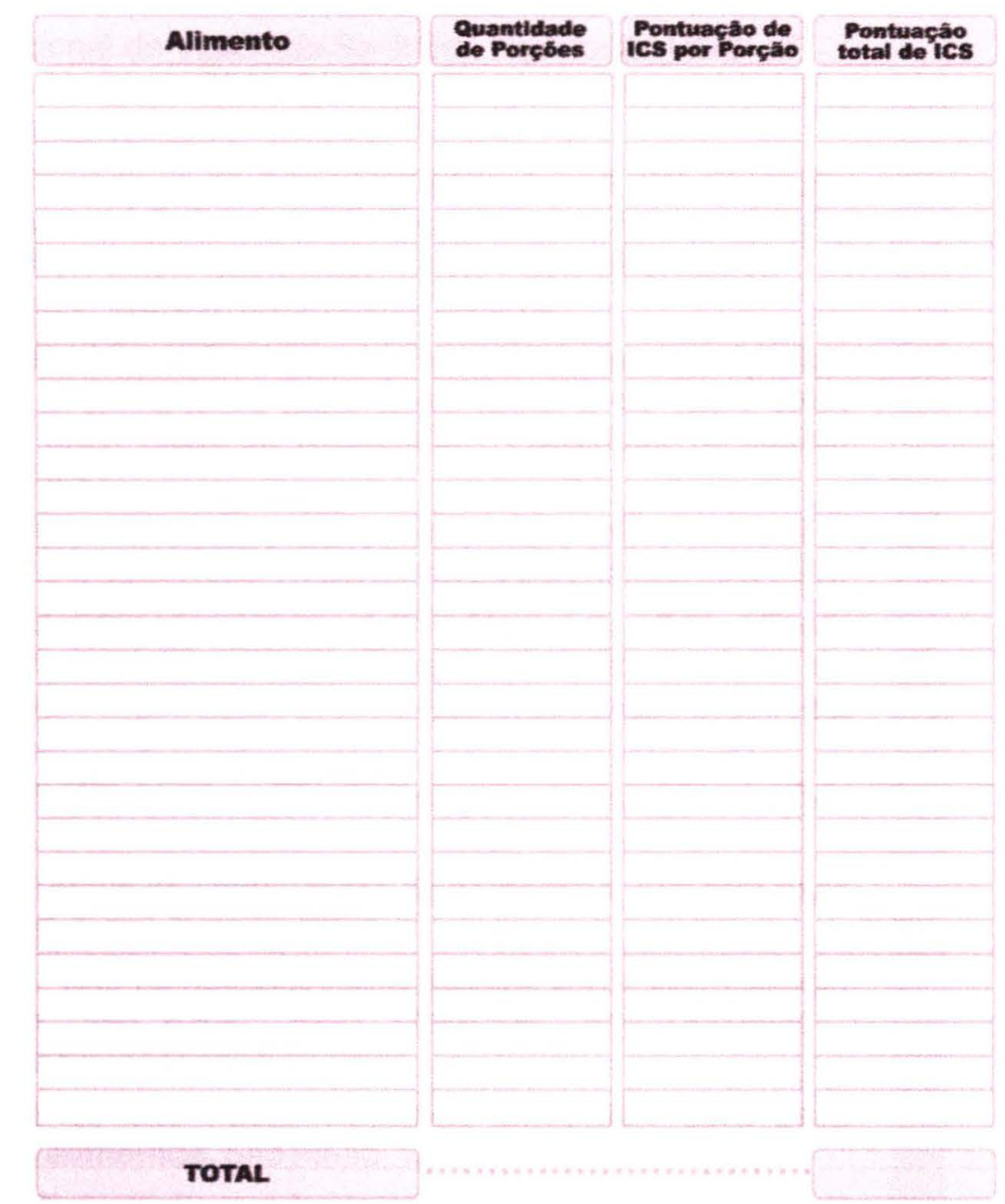

Não esqueça que não se deve ultrapassar os valores de ICS encontrados na tabela 1. Boa sorte!!!!! 


\section{Referências Bibliográficas}

American Heart Association, 2000 [on line]. Available from http://www.americanheartassociation.com [2002 jun 08].

Agência Nacional de Vigilância Sanitária. Resolução RDC- $n^{\circ}$ 39, de 21 de Março de 2001 [on line]. Disponivel em

http://www.anvisa.gov.br [2002 jun 10].

Connor SL, Gustafson JR, Artaud-Wild SM, Favell, DP, ClassickKohn CJ, Hatcher LF, Connor WE. The cholesterol/satured-fat index: an indication of hipercolesterolaemic and atherogenic potential of food. Lancet 1986; (May):1229-32.

Fornés, NS. Padrões alimentares e suas relações com lipídios séricos em população da área metrolopitana de São Paulo. São Paulo; 1998. [Tese de Doutorado - Faculdade de Saúde Pública da USP].

Fundação IBGE. Pesquisa de orçamentos familiares 1987 e 1996. [on line]. Disponivel em http://www.ibge.gov.br/sidra. [2001]

Lajolo FM, coordenador, Menezes EW, Penteado MVC, Filisetti TMCC, Marquez UML. Tabela Brasileira de composição de alimentos [on line]. Disponivel em http://www.usp.br/fcf/tabela [2002 jun 20].

McCance RA, Winddowson EM. The composition of foods. 5 th ed. Portland: Book News; 1991.

Philippi, ST. Tabela de composição de alimentos Suporte para decisão nutricional. Brasília; 2001.

Torres EAFS. Teor de lipídeos em alimentos e sua importância na nutrição. São Paulo; 2000. [Tese de Livre Docência Faculdade de Saúde Pública da USP].

Universidade de São Paulo. Pirâmide alimentar: guia para escolha dos alimentos. São Paulo; 1999.

Willett WC. Eat, drink, and be healthy. The Harvard Medical School Guide to Healthy Eating. New York; 2001

World Health Organization. Obesity: preventing and managing the global epidemic. Report. Geneva; 1998. 


\title{
HÁBITOS ALIMENTARES MAIS \\ SAUDÁVEIS VÃO TRAZER GRANDES \\ BENEFícIOS PARA A SUA SAÚdE
}

\author{
Elaboração: \\ Edeli Simioni de Abreu \\ Márcia A. L. Nacif \\ Prof . Assoc. Elizabeth A. F. S. Torres \\ Diagramação: \\ Osvaldo Salmazo Jr.
}

Apoio:

CAPES

CNPq

FAPESP

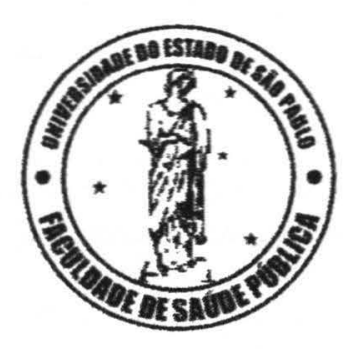

Universidade de São Paulo

Faculdade de Saúde Pública

Departamento de Nutrição 


\section{TERMO DE CONSENTIMENTO}

(Obrigatório para Pesquisas Científicas em Seres Humanos-Resolução n 196 de 10/10/1996 CNS)

Pesquisa: Influência de uma intervenção nutricional baseada no Sistema de Pontos para Controle de Colesterol e Gordura no Sangue em indivíduos hiperlipidêmicos coronarianos usuários de sinvastatina

Objetivo: Avaliar o efeito de uma dieta com baixos teores de gorduras sobre os lipídios do sangue em indivíduos coronarianos portadores de hiperlipidemias usuários de sinvastatina

A pesquisa a ser desenvolvida será realizada pelo Departamento de Nutrição da Faculdade de Saúde Pública e pelo Incor - FMUSP - de autoria e responsabilidade da nutricionista Marcia de Araujo Leite Nacif CRN3-9777, sob a orientação da Prof ${ }^{a}$.Assoc. Elizabeth AFS Torres e Prof. Dr. Raul Dias Santos.

Fui esclarecido sobre os procedimentos a serem realizados, e me, submeterei à dieta prescrita durante 3 meses. Permito a coleta de $10 \mathrm{ml}$ de sangue venoso antes e após a realização da dieta. Estou ciente que esta pesquisa é importante para o estudo de dietas adequadas à prevenção e controle do colesterol e gordura do sangue. Fui esclarecido pela pesquisadora que:

- terei acesso, a qualquer momento, às informações sobre procedimentos, riscos e benefícios relacionados a pesquisa, inclusive para sanar dúvidas;

- a participação é voluntária e a desistência não acarretará algum tipo de prejuízo e nem à continuidade da assistência;

- a pesquisadora se compromete a não identificar o indivíduo e a manter o caráter confidencial das informações relacionado a sua privacidade.

Declaro que, após ter sido convenientemente esclarecido pela pesquisadora, eu, , RG: consinto em participar desta pesquisa.

$\begin{array}{ll}\text { assinatura da pesquisadora } & \text { São Paulo, de de } \\ & \text { assinatura do participante }\end{array}$

Maiores informações: Marcia de Araujo Leite Nacif e Prof ${ }^{\mathrm{a}}$ Elizabeth AF.S. Torres - Departamento de Nutrição da Faculdade de Saúde Pública da Universidade de São Paulo, Av. Dr. Arnaldo, 715, ou pelos telefones: (011) 3066-7701, (011) 3871-3637, (011) 9118-5835. 
Pesquisa: Influência de uma intervenção nutricional baseada no Sistema de Pontos para Controle de Colesterol e Gordura no Sangue em indivíduos hiperlipidêmicos coronarianos usuários de sinvastatina

\section{FORMULÁRIO DE COLETA DE DADOS}

\section{Identificacão}

Nome:

Telefone para contato:

Endereço:

Data de Nascimento:

Data da Entrevista:

Idade: anos

Sexo: ( ) masculino ( ) feminino

Raça:

Escolaridade:

Ocupação:

Estado Civil:

Presença de Comorbidades:

( ) obesidade, sobrepeso

( ) hipertensão arterial

( ) outros

Faz uso de algum medicamento para controle de colesterol ? ( ) sim ( ) não Qual ?

Faz uso de outros medicamentos ? ( ) sim ( ) não Qual? 


\section{Hábito de fumar}

1. Nos últimos 12 meses o $\mathrm{Sr}$ (a) fumou algum tipo de cigarro, charutos ou cachimbos?

1. Não ( ) passar para a pergunta $n^{\circ} 5$

2. $\operatorname{Sim}($ )

2. Que tipo de cigarro o $\mathrm{Sr}$ (a) consome?
1. Cigarros sem filtro
1. Não ( ) 2.Sim ( )
2. Cigarros de palha
1. Não ( ) 2.Sim ( )
3. Cigarros com filtro branco
1. Não ( ) 2.Sim ( )
4. Cigarros com filtro amarelo
1. Não ( ) 2.Sim ( )

\section{Somente para fumantes}

3. Com que idade o $\mathrm{Sr}$ (a) começou a fumar? idade anos

4. Quantos cigarros o $\mathrm{Sr}$ (a) fuma por dia ? cigarros/dia

\section{Para não fumantes atualmente}

5. O Sr (a) alguma vez já fumou cigarros, charutos ou cachimbo ?

1. Não ( ) encerrar

2. Sim ( ) passar para pergunta 6

6. Quantos cigarros fumava por dia? cigarros/dia

7. Com que idade o $\mathrm{Sr}$ (a) começou a fumar? anos

8. Com que idade o $\mathrm{Sr}$ (a) parou de fumar? anos 


\section{Para todos que já fumaram alguma vez}

9. O Sr (a) pode me dizer quanto fumava nas seguintes idades ?

\begin{tabular}{|c|c|c|c|c|c|}
\hline & \multicolumn{5}{|c|}{ IDADE EM ANOS } \\
\hline & $20-30$ & $31-40$ & $41-50$ & $51-60$ & $61-70$ \\
\hline $\begin{array}{r}\text { Quantos cigarros fumava por dia quando tinha .... } \\
\text { Cigarros/dia }\end{array}$ & Perg. 9.1 & Perg. 9.2 & Perg. 9.3 & Perg. 9.4 & Perg. 9.5 \\
\hline $\begin{array}{l}\text { Que tipo de tabaco consumia quando tinha ....... } \\
\text { Cigarros sem filtro? } \\
\text { Cigarros de palha? } \\
\text { Cigarros com filtro branco? } \\
\text { Cigarros com filtro amarelo? }\end{array}$ & Perg. 9.6 & Perg. 9.7 & Perg. 9.8 & Perg. 9.9 & Perg. 9.10 \\
\hline $\begin{array}{l}\text { Quantas vezes fumava cachimbo por dia quando } \\
\text { tinha ..... } \\
\text { Cachimbo/dia }\end{array}$ & Perg. 9.11 & Perg. 9.12 & Perg. 9.13 & Perg. 9.14 & Perg. 9.15 \\
\hline $\begin{array}{r}\text { Quantos charutos fumava por dia quando tinha .... } \\
\text { Charutos/dia }\end{array}$ & Perg. 9.16 & Perg. 9.17 & Perg. 9.18 & Perg. 9.19 & Perg. 9.20 \\
\hline
\end{tabular}

10. Quando o $\mathrm{Sr}$ (a) fuma ou fumava ?

1. Traga ou tragava o fumo profundamente ? ( )

2. Traga ou tragava todo o fumo ? ( )

3. Traga ou tragava parte do fumo ? ( )

4. Não inala ou inalava o fumo ? ( )

5. Não sabe?

\section{$\underline{\text { Exames bioquímicos e antropometria }}$}

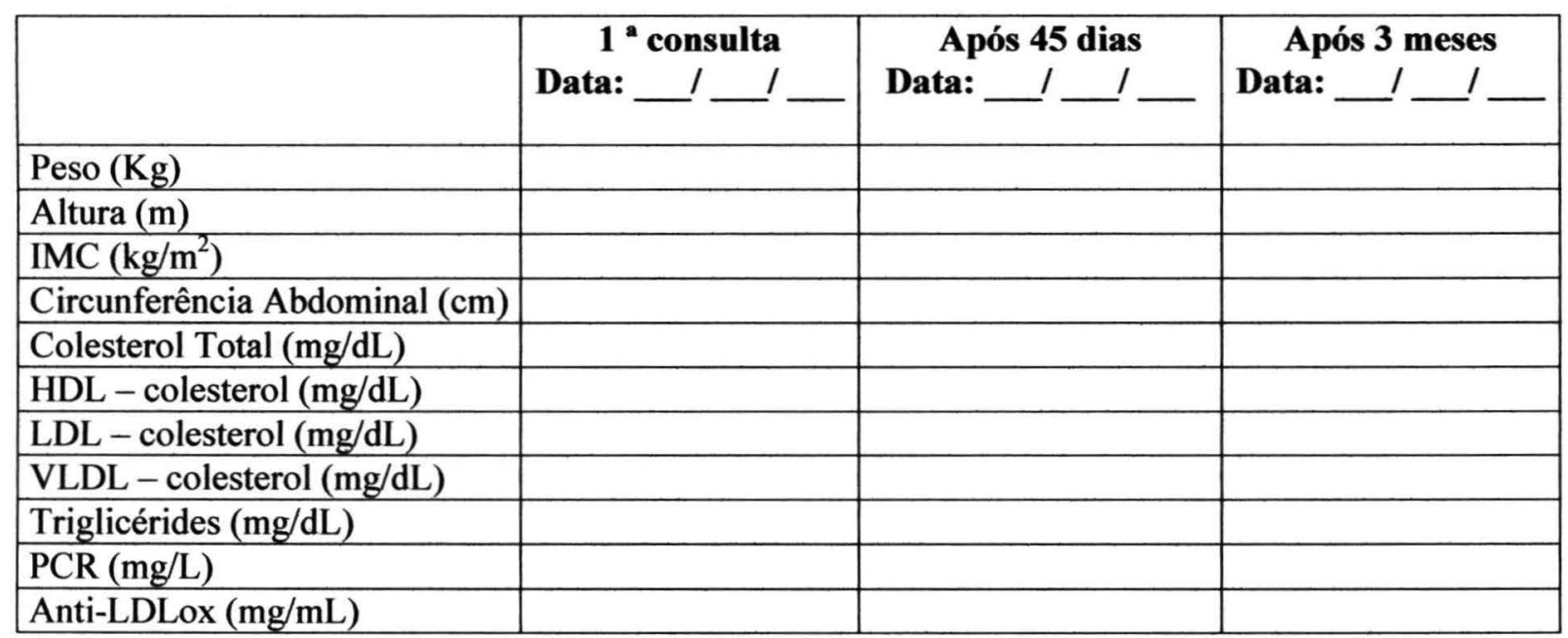




\section{RECORDATÓRIO DE 24 HORAS}

Nome:

Data:

Dia da Semana:

\begin{tabular}{|c|c|c|}
\hline Refeição & Alimento & Quantidade \\
\hline Desjejum & & \\
\hline Lanche - manhã & & \\
\hline Almoço & & \\
\hline Lanche - tarde & & \\
\hline Jantar & & \\
\hline Ceia & & \\
\hline
\end{tabular}




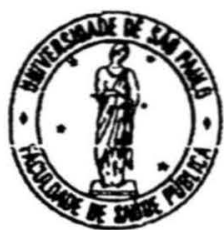

Anexo $V$

\section{Universidade de São Paulo}

Faculdade de Saúde Pública

COMITÊ DE ÉTICA - COEP

Av. Dr. Arnaldo, 715 - CEP 01246-904 - São Paulo - Brasil

Telefones: (55-11) 3066- 7779 - fone/fax (55-11) 3064 -7314 - e-mail: mdgracas@usp.br

\section{Of.COEP/219/03}

10 de dezembro de 2003

Pelo presente, informo que o Comitê de Ética em Pesquisa da Faculdade de Saúde Pública da Universidade de São Paulo-COEP, analisou e aprovou, em sua $10^{\mathrm{a}} / 03$, realizada em 09.12 .03 , de acordo com os requisitos da Resolução CNS/196/96, o Protocolo de Pesquisa n. ${ }^{\circ} 1058$, intitulado: “AVALIAÇÃO DA EFICÁCIA DO SISTEMA DE PONTOS PARA CONTROLE DE COLESTEROL E GORDURA NO SANGUE EM INDIVIDUOS HIPERLIPIDÊMICOS”, apresentado pela pesquisadora Márcia de Araújo Leite Nacif.

Atenciosamente,

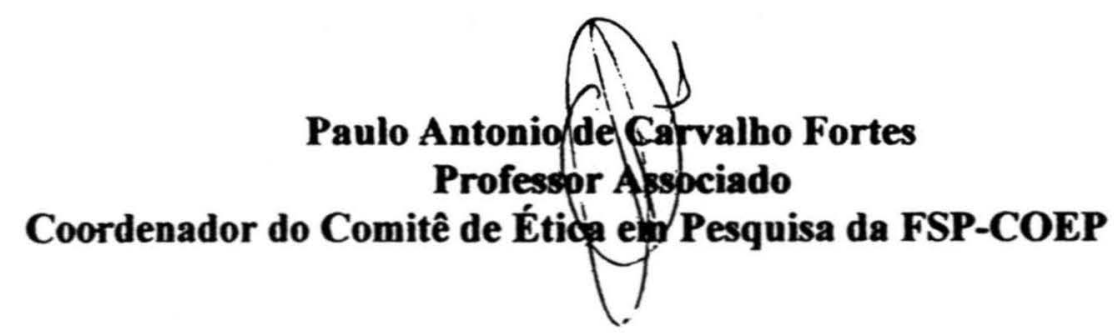


Mem. CC. 1905

São Paulo, 05 de agosto de 2004.

Ao

Dr. Raul Dias Santos

Ref.: Protocolo de Pesquisa SDC 2449/04/069

A Comissão Científica e de Ética do Instituto do Coração, apreciou na sessão 455/04/013 de 5.8.2004, a inclusão do Laboratório de Análises Clínicas no Protocolo de Pesquisa SDC 2449/04/069 “Avaliação da eficácia do Sistema de Pontos para Controle de Colesterol e Gordura no Sangue em individuos Hiperlipidêmicos", e foi o seguinte parecer: "Ciente".

Atenciosamente,

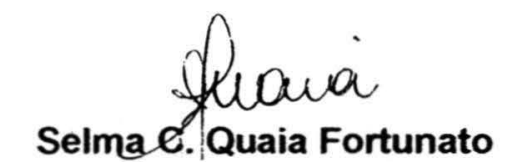

Secretária da Comissão Científica e de Ética InCor - HC.FMUSP 


\section{Dados descritivos da população em estudo}

\section{Estado Nutricional}

Distribuição da média e desvio padrão dos indivíduos, segundo as variáveis antropométricas e grupos de estudo. São Paulo, 2007.

\begin{tabular}{|c|c|c|c|}
\hline \multirow[b]{2}{*}{ Grupo } & \multicolumn{3}{|c|}{ Variáveis antropométricas } \\
\hline & Peso (kg) & IMC $\left(\mathrm{kg} / \mathrm{m}^{2}\right)$ & $\begin{array}{c}\text { Circunferência } \\
\text { Abdominal (cm) }\end{array}$ \\
\hline \multicolumn{4}{|c|}{ DHCB $(n=20)$} \\
\hline T0 & $70,87(6,34)$ & $27,04(1,95)$ & $94,70(6,91)$ \\
\hline T45 & $70,63(6,23)$ & $26,96(1,93)$ & $94,35(7,08)$ \\
\hline T90 & $70,86(6,50)$ & $27,10(1,84)$ & $94,35(7,05)$ \\
\hline \multicolumn{4}{|c|}{ DHCA $(n=6)$} \\
\hline T0 & $66,95(9,04)$ & $26,04(3,85)$ & $90,33(12,37)$ \\
\hline T45 & $67,12(9,96)$ & $26,07(4,08)$ & $90,67(12,72)$ \\
\hline T90 & $67,87(9,99)$ & $26,40(4,15)$ & $90,67(12,72)$ \\
\hline \multicolumn{4}{|c|}{ DPCB $(n=15)$} \\
\hline T0 & $74,16(9,62)$ & $27,81(1,68)$ & $93,00(6,73)$ \\
\hline T45 & $72,51(9,87)$ & $27,18(1,79)$ & $92,13(6,66)$ \\
\hline T90 & $71,55(10,13)$ & $26,78(1,97)$ & $91,60(6,65)$ \\
\hline \multicolumn{4}{|c|}{$\operatorname{DPCA}(n=9)$} \\
\hline T0 & $66,59(10,16)$ & $26,41(2,54)$ & $90,00(9,75)$ \\
\hline T45 & $65,62(9,56)$ & $26,00(2,01)$ & $89,67(8,85)$ \\
\hline T90 & $65,44(9,39)$ & $25,95(1,98)$ & $89,67(8,94)$ \\
\hline
\end{tabular}




\section{Consumo Alimentar}

Distribuição da média e desvio padrão dos indivíduos, segundo valor energético, macronutrientes e grupos de estudo. São Paulo, 2007.

\begin{tabular}{|c|c|c|c|c|c|c|}
\hline \multirow[b]{2}{*}{ Grupo } & \multicolumn{6}{|c|}{ Variáveis } \\
\hline & $\begin{array}{c}\text { Energia } \\
\text { (kcal) }\end{array}$ & $\begin{array}{c}\text { Carboidratos } \\
\text { (g) }\end{array}$ & $\begin{array}{l}\text { Proteínas } \\
\text { (g) }\end{array}$ & $\begin{array}{l}\text { Lipídios } \\
\text { (g) }\end{array}$ & $\begin{array}{c}\text { Fibra } \\
\text { solúvel (g) }\end{array}$ & $\begin{array}{c}\text { Fibra } \\
\text { insolúvel (g) }\end{array}$ \\
\hline \multicolumn{7}{|c|}{ DHCB $(n=8)$} \\
\hline T0 & $1757,67(635,95)$ & $173,99(56,65)$ & $66,06(26,80)$ & $52,19(13,97)$ & $3,08(1,46)$ & $10,32(4,57)$ \\
\hline T45 & $1455,22(431,55)$ & $156,47(46,64)$ & $70,54(20,22)$ & $47,09(8,97)$ & $2,11(1,43)$ & $7,99(4,18)$ \\
\hline T90 & $602,21(528,34)$ & $165,34(43,94)$ & $75,32(13,74)$ & $57,66(18,67)$ & $2,85(1,84)$ & $9,56(3,88)$ \\
\hline \multicolumn{7}{|c|}{ DHCA $(n=3)$} \\
\hline T0 & $1023,90(463,13)$ & $178,48(22,11)$ & $72,80(30,06)$ & $48,54(9,34)$ & $2,22(1,27)$ & $6,36(2,45)$ \\
\hline T45 & $1019,59(252,55)$ & $154,24(23,34)$ & $70,87(2,67)$ & $48,30(10,29)$ & $2,10(1,18)$ & $6,52(3,55)$ \\
\hline T90 & $954,09(109,08)$ & $153,31(23,30)$ & $83,83(8,59)$ & $54,95(10,40)$ & $1,57(1,03)$ & $5,44(5,01)$ \\
\hline \multicolumn{7}{|c|}{ DPCB $(n=8)$} \\
\hline T0 & $1475,50(258,33)$ & $181,53(41,72)$ & $73,37(20,54)$ & $45,16(14,58)$ & $2,32(1,21)$ & $11,45(3,77)$ \\
\hline $\mathrm{T} 45$ & $1516,63(534,30)$ & $187,54(34,96)$ & $65,74(32,72)$ & $37,88(7,75)$ & $2,50(1,40)$ & $8,16(3,14)$ \\
\hline T90 & $1761,39(848,38)$ & $172,32(45,56)$ & $84,31(29,72)$ & $47,39(16,81)$ & $2,91(1,62)$ & $10,42(4,17)$ \\
\hline \multicolumn{7}{|c|}{ DPCA $(n=3)$} \\
\hline T0 & $1052,79(376,47)$ & $190,74(50,96)$ & $65,93(15,88)$ & $44,68(15,29)$ & $2,43(2,02)$ & $10,36(4,15)$ \\
\hline T45 & $1106,14(430,96)$ & $122,93(15,03)$ & $76,27(11,82)$ & $59,75(13,21)$ & $1,66(1,55)$ & $8,86(3,01)$ \\
\hline T90 & $992,93(472,60)$ & $187,30(42,10)$ & $70,01(22,37)$ & $47,26(11,60)$ & $2,61(2,47)$ & $13,83(9,09)$ \\
\hline
\end{tabular}


Distribuição da média e desvio padrão dos indivíduos, segundo perfil de ácidos graxos e grupos de estudo. São Paulo, 2007.

\begin{tabular}{cccccc}
\hline & \multicolumn{5}{c}{ Variáveis } \\
\cline { 2 - 6 } Grupo & $\begin{array}{c}\text { Saturados } \\
\text { (g) }\end{array}$ & $\begin{array}{c}\text { Monoinsaturados Polinsaturados } \\
\text { (g) }\end{array}$ & $\begin{array}{c}\text { Ómega 3 } \\
\text { (g) }\end{array}$ & $\begin{array}{c}\text { Ómega 6 } \\
\text { (g) }\end{array}$ \\
\hline DHCB (n=8) & & & & & \\
T0 & $15,67(6,10)$ & $19,47(5,33)$ & $12,18(4,32)$ & $1,41(0,50)$ & $10,55(3,73)$ \\
T45 & $14,03(3,90)$ & $15,90(4,46)$ & $13,21(4,82)$ & $1,37(0,67)$ & $11,25(4,12)$ \\
T90 & $19,67(9,43)$ & $20,70(8,82)$ & $11,44(7,04)$ & $1,45(0,79)$ & $9,80(6,18)$ \\
DHCA (n=3) & & & & & \\
T0 & $13,61(4,24)$ & $17,42(5,77)$ & $13,32(0,92)$ & $1,26(0,08)$ & $11,54(0,61)$ \\
T45 & $15,59(4,74)$ & $16,15(4,47)$ & $12,56(3,48)$ & $1,39(0,36)$ & $10,92(3,18)$ \\
T90 & $16,60(3,89)$ & $20,45(3,62)$ & $12,89(1,81)$ & $1,32(0,35)$ & $11,27(1,52)$ \\
DPCB (n=8) & & & & & \\
T0 & $11,70(5,66)$ & $16,32(6,92)$ & $12,78(1,58)$ & $1,43(0,34)$ & $10,96(1,44)$ \\
T45 & $10,34(4,18)$ & $13,00(3,35)$ & $11,18(2,14)$ & $1,12(0,41)$ & $9,80(1,89)$ \\
T90 & $14,55(5,92)$ & $15,94(7,73)$ & $12,00(4,07)$ & $1,31(0,44)$ & $10,39(3,60)$ \\
DPCA (n=3) & & & & & \\
T0 & $10,67(5,60)$ & $14,92(7,52)$ & $15,08(1,21)$ & $1,68(0,17)$ & $13,25(1,08)$ \\
T45 & $17,70(4,71)$ & $22,43(7,73)$ & $14,14(1,19)$ & $1,55(0,09)$ & $12,38(1,21)$ \\
T90 & $13,65(5,55)$ & $15,56(5,60)$ & $13,95(0,55)$ & $1,62(0,13)$ & $12,13(0,41)$ \\
\hline & & & & &
\end{tabular}


Distribuição da média e desvio padrão dos indivíduos, segundo variáveis lipídicas e grupos de estudo. São Paulo, 2007.

\begin{tabular}{cccc}
\hline & \multicolumn{3}{c}{ Variáveis } \\
\cline { 2 - 4 } Grupo & $\begin{array}{c}\text { Colesterol } \\
(\mathbf{m g})\end{array}$ & $\begin{array}{c}\text { Trans } \\
(\mathbf{g})\end{array}$ & CSI \\
\hline DHCB (n=8) & & & \\
T0 & $154,91(108,64)$ & $2,44(1,51)$ & $23,57(10,79)$ \\
T45 & $244,74(190,17)$ & $3,01(2,30)$ & $26,41(9,72)$ \\
T90 & $255,81(248,55)$ & $3,63(4,62)$ & $32,65(13,96)$ \\
DHCA (n=3) & & & \\
T0 & $191,53(87,46)$ & $3,11(0,94)$ & $23,32(3,68)$ \\
T45 & $164,54(24,87)$ & $2,31(0,85)$ & $23,97(6,02)$ \\
T90 & $219,64(37,22)$ & $4,37(0,92)$ & $27,75(4,90)$ \\
DPCB (n=8) & & & \\
T0 & $154,61(74,84)$ & $3,07(2,21)$ & $19,55(7,92)$ \\
T45 & $120,83(90,10)$ & $2,48(1,50)$ & $16,48(6,61)$ \\
T90 & $258,45(67,53)$ & $2,62(0,85)$ & $27,62(7,04)$ \\
DPCA (n=3) & & & \\
T0 & $170,61(36,99)$ & $2,45(2,36)$ & $19,31(7,31)$ \\
T45 & $175,13(12,53)$ & $4,17(4,97)$ & $26,63(4,33)$ \\
T90 & $161,21(72,28)$ & $2,13(1,43)$ & $21,85(8,87)$ \\
\hline
\end{tabular}


Distribuição da média e desvio padrão dos indivíduos, segundo vitaminas antioxidantes e grupos de estudo. São Paulo, 2007.

\begin{tabular}{cccc}
\hline Grupo & $\begin{array}{c}\text { Vitamina C } \\
(\mathbf{m g})\end{array}$ & $\begin{array}{c}\text { Vitamina A } \\
(\mathbf{\mu g})\end{array}$ & $\begin{array}{c}\text { Vitamina E } \\
(\mathbf{m g})\end{array}$ \\
\cline { 2 - 4 } DHCB (n=8) & & & \\
T0 & $76,11(52,63)$ & $\mathbf{9 8 , 4 8}(112,17)$ & $4,11(1,05)$ \\
T45 & $35,09(50,54)$ & $188,59(91,72)$ & $4,31(1,19)$ \\
T90 & $\mathbf{6 0 , 4 4 ( 5 4 , 7 2 )}$ & $233,01(166,54)$ & $3,72(1,38)$ \\
DHCA (n=3) & & & \\
T0 & $\mathbf{6 3 , 7 9 ( 4 5 , 3 2 )}$ & $173,49(37,89)$ & $3,94(1,21)$ \\
T45 & $18,66(1,79)$ & $243,93(117,57)$ & $2,71(0,25)$ \\
T90 & $23,08(12,91)$ & $202,60(57,81)$ & $3,04(1,07)$ \\
DPCB (n=8) & & & \\
T0 & $50,59(62,05)$ & $129,76(130,85)$ & $4,45(1,01)$ \\
T45 & $53,28(32,01)$ & $181,84(102,60)$ & $3,49(0,83)$ \\
T90 & $101,16(89,79)$ & $133,57(111,69)$ & $4,54(1,55)$ \\
DPCA (n=3) & & & \\
T0 & $11,23(12,25)$ & $130,65(138,64)$ & $4,13(0,50)$ \\
T45 & $39,35(24,64)$ & $169,03(81,98)$ & $3,57(0,50)$ \\
T90 & $93,38(123,80)$ & $159,92(108,57)$ & $5,43(2,06)$ \\
\hline
\end{tabular}




\section{Análise Bioquímica}

Distribuição da média e desvio padrão dos indivíduos, segundo perfil lipídico e grupos de estudo. São Paulo, 2007.

\begin{tabular}{cccccc}
\hline Grupo & $\begin{array}{c}\text { Colesterol } \\
\text { Total (mg/dL) }\end{array}$ & $\begin{array}{c}\text { HDL } \\
(\mathbf{m g} / \mathbf{d L})\end{array}$ & $\begin{array}{c}\text { LDL } \\
(\mathbf{m g} / \mathbf{d L})\end{array}$ & $\begin{array}{c}\text { VLDL } \\
(\mathbf{m g} / \mathbf{d L})\end{array}$ & $\begin{array}{c}\text { Triglicérides } \\
(\mathbf{m g} / \mathbf{d L})\end{array}$ \\
\hline $\begin{array}{c}\text { DHCB (n=20) } \\
\text { T0 }\end{array}$ & $167,20(23,47)$ & $43,30(7,73)$ & $97,45(20,90)$ & $26,47(14,24)$ & $132,05(71,36)$ \\
T45 & $174,05(30,10)$ & $44,20(9,19)$ & $103,00(29,32)$ & $26,83(13,26)$ & $134,15(66,28)$ \\
T90 & $171,40(26,88)$ & $44,30(8,75)$ & $100,65(22,28)$ & $26,39(10,69)$ & $132,05(53,40)$ \\
DHCA (n=6) & & & & & \\
T0 & $247,17(56,64)$ & $48,50(10,33)$ & $146,00(39,19)$ & $50,23(30,87)$ & $251,50(155,04)$ \\
T45 & $219,50(22,81)$ & $48,00(8,74)$ & $132,50(31,89)$ & $39,17(15,60)$ & $195,83(78,01)$ \\
T90 & $232,33(45,15)$ & $48,00(13,13)$ & $130,67(30,70)$ & $51,87(24,06)$ & $259,33(120,28)$ \\
DPCB (n=15) & & & & & \\
T0 & $166,53(14,93)$ & $46,27(13,92)$ & $91,33(15,59)$ & $28,80(14,46)$ & $144,00(72,31)$ \\
T45 & $162,07(29,58)$ & $43,13(10,88)$ & $90,60(21,36)$ & $28,25(12,08)$ & $141,27(60,39)$ \\
T90 & $165,07(35,97)$ & $44,20(11,82)$ & $91,47(36,39)$ & $29,36(13,27)$ & $149,80(64,04)$ \\
DPCA (n=9) & & & & & \\
T0 & $240,44(35,80)$ & $50,89(14,07)$ & $158,44(33,74)$ & $31,07(14,99)$ & $155,33(74,93)$ \\
T45 & $221,89(40,76)$ & $51,67(11,81)$ & $137,11(42,40)$ & $32,09(19,45)$ & $160,44(97,23)$ \\
T90 & $215,22(37,71)$ & $51,11(12,42)$ & $132,78(40,39)$ & $31,36(17,63)$ & $154,22(87,15)$ \\
\hline
\end{tabular}


Distribuição da média e desvio padrão dos indivíduos, segundo as variáveis inflamatórias e grupos de estudo. São Paulo, 2007.

\begin{tabular}{ccc}
\hline & \multicolumn{2}{c}{ Variáveis } \\
\cline { 2 - 3 } Grupo & $\begin{array}{c}\text { anti-LDLox } \\
(\mathbf{m g} / \mathbf{m L})\end{array}$ & $\begin{array}{c}\text { PCR } \\
(\mathbf{m g} / \mathbf{L})\end{array}$ \\
\hline & & \\
DHCB & $(\mathbf{n}=\mathbf{8})$ & $(\mathbf{n}=\mathbf{2 0})$ \\
T0 & $86,60(19,97)$ & $5,86(6,00)$ \\
T45 & $91,37(44,75)$ & $3,86(4,81)$ \\
T90 & $91,28(40,71)$ & $3,38(3,35)$ \\
DHCA & $(\mathbf{n}=\mathbf{3})$ & $(\mathbf{n}=\mathbf{6})$ \\
T0 & $75,45(75,86)$ & $5,70(7,90)$ \\
T45 & $\mathbf{8 6 , 1 6 ( 4 6 , 0 3 )}$ & $10,77(9,34)$ \\
T90 & $111,80(21,07)$ & $3,27(2,13)$ \\
DPCB & $(\mathbf{n}=\mathbf{8})$ & $(\mathbf{n}=15)$ \\
T0 & $295,43(466,15)$ & $3,90(4,60)$ \\
T45 & $118,62(71,26)$ & $3,46(3,00)$ \\
T90 & $106,99(55,21)$ & $3,55(3,89)$ \\
DPCA & $(\mathbf{n}=\mathbf{3})$ & $(\mathbf{n}=\mathbf{9})$ \\
T0 & $105,38(17,94)$ & $2,49(1,76)$ \\
T45 & $103,06(71,61)$ & $2,90(1,83)$ \\
T90 & $205,02(195,68)$ & $4,62(5,94)$ \\
\hline
\end{tabular}

